Supplementary Information

\title{
Axially Chiral Spiro-conjugated Carbon-bridged p-Phenylenevinylene Congeners: Synthetic Design and Materials Properties
}

Hiroyoshi Hamada, Yuki Itabashi, Rui Shang*, and Eiichi Nakamura*

Department of Chemistry, The University of Tokyo, 7-3-1 Hongo, Bunkyo-ku, Tokyo 113-0033, Japan. 


\section{Table of Contents}

1. Synthesis of spiro-CPV and its congeners 3

$\begin{array}{ll}\text { 2. Crystallographic study } & 17\end{array}$

$\begin{array}{lr}\text { 3. Computational Study } & 19\end{array}$

4. UV-Vis Absorption, Fluorescence spectra 23

$\begin{array}{lr}\text { 5. Electrochemical studies } & 27\end{array}$

$\begin{array}{lr}\text { 6. Thermal studies } & 28\end{array}$

$\begin{array}{ll}\text { 7. Ionization potential } & 28\end{array}$

$\begin{array}{lr}\text { 8. Hole mobility } & 29\end{array}$

9. Electron spin resonance (ESR) spectrum 30

$\begin{array}{ll}\text { 10. Perovskite solar cell } & 30\end{array}$

11. NMR charts $\quad 33$

$\begin{array}{ll}\text { 11. References } & 69\end{array}$ 


\section{Synthesis of spiro-CPV and its congeners}

\section{1-1 General consideration}

All the reactions dealing with air- or moisture-sensitive compounds were carried out in a dry reaction vessel under a positive pressure of nitrogen or argon. Air- and moisture-sensitive liquids and solutions were transferred via syringe or Teflon cannula. Analytical thin-layer chromatography (TLC) was performed using glass plates pre-coated with $0.25 \mathrm{~mm}, 230-400$ mesh silica gel impregnated with a fluorescent indicator $(254 \mathrm{~nm})$. Thin-layer chromatography plates were visualized by exposure to ultraviolet light (UV). Organic solutions were concentrated by rotary evaporation at ca. 15 Torr (evacuated with a diaphragm pump). Flash column chromatography was performed as described by Still et al. ${ }^{1}$, employing Kanto Silica gel 60 (spherical, neutral, 140-325 mesh).

Unless otherwise noted, commercial reagents were purchased from Tokyo Kasei Co., Aldrich Inc., and other commercial suppliers and used as purchased. Anhydrous solvents were purchased from Kanto, and purified by a solvent purification system (GlassContour) equipped with columns of activated alumina and copper catalyst prior to use.

NMR spectra were recorded using a JEOL ECZ-500 $\left({ }^{1} \mathrm{H}\right.$ NMR, $500 \mathrm{MHz} ;{ }^{13} \mathrm{C}$ NMR, $125 \mathrm{MHz}$ ) NMR spectrometer. Chemical data for protons are reported in parts per million (ppm, $\delta$ scale) downfield from tetramethylsilane and are referenced to the residual protons in the NMR solvent $\left(\mathrm{CDCl}_{3}: \delta 7.26, \mathrm{CD}_{2} \mathrm{Cl}_{2}: \delta 5.32\right)$. Chemical data for carbons are reported in parts per million (ppm, $\delta$ scale) downfield from tetramethylsilane and are referenced to the carbon resonance of the solvent $\left(\mathrm{CDCl}_{3}: \delta\right.$ 77.0, $\mathrm{CD} 2 \mathrm{Cl} 2: \delta 54.0$ ). The data are presented as follows: chemical shift, multiplicity (s $=$ singlet, $\mathrm{d}=$ doublet, $\mathrm{t}=$ triplet, $\mathrm{m}=$ multiplet and/or multiple resonances, $\mathrm{br}=$ broad), coupling constant in Hertz $(\mathrm{Hz})$, and integration. Melting points of solid materials were determined on a Mel-Temp II capillary melting-point apparatus and are uncorrected. Mass spectra were obtained on JEOL AccuTOF JMS-T100LC (APCI) mass spectrometer. High-resolution mass spectra were obtained with a calibration standard of reserpine. HPLC analyses were conducted with a SHIMADZU Prominence (HPLC pump: LC-20AD; auto sampler: SIL-20AC; degasser: DGU-20A; column oven: CTO-20AC; diode array detector detector: SPD-M30A) equipped with DAICEL CHIRALPAK IF columns (4.6 mm x $250 \mathrm{~mm})$. 


\section{Synthetic procedures for all compounds.}

\section{3-Iodo-1,1,2-triphenyl-1H-indene (16)}

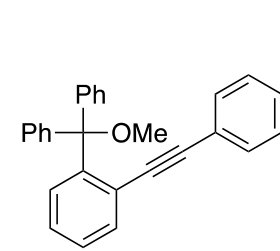

14

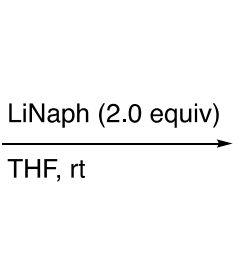

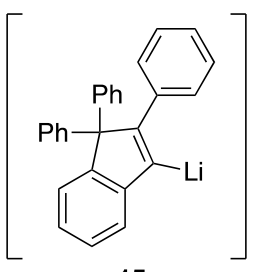

15
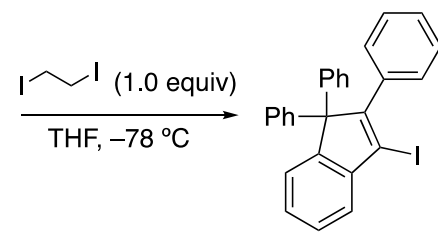

16
$78 \%$

A mixture of granular lithium (140 mg, $20 \mathrm{mmol})$ and naphthalene (19.2 g, 18 $\mathrm{mmol})$ in THF $(20 \mathrm{~mL})$ was stirred at room temperature under argon atmosphere for $4 \mathrm{~h}$. The LiNaph/THF was added to a solution of 1-phenylethynyl-2-diphenylhydroxymethylbenzene (14, $3.36 \mathrm{~g}, 9.0 \mathrm{mmol})$ in THF (20 $\mathrm{mL}$ ) at room temperature, and the resulting mixture was stirred for $1 \mathrm{~h}$. The resulting mixture was cooled down and 1,2-diiodoethane $(3.04 \mathrm{~g}, 10.8 \mathrm{mmol})$ was added at -78 ${ }^{\circ} \mathrm{C}$. The reaction mixture was gradually warmed to ambient temperature, stirred another $1 \mathrm{~h}$, and then quenched with aqueous $\mathrm{Na}_{2} \mathrm{~S}_{2} \mathrm{O}_{3}$ solution. The organic layer was extracted with EtOAc, dried over anhydrous $\mathrm{Na}_{2} \mathrm{SO}_{4}$, and evaporated in vacuo. The crude mixture was purified with reprecipitation from $\mathrm{CHCl}_{3} / \mathrm{MeOH}$ to afford compound $\mathbf{1 6}(3.31 \mathrm{~g}$, $78 \%$ ) as a white solid. The ${ }^{1} \mathrm{H}$ NMR spectrum of compound $\mathbf{1 6}$ was in agreement with the literature. ${ }^{2}$

\section{0,10-Diphenylindeno[2,1-a]inden-5(10H)-one (17)}

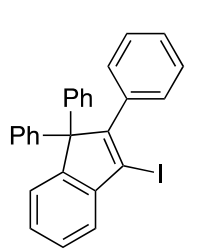

16

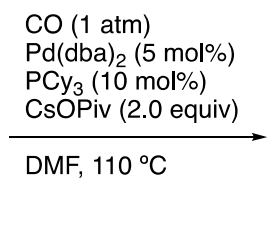

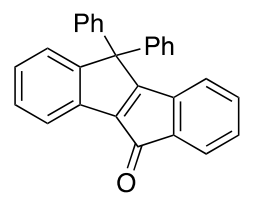

$92 \%$

A solution of 3-iodo-1,1,2-triphenyl-1H-indene (16, $920 \mathrm{mg}, 2.0 \mathrm{mmol}), \mathrm{Pd}(\mathrm{dba})_{2}$ (92 $\mathrm{mg}, 0.1 \mathrm{mmol})$, tricyclohexylphosphine (56 mg, $0.2 \mathrm{mmol}$ ) and anhydrous cesium pivalate $(936 \mathrm{mg}, 4.0 \mathrm{mmol})$ in DMF $(20 \mathrm{~mL})$ was stirred under CO gas atmosphere at $110{ }^{\circ} \mathrm{C}$ for $5 \mathrm{~h}$. The resulting red mixture was allowed to cooled down to ambient temperature and quenched with water. The organic layer was extracted with $\mathrm{Et}_{2} \mathrm{O}$, 
washed with brine, dried over anhydrous $\mathrm{MgSO}_{4}$ and evaporated in vacuo. The crude mixture was purified by reprecipitation from $\mathrm{DMF} / \mathrm{H}_{2} \mathrm{O}$ afforded compound 17 (681 mg, 92\%) as a reddish orange powder. Mp: $186-188^{\circ} \mathrm{C} ;{ }^{1} \mathrm{H} \mathrm{NMR}\left(500 \mathrm{MHz}, \mathrm{CDCl}_{3}\right) \delta 6.92$ $(\mathrm{dd}, J=6.3,1.1 \mathrm{~Hz}, 1 \mathrm{H}), 7.13-7.25(\mathrm{~m}, 3 \mathrm{H}), 7.27-7.29(\mathrm{~m} \mathrm{10H}), 7.33(\mathrm{td}, J=7.4,1.1$ $\mathrm{Hz}, 1 \mathrm{H}), 7.39$ (d, $J=8.0 \mathrm{~Hz}, 1 \mathrm{H}), 7.45(\mathrm{dd} J=6.3,1.7 \mathrm{~Hz}, 1 \mathrm{H}), 7.75(\mathrm{~d}, J=7.4 \mathrm{~Hz}$, $1 \mathrm{H}) ;{ }^{13} \mathrm{C}$ NMR $\left(125 \mathrm{MHz}, \mathrm{CD}_{2} \mathrm{Cl}_{2}\right) \delta 64.8,121.1,121.6,123.1,125.4,126.9,127.5$, $127.8,128.5,128.7,128.9,123.2$, 134.8, 136.4, 139.6, 139.8, 141.4, 155.7, 175.7, 190.9; HRMS (APCI+) calcd for $\mathrm{C}_{28} \mathrm{H}_{18} \mathrm{O}(\mathrm{M}+\mathrm{H})$ : 371.1436 ; found: 371.1423 .

\section{0,10,10',10'-tetraphenyl-10H,10'H-5,5'-spirobi[indeno[2,1-a]indene] (spiro-CPV,} 1)

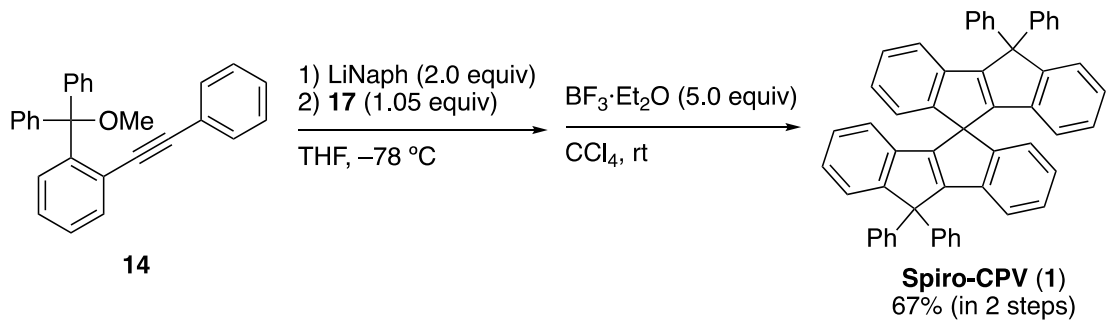

A mixture of granular lithium $(208 \mathrm{mg}, 30 \mathrm{mmol})$ and naphthalene $(3.19 \mathrm{~g}, 30$ $\mathrm{mmol})$ in THF $(60 \mathrm{~mL})$ was stirred at room temperature under argon atmosphere for $4 \mathrm{~h}$. The LiNaph/THF was added to a solution of 1-phenylethynyl-2-diphenylhydroxymethylbenzene $(\mathbf{1 4}, 5.60 \mathrm{~g}, 15 \mathrm{mmol})$ in THF (100 $\mathrm{mL}$ ) at room temperature, and the resulting mixture was stirred for $1 \mathrm{~h}$. The resulting mixture was cooled down and added 10,10-diphenylindeno[2,1- $a$ ] inden-5(10H)-one (17, $5.83 \mathrm{~g}, 15.8 \mathrm{mmol}$ ) at room temperature. The reaction mixture was gradually warmed to ambient temperature, stirred for another $1 \mathrm{~h}$, and then quenched with water. The organic layer was extracted with $\mathrm{CH}_{2} \mathrm{Cl}_{2}$, dried over anhydrous $\mathrm{Na}_{2} \mathrm{SO}_{4}$, and evaporated in vacuo. The resulting crude mixture was dissolved in $\mathrm{CH}_{2} \mathrm{Cl}_{2}$ and added $\mathrm{BF}_{3} \cdot \mathrm{Et}_{2} \mathrm{O}(213$ $\mathrm{mg}, 1.5 \mathrm{mmol}$ ) at room temperature. After stirred for $10 \mathrm{~min}$, the resulting mixture was quenched a few drops of $\mathrm{MeOH}$ and evaporated in vacuo. The crude mixture was purified by reprecipitation from $\mathrm{CH}_{2} \mathrm{Cl}_{2} / \mathrm{MeOH}$ to afford spiro-CPV $(1,7.00 \mathrm{~g}, 67 \%$ in 2 steps) as a white solid. Mp: $>315{ }^{\circ} \mathrm{C}$ (decomposition); ${ }^{1} \mathrm{H}$ NMR $\left(500 \mathrm{MHz}, \mathrm{CDCl}_{3}\right) \delta$ $6.18(\mathrm{~d}, J=7.4 \mathrm{~Hz}, 2 \mathrm{H}), 6.83(\mathrm{t}, J=7.7 \mathrm{~Hz}, 2 \mathrm{H}), 6.87(\mathrm{~d}, J=7.4 \mathrm{~Hz}, 2 \mathrm{H}), 7.00(\mathrm{q}, J=$ $7.1 \mathrm{~Hz}, 4 \mathrm{H}), 7.20$ (t $J=7.4 \mathrm{~Hz}, 2 \mathrm{H}), 7.28-7.38$ (m, 18H), 7.39 (d, $J=8.0 \mathrm{~Hz}, 2 \mathrm{H}), 7.52$ $(\mathrm{d}, J=8.0 \mathrm{~Hz}, 4 \mathrm{H}) ;{ }^{13} \mathrm{C} \mathrm{NMR}\left(125 \mathrm{MHz}, \mathrm{CD}_{2} \mathrm{Cl}_{2}\right) \delta 59.8,64.0,119.8,120.8,123.2$, 
$124.8,125.8,125.9,127.0,127.09,127.14,127.7,128.3,128.4,128.6,137.5,140.3$, 142.6, 143.0, 149.1, 149.7, 156.7, 158.9; HRMS (APCI+) calcd for $\mathrm{C}_{55} \mathrm{H}_{36}$ (M): 696.2817; found: 696.2846 .

\section{1-(4-Methoxyphenyl)ethynyl-2-diphenylhydroxybenzene}
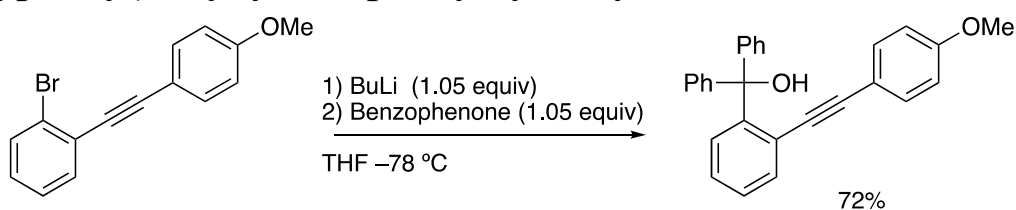

Butyllithium $(8.49 \mathrm{~mL}, 1.60 \mathrm{M})$ was dropwisely added into a solution of 1-bromo-2-((4-methoxyphenyl)ethynyl)benzene (3.60 g, $12.6 \mathrm{mmol})$ in THF (100 mL) at $-78{ }^{\circ} \mathrm{C}$ and stirred for $30 \mathrm{~min}$. The resulting mixture was added benzophenone $(2.40 \mathrm{~g}$, $13.2 \mathrm{mmol}$ ) and stirred for $1 \mathrm{~h}$. The reaction mixture was allowed to warm gradually to ambient temperature and then was added water. The organic layer was extracted with dichloromethane, dried over anhydrous $\mathrm{Na}_{2} \mathrm{SO}_{4}$, and evaporated in vacuo. The crude material was purified by reprecipitation in $\mathrm{CHCl}_{3} / \mathrm{MeOH}$ to afford the titled compound (3.54 g, 72\%) as a white solid. Mp: $118-120{ }^{\circ} \mathrm{C} ;{ }^{1} \mathrm{H}$ NMR $\left(500 \mathrm{MHz}, \mathrm{CD}_{2} \mathrm{Cl}_{2}\right) \delta 3.79$ (s, 3H), $4.95(\mathrm{~s}, 1 \mathrm{H}), 6.67(\mathrm{~d}, J=8.0 \mathrm{~Hz}, 1 \mathrm{H}), 6.79(\mathrm{dd}, J=6.9,2.3 \mathrm{~Hz}, 2 \mathrm{H}), 7.03(\mathrm{~d}, J=$ $8.6 \mathrm{~Hz}, 2 \mathrm{H}), 7.17(\mathrm{td}, J=7.7,1.1 \mathrm{~Hz}, 1 \mathrm{H}), 7.27-7.38(\mathrm{~m}, 11 \mathrm{H}), 7.59(\mathrm{dd}, J=7.4,1.1$ $\mathrm{Hz}, 1 \mathrm{H}) ;{ }^{13} \mathrm{C} \mathrm{NMR}\left(125 \mathrm{MHz}, \mathrm{CD}_{2} \mathrm{Cl}_{2}\right) \delta 56.6,82.7,87.3,97.7,144.2,144.3,122.0$, $127.5,127.7,127.76,127.83,128.1,128.3,129.6,133.1,134.2$, 146.7, 149.7, 149.3, 160.4; HRMS (APCI+) calcd for $\mathrm{C}_{28} \mathrm{H}_{22} \mathrm{O}_{2}$ (M): 390.1620; found: 390.1609 .

\section{1-(4-Methoxyphenyl)ethynyl-2-diphenylhydroxymethylbenzene (19)}
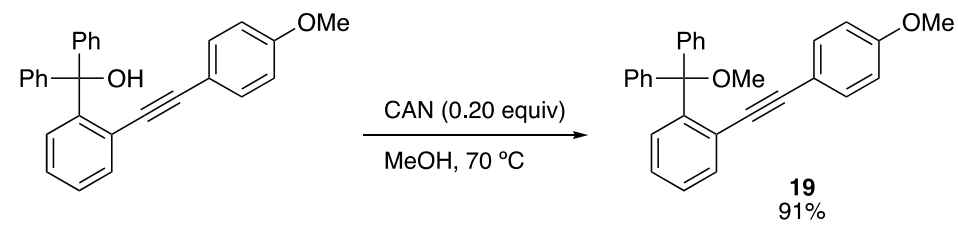

A suspension of 1-(4-methoxyphenyl)ethynyl-2-diphenylhydroxybenzene (600 $\mathrm{mg}, 1.54 \mathrm{mmol})$ in $\mathrm{MeOH}(20 \mathrm{~mL})$ was treated with ceric ammonium nitrate (CAN, 168 $\mathrm{mg}, 0.20 \mathrm{mmol}$ ) and heated to $70^{\circ} \mathrm{C}$ for $12 \mathrm{~h}$. The resulting mixture was allowed to cool down to ambient temperature. The precipitation in the mixture was collected by filtration and then washed with $\mathrm{MeOH}$ to afford compound 19 (567 $\mathrm{mg}, 91 \%$ ) as a white solid. Mp: $133-134{ }^{\circ} \mathrm{C} ;{ }^{1} \mathrm{H}$ NMR $\left(500 \mathrm{MHz}, \mathrm{CD}_{2} \mathrm{Cl}_{2}\right) \delta 3.04(\mathrm{~s}, 3 \mathrm{H}), 3.78(\mathrm{~s}, 3 \mathrm{H})$, 
$6.77(\mathrm{dt}, J=9.4,2.4 \mathrm{~Hz}, 2 \mathrm{H}), 6.90(\mathrm{dt}, J=9.4,2.4 \mathrm{~Hz}, 2 \mathrm{H}), 7.03(\mathrm{~d}, J=8.6 \mathrm{~Hz}, 2 \mathrm{H})$, $7.21-7.33(\mathrm{~m}, 7 \mathrm{H}), 7.36(\mathrm{td}, J=7.7,1.1 \mathrm{~Hz}, 1 \mathrm{H}), 7.50(\mathrm{dd}, J=7.4,1.7 \mathrm{~Hz}, 1 \mathrm{H}), 7.52-$ $7.58(\mathrm{~m}, 4 \mathrm{H}), 7.86(\mathrm{dd}, J=8.0,1.1 \mathrm{~Hz}, 1 \mathrm{H}) ;{ }^{13} \mathrm{C} \mathrm{NMR}\left(125 \mathrm{MHz}, \mathrm{CD}_{2} \mathrm{Cl}_{2}\right) \delta 52.3,55.6$, 87.3, 89.1, 96.8, 114.0, 115.6, 123.4, 127.2, 127.4, 127.9, 128.0, 128.8, 129.2, 133.0, 134.9, 143.0, 145.3, 159.9; HRMS (APCI+) calcd for $\mathrm{C}_{29} \mathrm{H}_{24} \mathrm{O}_{2}(\mathrm{M})$ : 404.1776; found: 404.1762 .

\section{3-Iodo-2-(4-methoxyphenyl)-1,1-diphenyl-1H-indene (21)}

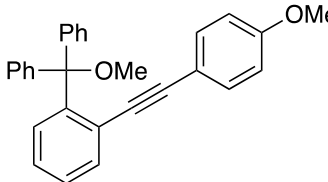

19

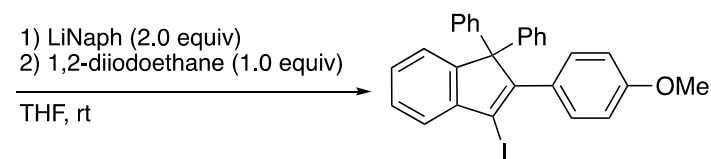

21

A mixture of granular lithium $(34.6 \mathrm{mg}, 4.99 \mathrm{mmol})$ and naphthalene $(507.1 \mathrm{mg}$, $3.96 \mathrm{mmol})$ in THF $(10 \mathrm{~mL})$ was stirred at room temperature under argon atmosphere for 4 h. The LiNaph/THF was added to a solution of 1-(4-methoxyphenyl)ethynyl-2-diphenylhydroxymethylbenzene $\quad(\mathbf{1 9}, 800 \mathrm{mg}, 1.98$ $\mathrm{mmol})$ in THF $(10 \mathrm{~mL})$ at room temperature, and the resulting mixture was stirred for 1 h. The resulting mixture was cooled down and added 1,2-diiodoethane (562 mg, 2.00 mmol) at room temperature. The reaction mixture was gradually warmed to ambient temperature, stirred another $1 \mathrm{~h}$, and then quenched with aqueous $\mathrm{Na}_{2} \mathrm{~S}_{2} \mathrm{O}_{3}$ solution. The organic layer was extracted three times with EtOAc, dried over anhydrous $\mathrm{Na}_{2} \mathrm{SO}_{4}$, and evaporated in vacuo. The crude mixture was purified with column chromatography (eluent: EtOAc/hexane = 1/10) to afford compound $21(530 \mathrm{mg}, 53 \%)$ as a white solid. Mp: $149-152{ }^{\circ} \mathrm{C} ;{ }^{1} \mathrm{H}$ NMR (500 MHz, $\mathrm{CD}_{2} \mathrm{Cl}_{2}$ ) $\delta 3.77$ (s, 3H), 4.96 (s, 1H), $6.66(\mathrm{dd}, J$ $=8.0,1.1 \mathrm{~Hz}, 1 \mathrm{H}), 6.78(\mathrm{dt}, J=9.4,2.3 \mathrm{~Hz}, 2 \mathrm{H}), 7.02(\mathrm{dt}, J=9.4,2.4 \mathrm{~Hz}, 2 \mathrm{H}), 7.15(\mathrm{td}$, $J=7.7,1.5 \mathrm{~Hz}, 1 \mathrm{H}), 7.24-7.35(\mathrm{~m}, 11 \mathrm{H}), 7.57(\mathrm{dd}, J=7.7,1.4 \mathrm{~Hz}, 1 \mathrm{H}) ;{ }^{13} \mathrm{C}$ NMR $(125$ $\left.\mathrm{MHz}, \mathrm{CD}_{2} \mathrm{Cl}_{2}\right) \delta 55.4,71.9,98.3,113.3,123.9,124.9,127.4,127.5,127.8,128.4,128.9$, $129.3,131.4,141.2,144.1,151.8,158.2,159.7$; HRMS (APCI+) calcd for $\mathrm{C}_{28} \mathrm{H}_{21} \mathrm{O}(\mathrm{M}-$ I): 373.1592 ; found: 373.1717 .

\section{7-Methoxy-10,10-diphenylindeno[2,1-a]inden-5(10H)-one (22)}




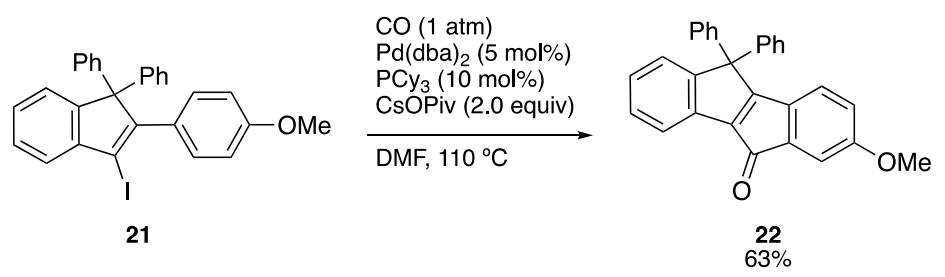

A solution of 3-iodo-2-(4-methoxyphenyl)-1,1-diphenyl-1H-indene (21, $500 \mathrm{mg}$, $2.00 \mathrm{mmol}), \mathrm{Pd}(\mathrm{dba})_{2}(29 \mathrm{mg}, 0.05 \mathrm{mmol})$, tricyclohexylphosphine $(28 \mathrm{mg}, 0.10 \mathrm{mmol})$ and anhydrous cesium pivalate (468 mg, $2.00 \mathrm{mmol})$ in DMF (20 mL) was stirred under $\mathrm{CO}$ gas atmosphere at $110^{\circ} \mathrm{C}$ for $5 \mathrm{~h}$. The resulting red mixture was allowed to cooled down to ambient temperature and quenched with water. The organic layer was extracted with $\mathrm{Et}_{2} \mathrm{O}$, washed with brine, dried over anhydrous $\mathrm{MgSO}_{4}$ and evaporated in vacuo. The crude mixture was purified by column chromatography $($ EtOAc/hexane $=1 / 4)$ and reprecipitation in $\mathrm{CH}_{2} \mathrm{Cl}_{2} / \mathrm{MeOH}$ to afford compound $22(251 \mathrm{mg}, 63 \%)$ as a purplish red powder. Mp: $217-220{ }^{\circ} \mathrm{C} ;{ }^{1} \mathrm{H}$ NMR $\left(500 \mathrm{MHz}, \mathrm{CD}_{2} \mathrm{Cl}_{2}\right) \delta 3.78(\mathrm{~s}, 3 \mathrm{H}), 6.62(\mathrm{dd}, J=$ $8.0,2.9 \mathrm{~Hz}, 1 \mathrm{H}), 6.83(\mathrm{~d}, J=8.0 \mathrm{~Hz}, 1 \mathrm{H}), 7.05(\mathrm{~d}, J=2.3 \mathrm{~Hz}, 1 \mathrm{H}), 7.21$ (td, $J=7.7,1.1$ $\mathrm{Hz}, 1 \mathrm{H}), 7.25-7.31(\mathrm{~m}, 10 \mathrm{H}), 7.33(\mathrm{t}, J=7.2 \mathrm{~Hz}, 1 \mathrm{H}), 7.38(\mathrm{~d}, J=7.4 \mathrm{~Hz}, 1 \mathrm{H}), 7.38$ (d, $J=7.4 \mathrm{~Hz}, 1 \mathrm{H}), 7.66(\mathrm{~d}, J=7.4 \mathrm{~Hz}, 1 \mathrm{H}) ;{ }^{13} \mathrm{C} \mathrm{NMR}\left(125 \mathrm{MHz}, \mathrm{CD}_{2} \mathrm{Cl}_{2}\right) \delta 56.1,65.1$, 112.2, 115.1, 121.3, 122.4, 125.6, 126.7, 127.8, 128.1, 128.8, 129.0, 131.4, 135.4, 138.7, 139.2, 141.8, 155.5, 161.5, 177.3, 190.3; HRMS (APCI+) calcd for $\mathrm{C}_{29} \mathrm{H}_{20} \mathrm{O}_{2}(\mathrm{M}+\mathrm{H})$ : 401.1542; found: 401.1482 .

\section{7,7’-Dimethoxy-spiro-CPV (6)}

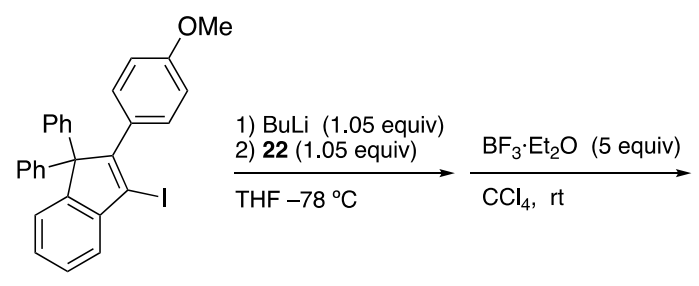

21

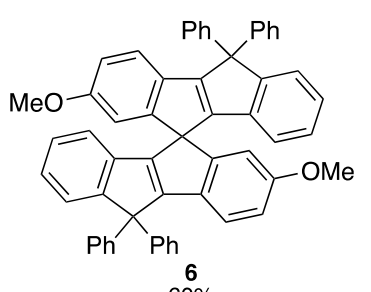

$60 \%$

Butyllithium (0.26 mL, $1.57 \mathrm{M})$ was added into a solution of 3-iodo-2-(4-methoxyphenyl)-1,1-diphenyl-1H-indene (21, $200 \mathrm{mg}, 0.40 \mathrm{mmol}$ ) in THF $(10 \mathrm{~mL})$ dropwisely at $-78{ }^{\circ} \mathrm{C}$ and stirred for $30 \mathrm{~min}$. The resulting mixture was added ketone $22(168 \mathrm{mg}, 0.42 \mathrm{mmol})$ and stirred for $1 \mathrm{~h}$. The reaction mixture was allowed to warm gradually to ambient temperature and then was added water. The organic layer was extracted with dichloromethane, dried over anhydrous $\mathrm{Na}_{2} \mathrm{SO}_{4}$, and evaporated in vacuo. The crude mixture was dissolved in $\mathrm{CCl}_{4}$ followed by addition of $\mathrm{BF}_{3} \bullet \mathrm{Et}_{2} \mathrm{O}(282$ 
$\mathrm{mg}, 2.0 \mathrm{mmol}$ ) at room temperature. After stirring for $5 \mathrm{~min}$, water was added. The organic layer was extracted with chloroform, dried over anhydrous $\mathrm{Na}_{2} \mathrm{SO}_{4}$ and evaporated in vacuo. The crude material was purified by column chromatography (eluent: $\mathrm{CH}_{2} \mathrm{Cl}_{2} /$ hexane $\left.=1 / 2\right)$ to afford compound $6(180 \mathrm{mg}, 60 \%)$ as a white solid. Mp: $278-281{ }^{\circ} \mathrm{C} ;{ }^{1} \mathrm{H}$ NMR (500 MHz, $\left.\mathrm{CD}_{2} \mathrm{Cl}_{2}\right) \delta 3.60$ (s, 3H), $6.20(\mathrm{~d}, J=7.4 \mathrm{~Hz}, 2 \mathrm{H})$, $6.42(\mathrm{~d}, J=2.3 \mathrm{~Hz}, 2 \mathrm{H}), 6.75(\mathrm{dd}, J=8.3,2.6 \mathrm{~Hz}, 2 \mathrm{H}), 6.88(\mathrm{t}, J=7.4 \mathrm{~Hz}, 2 \mathrm{H}), 7.01(\mathrm{td}$, $J=7.4,1.1 \mathrm{~Hz}, 2 \mathrm{H}), 7.23(\mathrm{~d}, J=8.6 \mathrm{~Hz}, 2 \mathrm{H}), 7.27-7.43(\mathrm{~m}, 18 \mathrm{H}), 7.49(\mathrm{dt}, J=6.5,1.7$ $\mathrm{Hz}, 4 \mathrm{H}) ;{ }^{13} \mathrm{C}$ NMR $\left(125 \mathrm{MHz}, \mathrm{CD}_{2} \mathrm{Cl}_{2}\right) \delta$ 55.6, 59.9, 64.2, 110.5, 112.6, 119.5, 121.4, 125.0, 125.7, 127.4, 127.5, 128.6, 128.7, 128.8, 128.9, 133.3, 138.2, 143.2, 143.3, 147.9, 152.1, 156.6, 159.06, 159.12; HRMS (APCI+) calcd for $\mathrm{C}_{57} \mathrm{H}_{40} \mathrm{O}_{2}(\mathrm{M})$ : 756.3028; found: 756.3028 .

\section{Hydrodemethylation of methoxy group.}

\section{7,7'-Dihydroxy-spiro-CPV (7)}
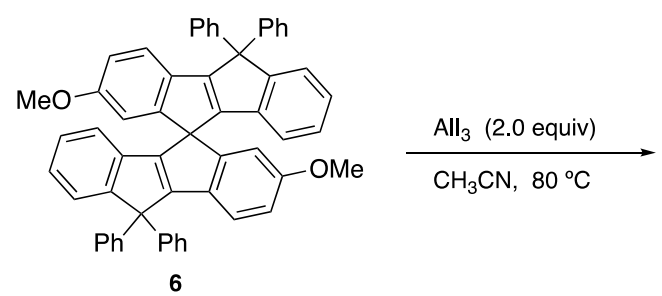

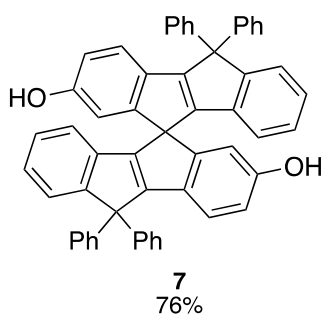

The dispersion of aluminum iodide $\left(\begin{array}{llll}130 & \mathrm{mg}, & 0.318 \mathrm{mmol}\end{array}\right)$ and 7,7'-dimethoxy-spiro-CPV $(6,120 \mathrm{mg}, 0.159 \mathrm{mmol})$ in acetonitrile $(5 \mathrm{~mL})$ was stirred overnight at $80{ }^{\circ} \mathrm{C}$. The mixture was cooled down to room temperature and water was added. The organic layer was extracted with chloroform, dried over $\mathrm{Na}_{2} \mathrm{SO}_{4}$ and evaporated in vacuo. The crude mixture was purified by column chromatography (eluent: EtOAc/hexane $=1 / 3)$ to afford compound $7(88.3 \mathrm{mg}, 76 \%)$ as a white solid. The racemic compound can be separated into $(R)$ - and $(S)-7$ by chiral HPLC equipped with a DAICEL CHIRALPAK IF-3 $(4.6 \mathrm{~mm} \times 250 \mathrm{~mm})$ column. $t_{\mathrm{R}}=14.88 \mathrm{~min}$ for (+)-7, $21.30 \mathrm{~min}$ for (-)-7 (flow rate: $1.0 \mathrm{~mL} / \mathrm{min}$, eluent: $\mathrm{CHCl}_{3} / \mathrm{Hexane}=9 / 1$ ). $\mathrm{Mp}$ : 238-239 ${ }^{\circ} \mathrm{C} ;{ }^{1} \mathrm{H}$ NMR (500 MHz, $\left.\mathrm{CD}_{2} \mathrm{Cl}_{2}\right) \delta 4.79$ (s, 2H), $6.20(\mathrm{~d}, J=7.4 \mathrm{~Hz}, 2 \mathrm{H}), 6.37$ $(\mathrm{d}, J=2.3 \mathrm{~Hz}, 2 \mathrm{H}), 6.68(\mathrm{dd}, J=8.0,2.3 \mathrm{~Hz}, 2 \mathrm{H}), 6.88(\mathrm{td}, J=7.4,1.1 \mathrm{~Hz}, 2 \mathrm{H}), 6.99-$ 7.04 (m, 2H), 7.18 (d, $J=8.6 \mathrm{~Hz}, 2 \mathrm{H}), 7.29-7.41$ (m, 20H), 7.50 (dt, $J=6.7,1.6 \mathrm{~Hz}$, $4 \mathrm{H}) ;{ }^{13} \mathrm{C}$ NMR $\left(125 \mathrm{MHz}, \mathrm{CD}_{2} \mathrm{Cl}_{2}\right) \delta 64.2,111.5,114.5,119.5,121.7,125.1,125.8$, $127.4,127.49,127.54,128.7,128.8,128.9,133.3,138.0,143.0,143.3,147.7,152.2$, 
155.0, 156.6, 159.1; HRMS (APCI+) calcd for $\mathrm{C}_{55} \mathrm{H}_{36} \mathrm{O}_{2}(\mathrm{M})$ : 728.2715; found: 728.2708 .

m AU Chiralpak IF/ $\mathrm{CHCl}_{3}:$ Hexane=9:1/ Flow rate $=1.0 \mathrm{~mL} / \mathrm{min}$

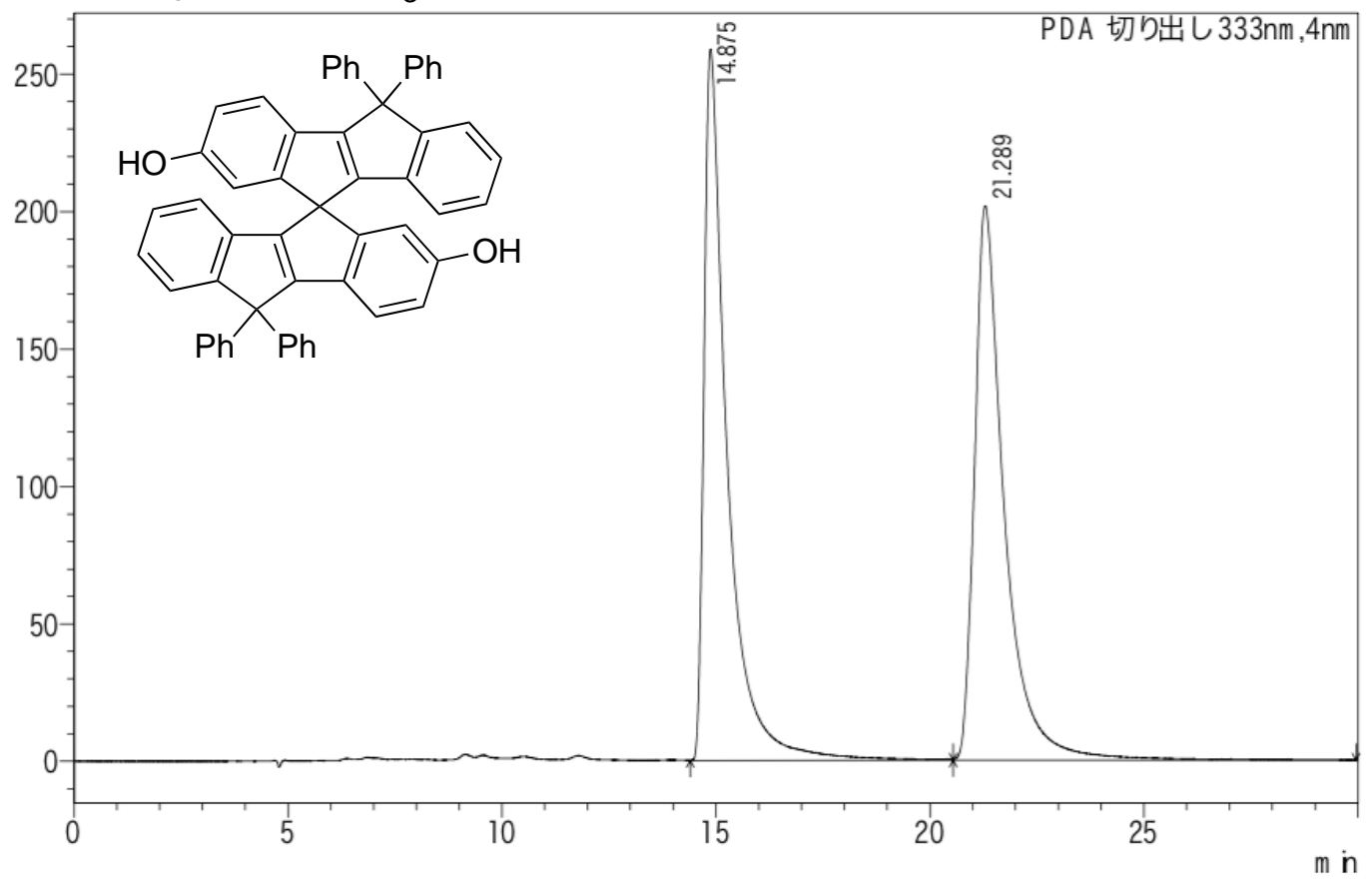

\section{2,2'-Dibromo-7,7'-dihydroxy-spiro-CPV (10)}
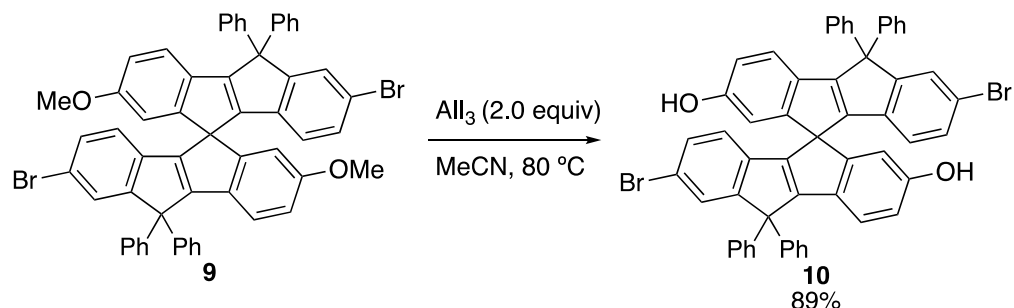

Using $9(701 \mathrm{mg}, 0.766 \mathrm{mmol})$ in the hydromethylation procedure afforded $\mathbf{1 0}$ (606 mg, 89\%) as a white solid. Mp: $268-271{ }^{\circ} \mathrm{C} ;{ }^{1} \mathrm{H}$ NMR $\left(500 \mathrm{MHz}, \mathrm{CD}_{2} \mathrm{Cl}_{2}\right) \delta 4.91$ (s, 2H), 5.99 (d, $J=8.0 \mathrm{~Hz}, 2 \mathrm{H}), 6.38$ (d, $J=2.3 \mathrm{~Hz}, 2 \mathrm{H}), 6.69$ (dd, $J=8.3,2.6 \mathrm{~Hz}, 2 \mathrm{H})$, $7.01(\mathrm{dd}, J=8.0,1.7 \mathrm{~Hz}, 2 \mathrm{H}), 7.18(\mathrm{~d}, J=8.0 \mathrm{~Hz}, 2 \mathrm{H}), 7.26-7.41$ (m, 16H), 7.45-7.49 $(\mathrm{m}, 4 \mathrm{H}), 7.50(\mathrm{~d}, J=1.7 \mathrm{~Hz}, 2 \mathrm{H}) ;{ }^{13} \mathrm{C} \mathrm{NMR}\left(125 \mathrm{MHz}, \mathrm{CD}_{2} \mathrm{Cl}_{2}\right) \delta$ 59.6, 64.5, 111.7, $114.8,119.6,120.6,122.0,127.78,127.82$, 128.5, 128.6, 128.7, 128.9, 129.2, 130.6, 132.9, 136.9, 142.0, 142.5, 146.5, 151.8, 155.3, 158.5, 159.7; HRMS (APCI+) calcd for $\mathrm{C}_{55} \mathrm{H}_{34} \mathrm{Br}_{2} \mathrm{O}_{2}(\mathrm{M}): 844.0926$; found 844.0899.

\section{Triflation of hydroxy group}




\section{Spiro-CPV-7,7'-Ditriflate (8)}
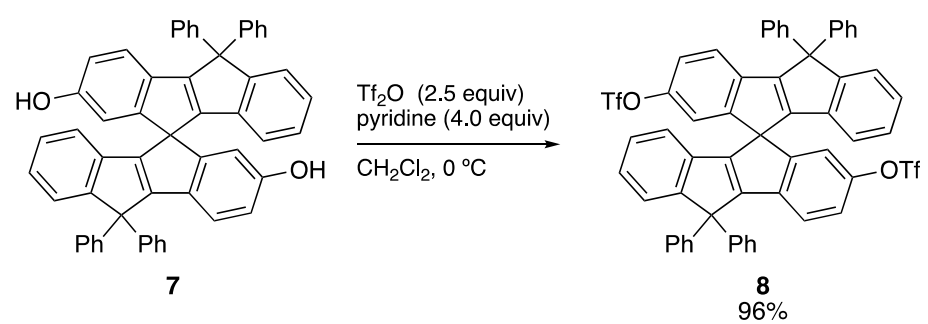

Trifluoromethanesulfonic anhydride $\left(\mathrm{Tf}_{2} \mathrm{O}, 193 \mathrm{mg}, 0.6 .89 \mathrm{mmol}\right)$, pyridine $(87$ $\mathrm{mg}, 1.098 \mathrm{mmol})$ and $7(200 \mathrm{mg}, 0.275 \mathrm{mmol})$ were dissolved in dichloromethane $(2.0$ $\mathrm{mL}$ ) and stirred for $18 \mathrm{~h}$ at $0{ }^{\circ} \mathrm{C}$. The reaction mixture was allowed to warm gradually to ambient temperature and then was added $1 \mathrm{M}$ aqueous $\mathrm{HCl}$ solution. The organic layer was extracted with dichloromethane, dried over anhydrous $\mathrm{Na}_{2} \mathrm{SO}_{4}$, and evaporated in vacuo. The crude mixture was purified by column chromatography (eluent: $\mathrm{CH}_{2} \mathrm{Cl}_{2} /$ hexane $\left.=1 / 4\right)$ to afford compound $\mathbf{8}(271 \mathrm{mg}, 96 \%)$ as a white solid. Mp: 150 $152{ }^{\circ} \mathrm{C} ;{ }^{1} \mathrm{H}$ NMR $\left(500 \mathrm{MHz}, \mathrm{CD}_{2} \mathrm{Cl}_{2}\right) \delta 6.26(\mathrm{~d}, J=7.4 \mathrm{~Hz}, 2 \mathrm{H}), 6.71(\mathrm{~s}, 2 \mathrm{H}), 6.94(\mathrm{t}, J$ $=8.0 \mathrm{~Hz}, 2 \mathrm{H}), 7.12(\mathrm{td}, J=7.4,1.1 \mathrm{~Hz}, 2 \mathrm{H}), 7.19(\mathrm{dd}, J=8.0,2.3 \mathrm{~Hz}, 2 \mathrm{H}), 7.33-7.46$ (m, 24H); ${ }^{13} \mathrm{C}$ NMR $\left(125 \mathrm{MHz}, \mathrm{CD}_{2} \mathrm{Cl}_{2}\right) \delta 60.1,64.5,116.9,120.2,121.8,122.0,125.4$, 127.4, 127.9, 128.3, 128.7, 129.0, 129.2, 136.6, 140.6, 142.3, 142.4, 148.2, 150.6, 151.0, 157.1, 158.4; HRMS (APCI+) calcd for $\mathrm{C}_{57} \mathrm{H}_{34} \mathrm{~F}_{6} \mathrm{~S}_{2} \mathrm{O}_{6}(\mathrm{M}+\mathrm{H})$ : 993.1779; found: 993.1779 .

\section{2,2'-Dibromo-spiro-CPV-7,7'-ditriflate (11)}

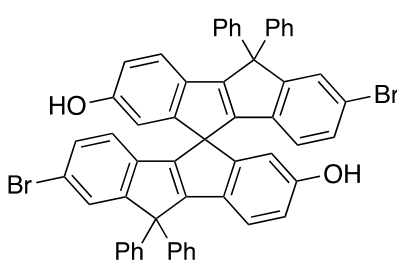

10

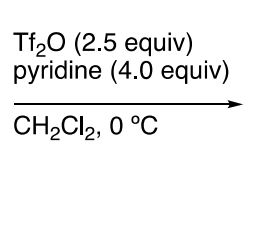

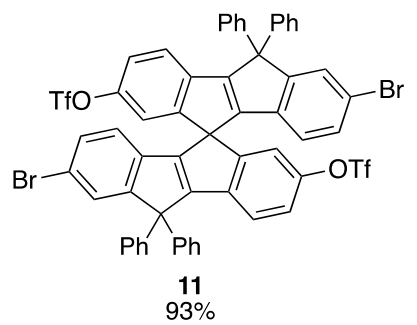

Using 10 (13 $\mathrm{mg}, 0.0147 \mathrm{mmol})$ in the triflation procedure afforded $11(15.7 \mathrm{mg}, 93 \%)$ as a white solid. Mp: $250-254{ }^{\circ} \mathrm{C} ;{ }^{1} \mathrm{H}$ NMR $\left(500 \mathrm{MHz}, \mathrm{CD}_{2} \mathrm{Cl}_{2}\right) \delta 6.05(\mathrm{~d}, J=8.0 \mathrm{~Hz}$, 2H), $6.72(\mathrm{~d}, J=2.3 \mathrm{~Hz}, 2 \mathrm{H}), 7.07$ (dd, $J=8.0,1.7 \mathrm{~Hz}, 2 \mathrm{H}), 7.21$ (dd, $J=8.6,2.3 \mathrm{~Hz}$, 2H), 7.29-7.34 (m, 4H), 7.36-7.43 (m, 18H), 7.56 (d, $J=1.7 \mathrm{~Hz}, 2 \mathrm{H}) ;{ }^{13} \mathrm{C}$ NMR (125 $\left.\mathrm{MHz}, \mathrm{CD}_{2} \mathrm{Cl}_{2}\right)$ 860.0, 64.7, 117.1, 121.2, 121.4, 122.1, 122.3, 128.2, 128.3, 128.6, 128.9, $129.2,129.4,131.0,135.5,140.2,141.3,141.5,148.4,149.6,150.2,158.9,159.0$; HRMS (APCI+) calcd for $\mathrm{C}_{57} \mathrm{H}_{32} \mathrm{Br}_{2} \mathrm{~F}_{6} \mathrm{~S}_{2} \mathrm{O}_{6}(\mathrm{M}+\mathrm{H})$ : 1148.9989 ; found: 1149.0042 . 
Spiro-CPV (1) from 8
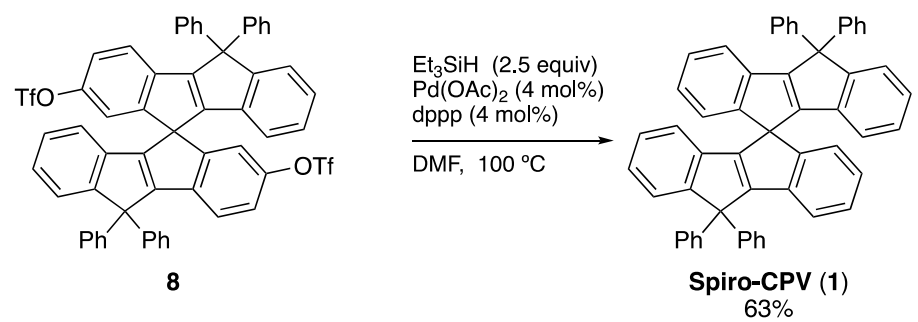

Triethylsilane (6.16 mg, $0.053 \mathrm{mmol}), \operatorname{Pd}(\mathrm{OAc})_{2} \quad(0.19 \mathrm{mg}, 0.84 \mu \mathrm{mol})$, 1,3-bis(diphenylphosphino)propane (0.35 mg, $0.84 \mu \mathrm{mol})$, and 8 (21 mg, $0.021 \mathrm{mmol})$ were dissolved in DMF $(1.0 \mathrm{~mL})$. After stirring for $12 \mathrm{~h}$ at $100{ }^{\circ} \mathrm{C}$, the mixture was allowed to cool down to ambient temperature and water was added to the mixture. Organic layer was extracted with chloroform, dried over anhydrous $\mathrm{Na}_{2} \mathrm{SO}_{4}$, and evaporated in vacuo. The crude mixture was filtrated through a pad of silica-gel with chloroform and further purified by reprecipitation $\left(\mathrm{CH}_{2} \mathrm{Cl}_{2} / \mathrm{MeOH}\right)$ to afford spiro-CPV $(\mathbf{1}, 9.23 \mathrm{mg}, 63 \%)$ as a white solid.

\section{Bromination}

\section{Preparation of $\mathrm{CuBr}_{2} \bullet \mathrm{Al}_{2} \mathrm{O}_{3}$}

$\mathrm{CuBr}_{2}(102.2 \mathrm{~g})$ and $\mathrm{Al}_{2} \mathrm{O}_{3}(204 \mathrm{~g})$ are mixed in water $(500 \mathrm{~mL})$ for $2 \mathrm{~h}$. After evaporation of water and drying in vacuo for $12 \mathrm{~h}$, the dark brown powder of $\mathrm{CuBr}_{2} \bullet \mathrm{Al}_{2} \mathrm{O}_{3}$ (285 g) was obtained to be utilized for the following bromination reactons.

\section{2,2',7,7'-Tetrabromo-spiro-CPV (2)}
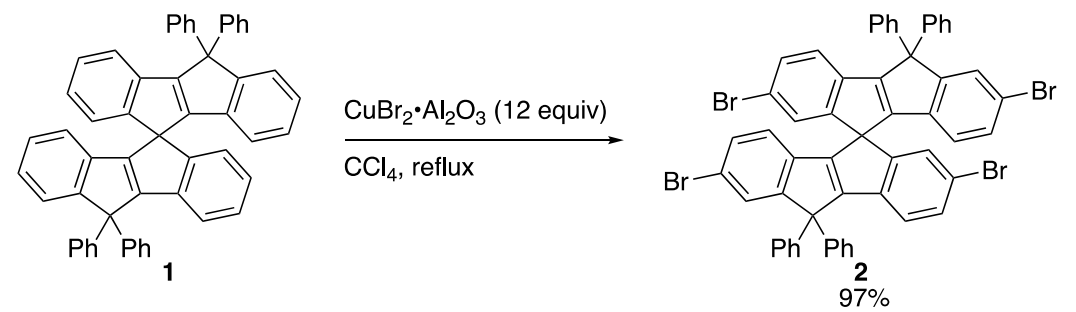

The suspension of $\mathrm{CuBr}_{2} \bullet \mathrm{Al}_{2} \mathrm{O}_{3}(69.3 \mathrm{~g}, 10.3 \mathrm{mmol}, 33 \mathrm{wt} \%)$ and $1(6.0 \mathrm{~g}, 8.62$ mmol) in $\mathrm{CCl}_{4}$ was refluxed for $15 \mathrm{~h}$. The reaction mixture was cooled to ambient temperature and passed through a pad of celite with dichloromethane. After evaporation of the solvent, the residue was purified by reprecipitation $\left(\mathrm{CH}_{2} \mathrm{Cl}_{2} / \mathrm{MeOH}\right)$ to afford 2 (9.86 g, 97\%) as a white solid. Mp: $361-366{ }^{\circ} \mathrm{C} ;{ }^{1} \mathrm{H}$ NMR $\left(500 \mathrm{MHz}, \mathrm{CD}_{2} \mathrm{Cl}_{2}\right) \delta 5.99$ (d, 
$J=8.0 \mathrm{~Hz}, 2 \mathrm{H}), 6.99(\mathrm{~d}, J=1.7 \mathrm{~Hz}, 2 \mathrm{H}), 7.04(\mathrm{dd}, J=8.0,1.7 \mathrm{~Hz}, 2 \mathrm{H}), 7.22(\mathrm{~d}, J=8.0$ $\mathrm{Hz}, 2 \mathrm{H}), 7.24-7.30(\mathrm{~m}, 4 \mathrm{H}), 7.31-7.46(\mathrm{~m}, 18 \mathrm{H}), 7.54(\mathrm{~d}, J=1.7 \mathrm{~Hz}, 2 \mathrm{H}),{ }^{13} \mathrm{C} \mathrm{NMR}$ $\left(125 \mathrm{MHz}, \mathrm{CD}_{2} \mathrm{Cl}_{2}\right) \delta 59.8,64.6,120.6,120.8,121.2,122.6,126.9,128.0,128.1,128.5$, $128.6,128.7,129.0,129.3,130.8,131.7,139.0,141.5,141.9,148.4,150.3,158.8$, 159.3; HRMS (APCI+) calcd for $\mathrm{C}_{55} \mathrm{H}_{32} \mathrm{Br}_{4}(\mathrm{M})$ : 1007.9238; found: 1007.9243 .

\section{2,2'-Dibromo-7,7'-dimethoxy-spiro-CPV (9)}
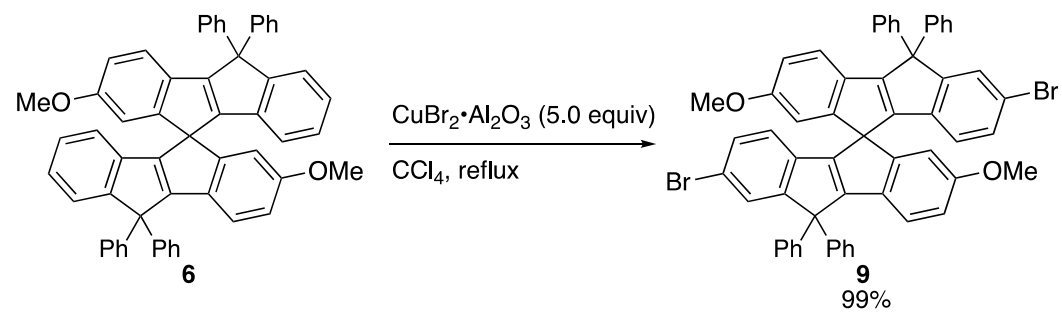

Using 6 (200 mg, $0.264 \mathrm{mmol})$ in the bromination procedure afforded 9 (241 $\mathrm{mg}$, 99\%) as a white solid. Mp: $306-308{ }^{\circ} \mathrm{C} ;{ }^{1} \mathrm{H}$ NMR (500 MHz, $\left.\mathrm{CD}_{2} \mathrm{Cl}_{2}\right) \delta 3.61(\mathrm{~s}, 6 \mathrm{H})$, $5.99(\mathrm{~d}, J=8.0 \mathrm{~Hz}, 2 \mathrm{H}), 6.42(\mathrm{~d}, J=2.3 \mathrm{~Hz}, 2 \mathrm{H}), 6.75(\mathrm{dd}, J=8.6,2.3 \mathrm{~Hz}, 2 \mathrm{H}), 7.00$ $(\mathrm{dd}, J=8.0,1.7 \mathrm{~Hz}, 2 \mathrm{H}), 7.23(\mathrm{~d}, J=8.6 \mathrm{~Hz}, 2 \mathrm{H}), 7.28-7.40(\mathrm{~m}, 18 \mathrm{H}), 7.46(\mathrm{dt}, J=8.2$, $1.9 \mathrm{~Hz}, 4 \mathrm{H}), 7.49(\mathrm{~d}, J=1.7 \mathrm{~Hz}, 2 \mathrm{H}) ;{ }^{13} \mathrm{C}$ NMR $\left(125 \mathrm{MHz}, \mathrm{CD}_{2} \mathrm{Cl}_{2}\right)$ $\delta 53.9,64.2,110.3,112.5,119.2,120.2,121.5,127.5,128.1,128.3,128.4,128.6,128.8$, $130.3,132.5,136.7,141.9,142.2,146.3,151.4,158.2,159.1,159.5 ; \quad H R M S \quad$ (APCI+) calcd for $\mathrm{C}_{57} \mathrm{H}_{38} \mathrm{Br}_{2} \mathrm{O}_{2}(\mathrm{M}+\mathrm{H})$ : 913.1317; found: 913.1304 .

\section{Iodination}

\section{2,2'-7,7'-Tetraiodo-spiro-CPV (3)}
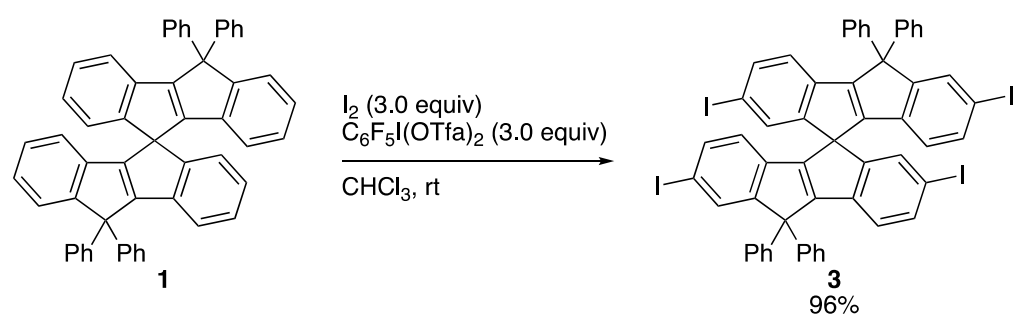

Iodine (326 mg, $1.29 \mathrm{mmol})$, [bis(trifluorocetoxy)iodo]pentafluorobenzene (671 $\mathrm{mg}, 1.29 \mathrm{mmol})$, and 1 (300 $\mathrm{mg}, 0.430 \mathrm{mmol})$ were dissolved in chloroform (10 $\mathrm{mL})$ and stirred for $18 \mathrm{~h}$ at ambient temperature. The reaction mixture added saturated aqueous solution of $\mathrm{Na}_{2} \mathrm{~S}_{2} \mathrm{O}_{3}$. The organic layer was extracted with chloroform, dried over anhydrous $\mathrm{Na}_{2} \mathrm{SO}_{4}$, and evaporated in vacuo. The crude mixture was purified by 
reprecipitation $\left(\mathrm{CH}_{2} \mathrm{Cl}_{2} / \mathrm{MeOH}\right)$ to afford compound 3 (494 $\left.\mathrm{mg}, 96 \%\right)$ as a white solid. Mp: $322-324{ }^{\circ} \mathrm{C} ;{ }^{1} \mathrm{H}$ NMR $\left(500 \mathrm{MHz}, \mathrm{CD}_{2} \mathrm{Cl}_{2}\right) \delta 5.87(\mathrm{~d}, J=8.0 \mathrm{~Hz}, 2 \mathrm{H}), 7.09(\mathrm{~d}, J=$ $8.0 \mathrm{~Hz}, 2 \mathrm{H}), 7.15$ (d, $J=1.1 \mathrm{~Hz}, 2 \mathrm{H}), 7.21-7.29$ (m, 6H), 7.31-7.46 (m, 16H), 7.59 (dd, $J=8.0,1.7 \mathrm{~Hz}, 2 \mathrm{H}), 7.73(\mathrm{~d}, J=1.7 \mathrm{~Hz}, 2 \mathrm{H}) ;{ }^{13} \mathrm{C} \mathrm{NMR}\left(125 \mathrm{MHz}, \mathrm{CD}_{2} \mathrm{Cl}_{2}\right) \delta 64.5$, 77.9, 91.8, 92.1, 121.6, 123.0, 127.99, 128.02, 128.5, 128.6, 129.0, 129.3, 132.5, 134.3, 136.5, 136.9, 137.7, 139.4, 141.4, 141.9, 148.3, 150.4, 158.9, 159.3, ; HRMS (APCI+) calcd for $\mathrm{C}_{55} \mathrm{H}_{32} \mathrm{I}_{4}(\mathrm{M}): 1199.8683$; found: 1199.8740 .

\section{Borylation}

2,2',7,7'-Tetrakis(4,4,5,5-tetramethyl-1,3,2-dioxaboran-2-yl)-spiro-CPV (4)
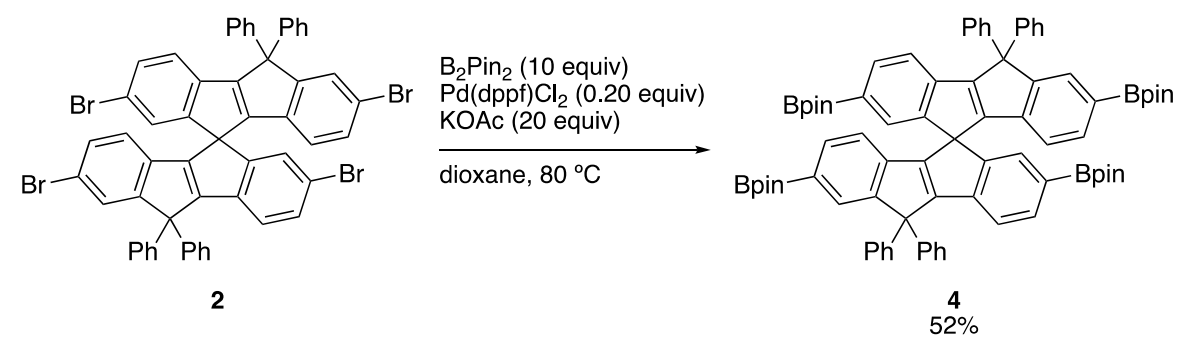

Bis(pinacolato)diborone (1.01 g, $4.0 \mathrm{mmol}), \mathrm{Pd}(\mathrm{dppf}) \mathrm{Cl}_{2}(65.3 \mathrm{mg}, 0.080 \mathrm{mmol})$, potassium acetate $(785 \mathrm{mg}, 8.0 \mathrm{mmol})$, and $2(400 \mathrm{mg}, 0.40 \mathrm{mmol})$ was dissolved in dioxane $(16 \mathrm{~mL})$ and heated to $80{ }^{\circ} \mathrm{C}$. After stirring for $22 \mathrm{~h}$, the reaction mixture was cooled to ambient temperature and added water. The organic layer was extracted with chloroform, dried over anhydrous $\mathrm{Na}_{2} \mathrm{SO}_{4}$, and evaporated in vacuo. The crude mixture was purified by column chromatography (eluent: EtOAc/hexane $=1 / 1)$ to afford $4(251$ mg, 52\%) as a white solid. Mp: 332-335 ${ }^{\circ} \mathrm{C} ;{ }^{1} \mathrm{H}$ NMR (500 MHz, $\left.\mathrm{CD}_{2} \mathrm{Cl}_{2}\right) \delta 1.19$ (s, $24 \mathrm{H}), 1.23(\mathrm{~s}, 24 \mathrm{H}), 6.22(\mathrm{~d}, J=8.0 \mathrm{~Hz}, 2 \mathrm{H}), 7.16(\mathrm{~s}, 2 \mathrm{H}), 7.30(\mathrm{~d}, J=7.4 \mathrm{~Hz}, 2 \mathrm{H})$, $7.31-7.40(\mathrm{~m}, 18 \mathrm{H}), 7.53(\mathrm{dt}, J=6.9,1.6 \mathrm{~Hz}, 4 \mathrm{H}), 7.65(\mathrm{dd}, J=7.4,1.1 \mathrm{~Hz}, 2 \mathrm{H}), 7.74$ $(\mathrm{s}, 2 \mathrm{H}) ;{ }^{13} \mathrm{C}$ NMR $\left(125 \mathrm{MHz}, \mathrm{CD}_{2} \mathrm{Cl}_{2}\right) \delta 24.9,25.0,64.3,84.0,119.6,121.0,127.57$, $127.61,128.7,128.8,128.9,129.0,130.6,134.5,134.9,140.5,142.5,142.6,143.1$, 148.8, 150.9, 156.6, 161.3; HRMS (APCI+) calcd for $\mathrm{C}_{79} \mathrm{H}_{80} \mathrm{~B}_{4} \mathrm{O}_{8}(\mathrm{M}+\mathrm{H}): 1201.6344$; found: 1201.6314 .

\section{7,7'-Dimethoxy-2,2'-diphenyl-spiro-CPV (12)}



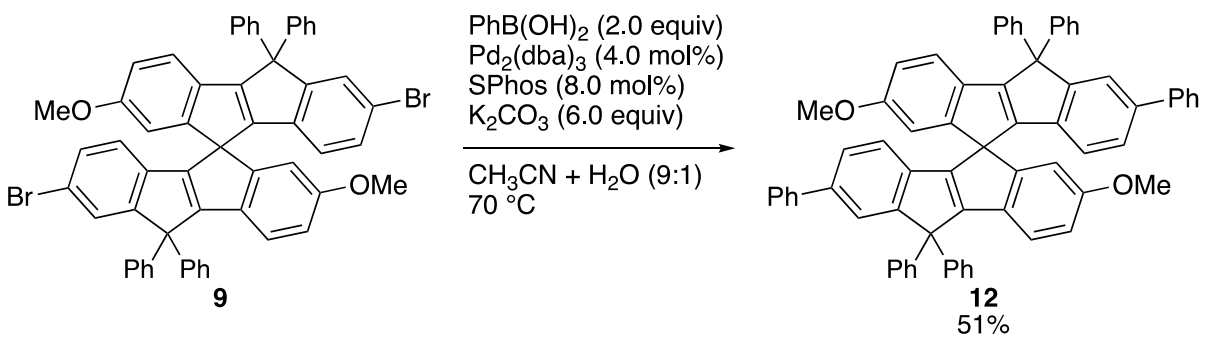

Phenylboronic acid (6.3 mg, $0.026 \mathrm{mmol}), \mathrm{Pd}_{2}(\mathrm{dba})_{3}(0.1 \mathrm{mg}, 0.10 \mu \mathrm{mol})$, SPhos $(0.09$ $\mathrm{mg}, 0.21 \mu \mathrm{mol})$, potassium carbonate $(21.6 \mathrm{mg}, 0.16 \mathrm{mmol})$, and 9 (23.8 $\mathrm{mg}, 0.026$ mmol) was dissolved in acetonitrile $(0.90 \mathrm{~mL})$ and water $(0.10 \mathrm{~mL})$, and heated to $70{ }^{\circ} \mathrm{C}$. After stirring for $15 \mathrm{~h}$, the reaction mixture was cooled to ambient temperature and added water. The organic layer was extracted with $\mathrm{CH}_{2} \mathrm{Cl}_{2}$, dried over anhydrous $\mathrm{Na}_{2} \mathrm{SO}_{4}$, and evaporated in vacuo. The crude mixture was purified by column chromatography (eluent: $\mathrm{CH}_{2} \mathrm{Cl}_{2} /$ hexane $\left.=1 / 2\right)$ to afford $12(12.0 \mathrm{mg}, 51 \%)$ as a white solid. Mp: $340-344{ }^{\circ} \mathrm{C} ;{ }^{1} \mathrm{H}$ NMR (500 MHz, $\left.\mathrm{CD}_{2} \mathrm{Cl}_{2}\right) \delta 3.63$ (s, 6H), 6.29 (d, J=7.4 Hz, $2 \mathrm{H}), 6.47(\mathrm{~d}, J=2.3 \mathrm{~Hz}, 2 \mathrm{H}), 6.77(\mathrm{dd}, J=8.6,2.3 \mathrm{~Hz}, 2 \mathrm{H}), 6.77(\mathrm{dd}, J=8.0,1.7 \mathrm{~Hz}$, 2H), $7.13(\mathrm{dd}, J=8.0,1.7 \mathrm{~Hz}, 2 \mathrm{H}), 7.26$ (t, $J=7.7 \mathrm{~Hz}, 2 \mathrm{H}), 7.31-7.44(\mathrm{~m}, 24 \mathrm{H}), 7.54-$ $7.58(\mathrm{~m}, 4 \mathrm{H}), 7.62(\mathrm{~d}, J=1.7 \mathrm{~Hz}, 2 \mathrm{H}), 7.62(\mathrm{~d}, J=1.7 \mathrm{~Hz}, 2 \mathrm{H}) ;{ }^{13} \mathrm{C}$ NMR (125 MHz, $\left.\mathrm{CD}_{2} \mathrm{Cl}_{2}\right) \delta 55.7,60.0,64.5,110.6,112.7,119.7,121.5,124.0,126.6,127.3,127.5,128.7$, 128.8, 128.92, 128.95, 128.99, 133.4, 137.4, 139.0, 141.6, 143.1, 143.3, 147.6, 152.1, 157.4, 159.2, 159.6; HRMS (APCI+) calcd for $\mathrm{C}_{69} \mathrm{H}_{48} \mathrm{O}_{2}(\mathrm{M})$ : 909.1182; found: 909.1168.

\section{7,7'-Dimethoxy-2,2'-bis(phenylethynyl)-spiro-CPV (13)}
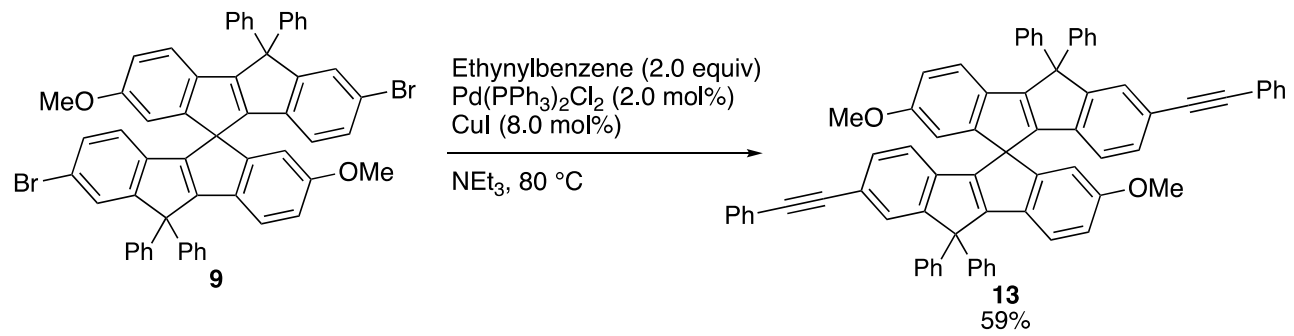

Ethynylbenzene (5.84 mg, $0.57 \mathrm{mmol}), \mathrm{Pd}\left(\mathrm{PPh}_{3}\right)_{2} \mathrm{Cl}_{2}(0.38 \mathrm{mg}, 0.54 \mu \mathrm{mol}), \mathrm{CuI}(0.21$ $\mathrm{mg}, 1.09 \mu \mathrm{mol})$, and $9(24.9 \mathrm{mg}, 0.027 \mathrm{mmol})$ was dissolved in triethylamine $(1.0 \mathrm{~mL})$ and heated to $80^{\circ} \mathrm{C}$. After stirring for $15 \mathrm{~h}$, the reaction mixture was cooled to ambient temperature and added aqueous $\mathrm{NH}_{4} \mathrm{Cl}$ solution. The organic layer was extracted with $\mathrm{CH}_{2} \mathrm{Cl}_{2}$, dried over anhydrous $\mathrm{Na}_{2} \mathrm{SO}_{4}$, and evaporated in vacuo. The crude mixture was purified by column chromatography (eluent: $\mathrm{CH}_{2} \mathrm{Cl}_{2} /$ hexane $\left.=1 / 2\right)$ to afford $12(15.3$ 
mg, 59\%) as a white solid. Mp: $338-341{ }^{\circ} \mathrm{C} ;{ }^{1} \mathrm{H}$ NMR $\left(500 \mathrm{MHz}, \mathrm{CD}_{2} \mathrm{Cl}_{2}\right) \delta 3.63$ (s, $6 \mathrm{H}), 6.15(\mathrm{~d}, J=7.4 \mathrm{~Hz}, 2 \mathrm{H}), 6.45(\mathrm{~d}, J=2.3 \mathrm{~Hz}, 2 \mathrm{H}), 6.78(\mathrm{dd}, J=8.3,2.6 \mathrm{~Hz}, 2 \mathrm{H})$, $7.06(\mathrm{dd}, J=7.4,1.1 \mathrm{~Hz}, 2 \mathrm{H}), 7.26(\mathrm{~d}, J=8.0 \mathrm{~Hz}, 2 \mathrm{H}), 7.29-7.33$ (m, 6H), 7.34-7.41 $(\mathrm{m}, 16 \mathrm{H}), 7.42-7.45(\mathrm{~m}, 4 \mathrm{H}), 7.52(\mathrm{t}, J=6.9 \mathrm{~Hz}, 6 \mathrm{H}) ;{ }^{13} \mathrm{C} \mathrm{NMR}\left(125 \mathrm{MHz}, \mathrm{CD}_{2} \mathrm{Cl}_{2}\right) \delta$ 52.5 , 55.4, 64.0, 90.1, 103.3, 110.3, 112.6, 119.1, 119.9, 121.6, 123.3, 127.4, 127.7, 128.2, 128.4, 128.5, 128.6, 128.7, 131.0, 131.4, 132.7, 138.0, 142.2, 142.4, 151.7, 156.5, 159.1, 160.4; HRMS (APCI+) calcd for $\mathrm{C}_{73} \mathrm{H}_{48} \mathrm{O}_{2}(\mathrm{M})$ : 957.1516; found: 957.1489.

\section{2,2'-7,7'-Tetrakis(di-p-anisyl)amino-spiro-CPV (5)}
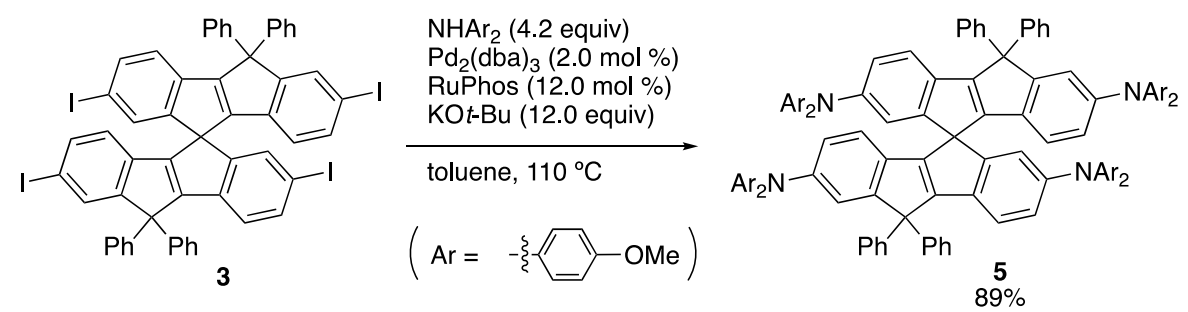

4,4'-Dimethoxydiphenylamine (160 mg, $0.698 \mathrm{mmol}), \mathrm{Pd}_{2}(\mathrm{dba})_{3}(3.05 \mathrm{mg}, 3.3$ $\mu \mathrm{mol})$, RuPhos (3.11 mg, $6.7 \mu \mathrm{mol})$, potassium tert-butoxide (224 mg, $2.00 \mathrm{mmol}$ ), and 3 (200 mg, $0.167 \mathrm{mmol}$ ) were dissolved in toluene $(5.0 \mathrm{~mL})$ and stirred for $15 \mathrm{~h}$ at 110 ${ }^{\circ} \mathrm{C}$. The reaction mixture was allowed to cool gradually down to ambient temperature and then was added water. The organic layer was extracted with dichloromethane, dried over anhydrous $\mathrm{Na}_{2} \mathrm{SO}_{4}$, and evaporated in vacuo. The crude mixture was purified by column chromatography (eluent: EtOAc/hexane $=1 / 3$ ) and reprecipitation $\left(\mathrm{CH}_{2} \mathrm{Cl}_{2} /\right.$ hexane $)$ to afford compound $5(239 \mathrm{mg}, 89 \%)$ as a yellow solid. Mp: $171{ }^{\circ} \mathrm{C}$ ( $T_{\mathrm{g}}$ from DSC data); ${ }^{1} \mathrm{H}$ NMR $\left(500 \mathrm{MHz}, \mathrm{CD}_{2} \mathrm{Cl}_{2}\right) \delta 3.71(\mathrm{~s}, 12 \mathrm{H}), 3.76(\mathrm{~s}, 12 \mathrm{H}), 6.29$ $(\mathrm{d}, J=8.0 \mathrm{~Hz}, 2 \mathrm{H}), 6.54-6.62(\mathrm{~m}, 6 \mathrm{H}), 6.67(\mathrm{td}, J=6.3,3.8 \mathrm{~Hz}, 8 \mathrm{H}), 6.75(\mathrm{td}, J=6.2$, $3.8 \mathrm{~Hz}, 8 \mathrm{H}), 6.82(\mathrm{td}, J=6.2,4.0 \mathrm{~Hz}, 8 \mathrm{H}), 6.88(\mathrm{~d}, J=8.0 \mathrm{~Hz}, 2 \mathrm{H}), 6.91-7.03(\mathrm{~m}, 16 \mathrm{H})$, $7.09(\mathrm{~d}, J=2.3 \mathrm{~Hz}, 2 \mathrm{H}), 7.10-7.16(\mathrm{~m}, 2 \mathrm{H}), 7.21-7.28(\mathrm{~m}, 6 \mathrm{H}), 7.30-7.36(\mathrm{~m}, 4 \mathrm{H}) ;{ }^{13} \mathrm{C}$ NMR (125 MHz, $\left.\mathrm{CD}_{2} \mathrm{Cl}_{2}\right) \delta 55.67,55.74,63.9,114.7,114.8,117.7,118.9,119.5,119.9$, 120.3, 120.8, 125.9, 126.3, 126.9, 127.2, 128.5, 128.6, 128.8, 131.5, 134.1, 141.4, 143.5, 143.6, 146.8, 147.0, 148.3, 151.0, 155.8, 156.1, 157.4, 158.5; HRMS (APCI+) calcd for $\mathrm{C}_{111} \mathrm{H}_{88} \mathrm{~N}_{4} \mathrm{O}_{8}(\mathrm{M}): 1604.6602$; found: 1604.6610 . 


\section{Crystallographic study}

The diffraction images for X-ray crystallographic analysis were collected on a Rigaku Rapid II diffractometer equipped with an imaging plate (IP) using $\mathrm{Cu} \mathrm{K} \alpha(\lambda=$ $1.5419 \AA$ ) radiation. The positional and thermal parameters were refined by the full-matrix least-squares method using SHELXL-2014/7 program. ${ }^{3}$ The Yadokari-XG software was used for refinement of the structure. ${ }^{4}$

CCDC 1951838 contains the supplementary crystallographic data for this paper.

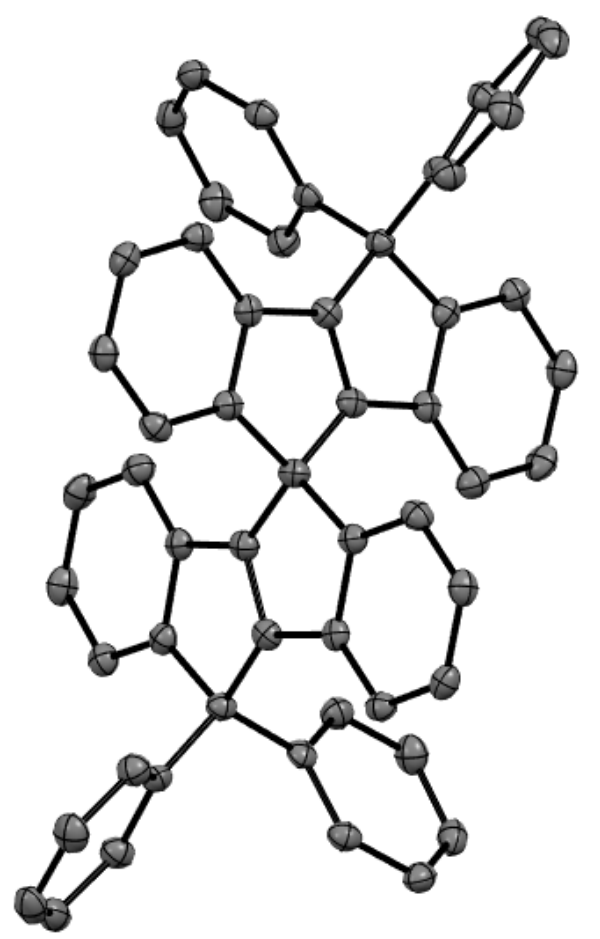

Figure S1. ORTEP drawing of spiro-CPV (1) (50\% thermal ellipsoids. All hydrogen atoms and $\mathrm{CHCl}_{3}$ solvent are omitted for clarity.) 
Table S1. Crystallographic data for Spiro-CPV (1) (CCDC 1951838)

\begin{tabular}{ll}
\hline Formula & $\mathrm{C}_{57} \mathrm{H}_{40} \mathrm{Cl}_{4}$ \\
Formula weight & 866.69 \\
Measurement temperature & $123(2) \mathrm{K}$ \\
Crystal system & monoclinic \\
Space group & $\mathrm{C} 2 / \mathrm{c}$ \\
Lattice parameters & $a=11.9001(3) \AA$ \\
& $b=15.8666(4) \AA$ \\
& $c=22.74 .72(5) \AA$ \\
& $\alpha=90^{\circ}$ \\
& $\beta=102.900(7)^{\circ}$ \\
Volume & $\gamma=90^{\circ}$ \\
$Z$ value & $4186.6(2)$ \\
Density (calculated) & 4 \\
$F(000)$ & $1.375 \mathrm{~g} / \mathrm{cm}^{3}$ \\
Number of reflections measured & 1800.0 \\
Number of unique reflections & 23863 \\
$R_{\text {int }}$ & 3828 \\
Number of observed reflections $(I>2 \sigma(I))$ & 3230 \\
Goodness of fit indicator & 1.040 \\
Final $R_{1}$ indices $[I>2 \sigma(I)]\left(R_{\text {obs, }} w R_{\text {obs }}\right)$ & $0.0360,0.0867$ \\
$R$ indices [all data] $\left(R_{\text {all }}, w R_{\text {all }}\right)$ & $0.0457,0.0907$ \\
Largest diff. peak and hole & $0.332 /-0.393 \mathrm{e} \cdot \AA^{-3}$ \\
\hline &
\end{tabular}




\section{Computational Study}

The Density Functional Theory (DFT) calculation for spiro-CPV (1) were conducted at the B3LYP/6-31G $(\mathrm{d}, \mathrm{p})$ level on Gaussian09 packages. $^{5}$

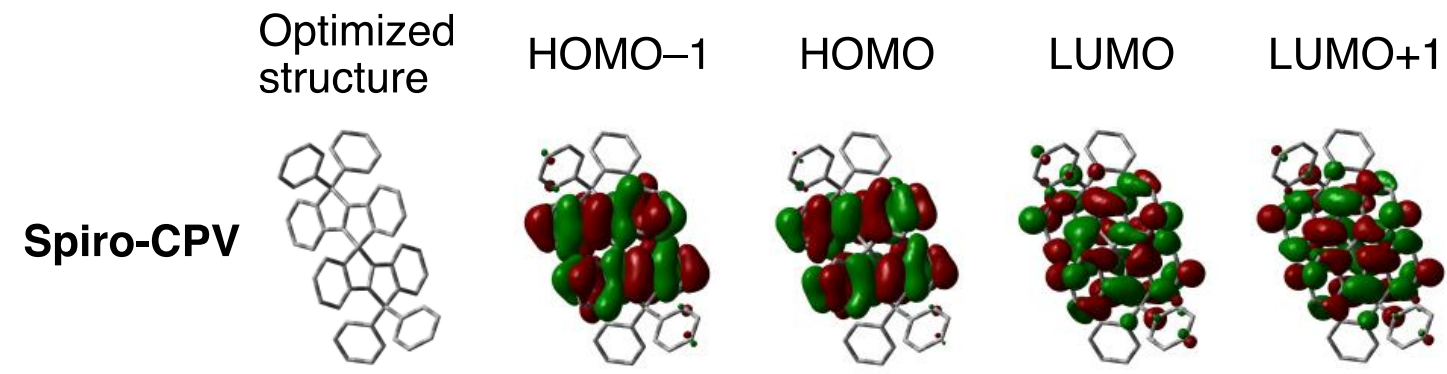

Figure S2 Optimized structures and molecular orbitals of spiro-CPV (1) calculated by DFT method at the B3LYP/6-31G(d,p) level of theory.

Table S2. Orbital energies of $\mathbf{1}$ and COPV1 calculated by DFT method at the B3LYP/6-31G(d,p) level of theory.

\begin{tabular}{ccccc}
\hline & HOMO-1 $(\mathrm{eV})$ & HOMO $(\mathrm{eV})$ & LUMO $(\mathrm{eV})$ & LUMO+1 $(\mathrm{eV})$ \\
\hline $\mathbf{1}$ & -5.39 & -5.13 & -1.25 & -1.21 \\
COPV1 & -6.30 & -5.24 & -1.25 & -0.35 \\
\hline
\end{tabular}

Table S3. Theoretically optimized coordinates of 1 (calculated at the B3LYP/6-31G(d,p) level of theory).

Total energy: $E(\mathrm{RB} 3 \mathrm{LYP} / 6-31 \mathrm{G}(\mathrm{d}, \mathrm{p}))=-2117.58545606$ Hartree

\begin{tabular}{cccccc}
\hline $\begin{array}{c}\text { Center } \\
\text { Number }\end{array}$ & $\begin{array}{c}\text { Atomic } \\
\text { Number }\end{array}$ & Atomic & \multicolumn{3}{c}{ Coordinates (Angstroms) } \\
\hline 1 & 6 & 0 & 1.938326 & 2.93705 & 2.045285 \\
2 & 1 & 0 & 1.941171 & 4.006761 & 1.867669 \\
3 & 6 & 0 & 2.824541 & 2.370433 & 2.966903 \\
4 & 1 & 0 & 3.516884 & 3.01102 & 3.505516 \\
5 & 6 & 0 & 2.832485 & 0.993407 & 3.201304 \\
6 & 1 & 0 & 3.529944 & 0.572016 & 3.919133 \\
7 & 6 & 0 & 1.947582 & 0.148506 & 2.516523
\end{tabular}




\begin{tabular}{|c|c|c|c|c|c|}
\hline 8 & 6 & 0 & 1.053854 & 2.101203 & 1.359668 \\
\hline 9 & 6 & 0 & 1.066933 & 0.705374 & 1.603626 \\
\hline 10 & 1 & 0 & 1.954364 & -0.922653 & 2.69719 \\
\hline 11 & 6 & 0 & 0.042972 & 2.348225 & 0.334819 \\
\hline 12 & 6 & 0 & -0.533252 & 1.180376 & -0.045741 \\
\hline 13 & 6 & 0 & -0.588351 & 3.550087 & -0.367332 \\
\hline 14 & 6 & 0 & -1.593671 & 2.812607 & -1.288747 \\
\hline 15 & 6 & 0 & -1.540717 & 1.414374 & -1.06729 \\
\hline 16 & 6 & 0 & -2.465629 & 3.33481 & -2.232397 \\
\hline 17 & 6 & 0 & -3.292444 & 2.462607 & -2.954982 \\
\hline 18 & 6 & 0 & -3.239147 & 1.084149 & -2.735349 \\
\hline 19 & 6 & 0 & -2.361727 & 0.547004 & -1.789675 \\
\hline 20 & 1 & 0 & -2.311103 & -0.52458 & -1.627098 \\
\hline 21 & 1 & 0 & -3.882869 & 0.422554 & -3.307668 \\
\hline 22 & 1 & 0 & -3.977347 & 2.864923 & -3.695492 \\
\hline 23 & 1 & 0 & -2.510911 & 4.402964 & -2.419658 \\
\hline 24 & 6 & 0 & 0.389219 & 4.369146 & -1.227982 \\
\hline 25 & 6 & 0 & 1.655911 & 3.878236 & -1.567173 \\
\hline 26 & 6 & 0 & 0 & 5.612922 & -1.75138 \\
\hline 27 & 6 & 0 & 2.505683 & 4.601705 & -2.406921 \\
\hline 28 & 1 & 0 & 1.987907 & 2.927427 & -1.165177 \\
\hline 29 & 6 & 0 & 0.845143 & 6.334695 & -2.592188 \\
\hline 30 & 1 & 0 & -0.966422 & 6.028339 & -1.484177 \\
\hline 31 & 6 & 0 & 2.103822 & 5.831075 & -2.92591 \\
\hline 32 & 1 & 0 & 3.484965 & 4.20008 & -2.651305 \\
\hline 33 & 1 & 0 & 0.520462 & 7.294782 & -2.983276 \\
\hline 34 & 1 & 0 & 2.764669 & 6.394404 & -3.5781 \\
\hline 35 & 6 & 0 & -1.294348 & 4.405633 & 0.714523 \\
\hline 36 & 6 & 0 & -2.589275 & 4.090187 & 1.150531 \\
\hline 37 & 6 & 0 & -0.620278 & 5.456968 & 1.35232 \\
\hline 38 & 6 & 0 & -3.192247 & 4.806569 & 2.184611 \\
\hline 39 & 1 & 0 & -3.13316 & 3.280965 & 0.675715 \\
\hline
\end{tabular}




\begin{tabular}{|c|c|c|c|c|c|}
\hline 40 & 6 & 0 & -1.223249 & 6.175164 & 2.38582 \\
\hline 41 & 1 & 0 & 0.37904 & 5.729043 & 1.029618 \\
\hline 42 & 6 & 0 & -2.513082 & 5.854173 & 2.807286 \\
\hline 43 & 1 & 0 & -4.198692 & 4.545435 & 2.499376 \\
\hline 44 & 1 & 0 & -0.680369 & 6.988119 & 2.859717 \\
\hline 45 & 1 & 0 & -2.98409 & 6.414698 & 3.609417 \\
\hline 46 & 6 & 0 & 0 & 0 & 0.742559 \\
\hline 47 & 6 & 0 & -1.066933 & -0.705374 & 1.603626 \\
\hline 48 & 6 & 0 & 0.533252 & -1.180376 & -0.045741 \\
\hline 49 & 6 & 0 & -1.053854 & -2.101203 & 1.359668 \\
\hline 50 & 6 & 0 & -0.042972 & -2.348225 & 0.334819 \\
\hline 51 & 6 & 0 & 1.540717 & -1.414374 & -1.06729 \\
\hline 52 & 6 & 0 & 0.588351 & -3.550087 & -0.367332 \\
\hline 53 & 6 & 0 & 1.593671 & -2.812607 & -1.288747 \\
\hline 54 & 6 & 0 & 1.294348 & -4.405633 & 0.714523 \\
\hline 55 & 6 & 0 & 0.620278 & -5.456968 & 1.35232 \\
\hline 56 & 6 & 0 & 2.589275 & -4.090187 & 1.150531 \\
\hline 57 & 6 & 0 & 1.223249 & -6.175164 & 2.38582 \\
\hline 58 & 1 & 0 & -0.37904 & -5.729043 & 1.029618 \\
\hline 59 & 6 & 0 & 3.192247 & -4.806569 & 2.184611 \\
\hline 60 & 1 & 0 & 3.13316 & -3.280965 & 0.675715 \\
\hline 61 & 6 & 0 & 2.513082 & -5.854173 & 2.807286 \\
\hline 62 & 1 & 0 & 0.680369 & -6.988119 & 2.859717 \\
\hline 63 & 1 & 0 & 4.198692 & -4.545435 & 2.499376 \\
\hline 64 & 1 & 0 & 2.98409 & -6.414698 & 3.609417 \\
\hline 65 & 6 & 0 & -0.389219 & -4.369146 & -1.227982 \\
\hline 66 & 6 & 0 & -1.655911 & -3.878236 & -1.567173 \\
\hline 67 & 6 & 0 & 0 & -5.612922 & -1.75138 \\
\hline 68 & 6 & 0 & -2.505683 & -4.601705 & -2.406921 \\
\hline 69 & 1 & 0 & -1.987907 & -2.927427 & -1.165177 \\
\hline 70 & 6 & 0 & -0.845143 & -6.334695 & -2.592188 \\
\hline 71 & 1 & 0 & 0.966422 & -6.028339 & -1.484177 \\
\hline
\end{tabular}




\begin{tabular}{cccccc}
72 & 6 & 0 & -2.103822 & -5.831075 & -2.92591 \\
73 & 1 & 0 & -3.484965 & -4.20008 & -2.651305 \\
74 & 1 & 0 & -0.520462 & -7.294782 & -2.983276 \\
75 & 1 & 0 & -2.764669 & -6.394404 & -3.5781 \\
76 & 6 & 0 & -1.938326 & -2.93705 & 2.045285 \\
77 & 6 & 0 & -1.947582 & -0.148506 & 2.516523 \\
78 & 6 & 0 & -2.832485 & -0.993407 & 3.201304 \\
79 & 1 & 0 & -3.529944 & -0.572016 & 3.919133 \\
80 & 6 & 0 & -2.824541 & -2.370433 & 2.966903 \\
81 & 1 & 0 & -3.516884 & -3.01102 & 3.505516 \\
82 & 1 & 0 & -1.954364 & 0.922653 & 2.69719 \\
83 & 1 & 0 & -1.941171 & -4.006761 & 1.867669 \\
84 & 6 & 0 & 2.465629 & -3.33481 & -2.232397 \\
85 & 6 & 0 & 2.361727 & -0.547004 & -1.789675 \\
86 & 6 & 0 & 3.239147 & -1.084149 & -2.735349 \\
87 & 1 & 0 & 3.882869 & -0.422554 & -3.307668 \\
88 & 1 & 0 & 3.292444 & -2.462607 & -2.954982 \\
89 & 6 & 0 & 3.977347 & -2.864923 & -3.695492 \\
90 & 1 & 0 & 2.311103 & 0.52458 & -1.627098 \\
91 & 0 & 0.510911 & -4.402964 & -2.419658 \\
\hline & 0 & 0 & &
\end{tabular}




\section{UV-Vis Absorption, Fluorescence spectra}

UV-Vis absorption spectra in solution (ca. $1.0 \times 10^{-5} \mathrm{M}$ ) were measured with a JASCO V-670 spectrometer. Fluorescence spectra in solution (ca. $1.0 \times 10^{-6} \mathrm{M}$ ) were measured with a HITACHI F-4500 spectrometer for solution and Horiba Jobin-Yvon Fluorolog-3 spectrofluorometer for solid. Photoluminescence quantum yields were measured on Hamamatsu Photonics C9920-02 Absolute PL Quantum Yield Measurement System for both of solutions (ca. $1.0 \times 10^{-6} \mathrm{M}$ ) and powders, and absolute quantum yields were determined by using a calibrated integrating sphere system. Fluorescence lifetimes were measured on Hamamatsu Photonics C11367-02 Quantaurus-Tau. Circular dichroism (CD) spectra were measured on a JASCO J-1500 spectropolarimeter. CPL spectra were measured on a JASCO CPL-200 spectrometer. Optical rotations were measured on a JASCO P-1030 polarimeter using a 50-mm cell. The absorption maximum wavelengths were used as excitation wavelengths. Spectral grade solvent (dichloromethane) was used as solvent for UV-Vis absorption fluorescence, CD, CPL, and optical rotation measurements.

The radiative and nonradiative rate constants $k_{\mathrm{r}}$ and $k_{\mathrm{nr}}$ are calculated by substituting fluorescence quantum yield $\Phi_{\mathrm{FL}}$ and fluorescence lifetime $\tau$ for the following formula:

$$
\begin{aligned}
& k_{\mathrm{r}}=\Phi_{\mathrm{FL}} / \tau \\
& k_{\mathrm{nr}}=\left(1-\Phi_{\mathrm{FL}}\right) / \tau
\end{aligned}
$$

Table S4. Extinction coefficients of COPV1 and spiro-CPV derivatives.

\begin{tabular}{lll}
\hline & $\lambda_{\text {abs }}(\mathrm{nm})$ & $\mathcal{E}_{\max }\left(\mathrm{L} \mathrm{mol}^{-1} \mathrm{~cm}^{-1}\right)$ \\
\hline COPV1 & 336 & $9.12 \times 10^{3}$ \\
$\mathbf{1}$ & 338 & $3.22 \times 10^{4}$ \\
$\mathbf{6}$ & 351 & $4.10 \times 10^{4}$ \\
$\mathbf{1 2}$ & 360 & $1.03 \times 10^{5}$ \\
$\mathbf{1 3}$ & 374 & $1.01 \times 10^{5}$ \\
$\mathbf{5}$ & 411 & $9.02 \times 10^{4}$ \\
\hline
\end{tabular}




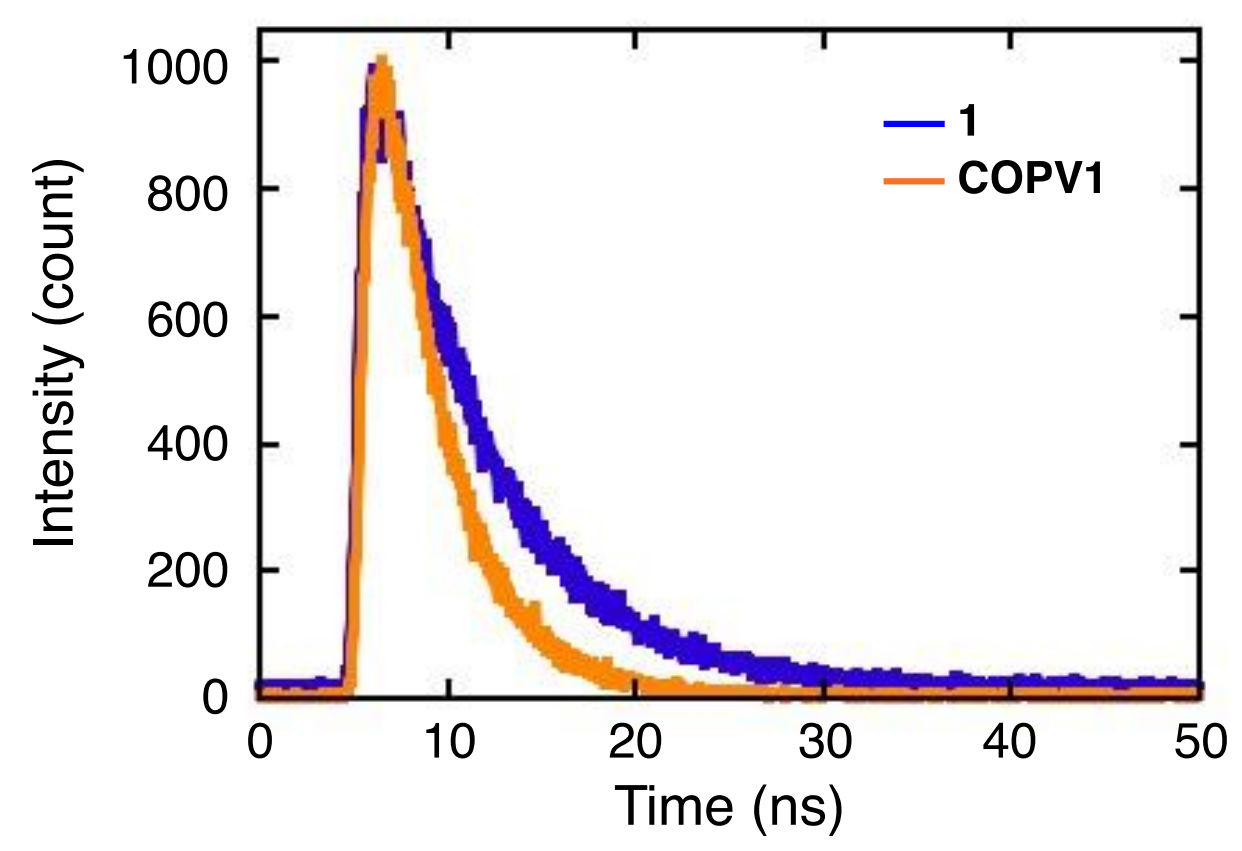

Figure S3. Fluorescence lifetime of $\mathbf{1}$ and COPV1.

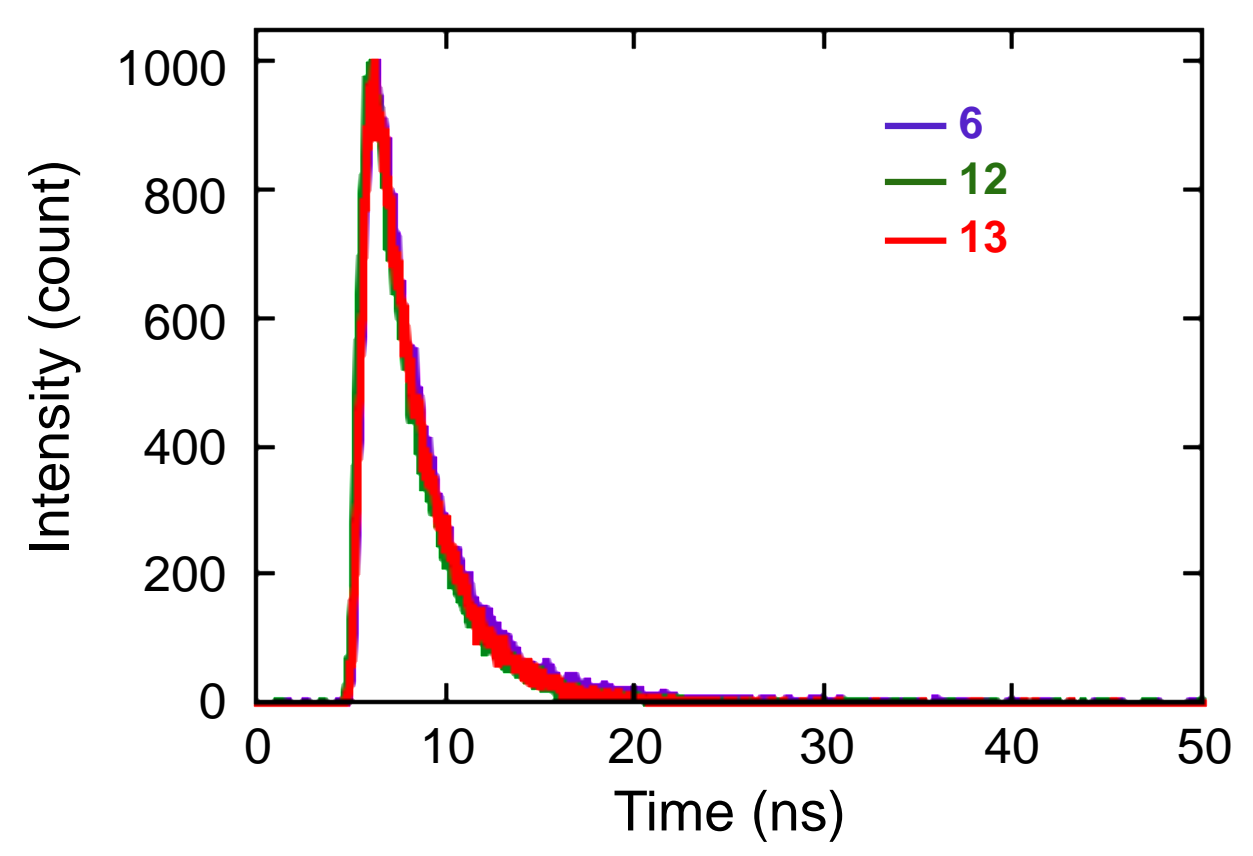

Figure S4. Fluorescence lifetime of 6, 12, and 13. 


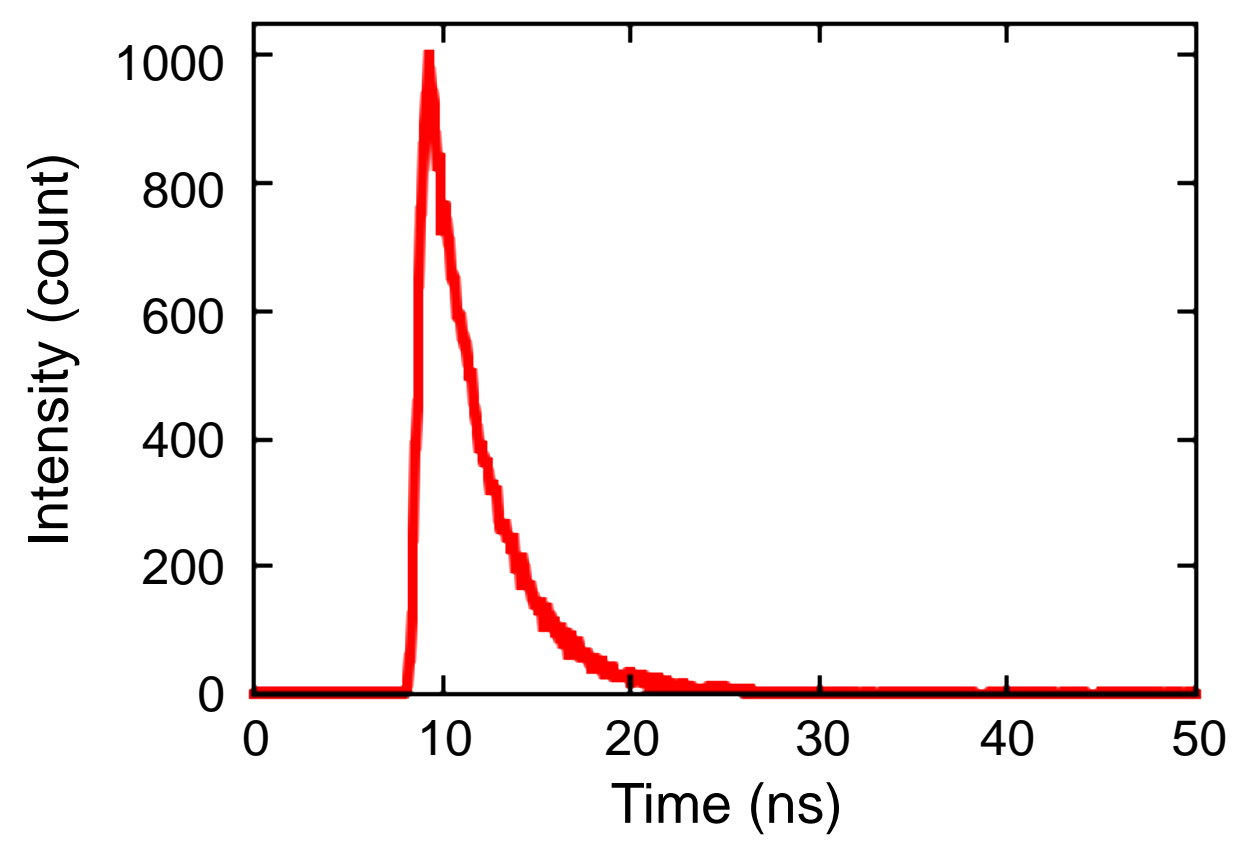

Figure S5. Fluorescence lifetime of 5.
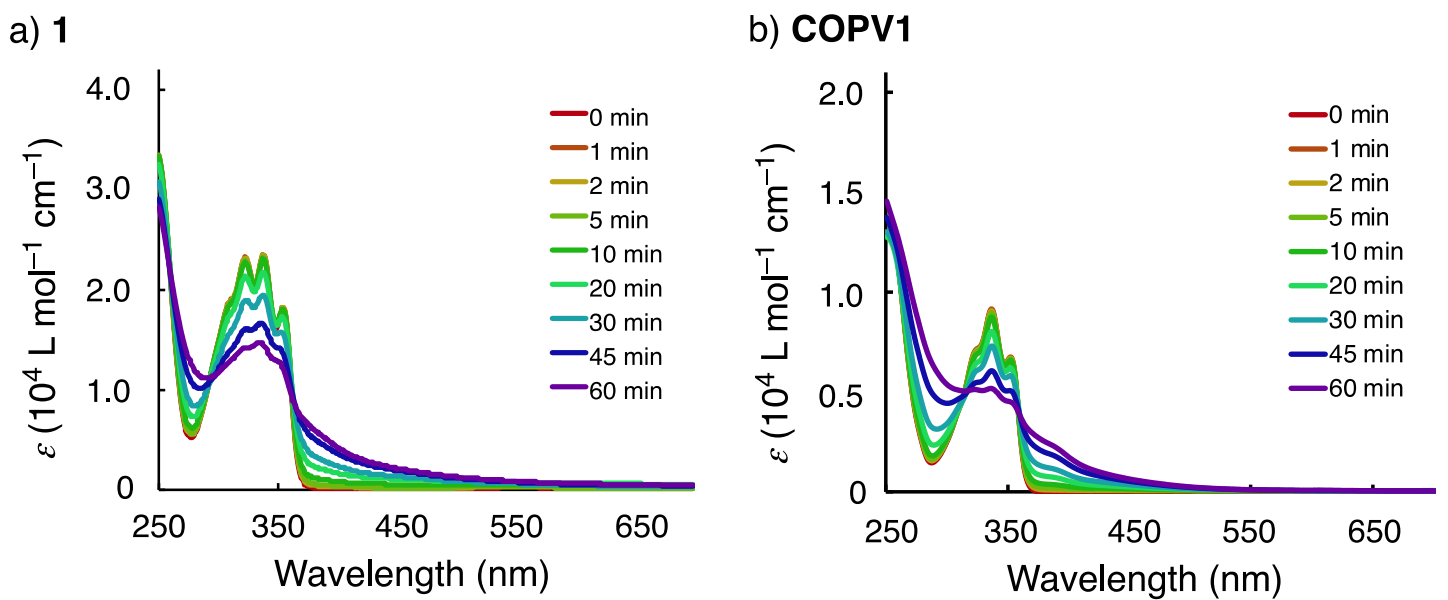

Figure S6. The change of absorption spectra of a) $\mathbf{1}$ and b) COPV1 in dichloromethane $\left(1.0 \times 10^{-5} \mathrm{M}\right)$ under photoirradiation by Xe lamp (300 W). 

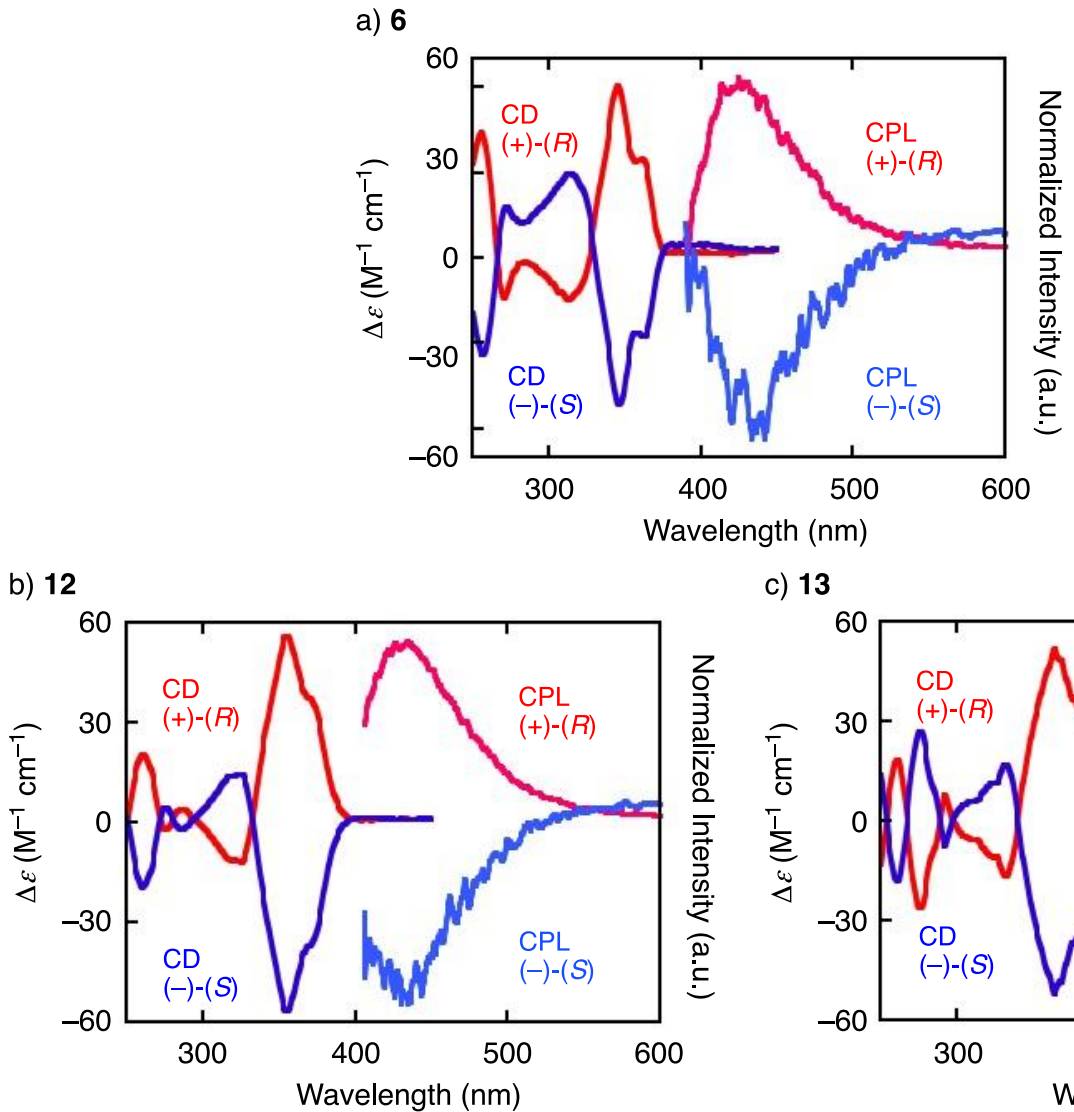

c) 13

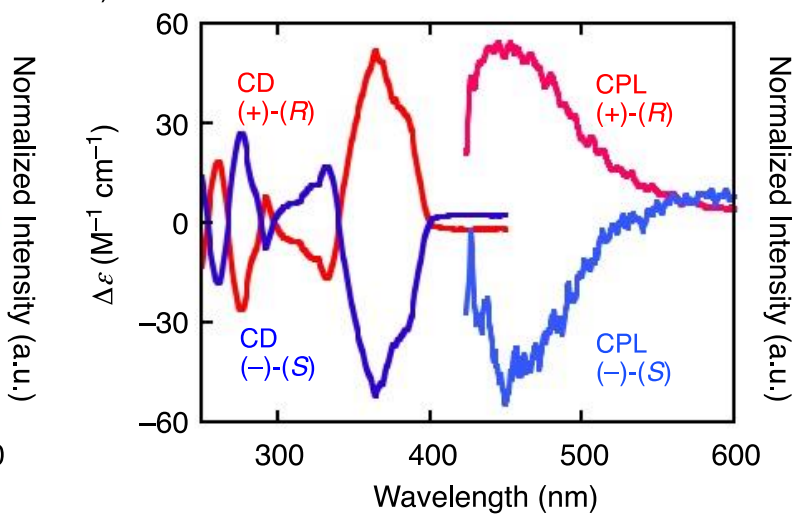

Figure S7. CD and CPL spectra of a) 6, b) 12, and c) 13. 


\section{Electrochemical studies}

Cyclic voltammetry (CV) and differential pulse voltammetry (DPV) were conducted with HOKUTO DENKO HZ-7000 voltammetric analyzer. Measurements were carried out in a one-compartment cell under argon gas, equipped with a platinum counter electrode, a glassy-carbon working electrode, and an $\mathrm{Ag} / \mathrm{Ag}^{+}$reference electrode. The supporting electrolyte was a $0.5 \mathrm{M}$ dichloromethane solution of tetrabutylammonium hexafluorophosphate. All potentials were collected against $\mathrm{Fc} / \mathrm{Fc}^{+}$.
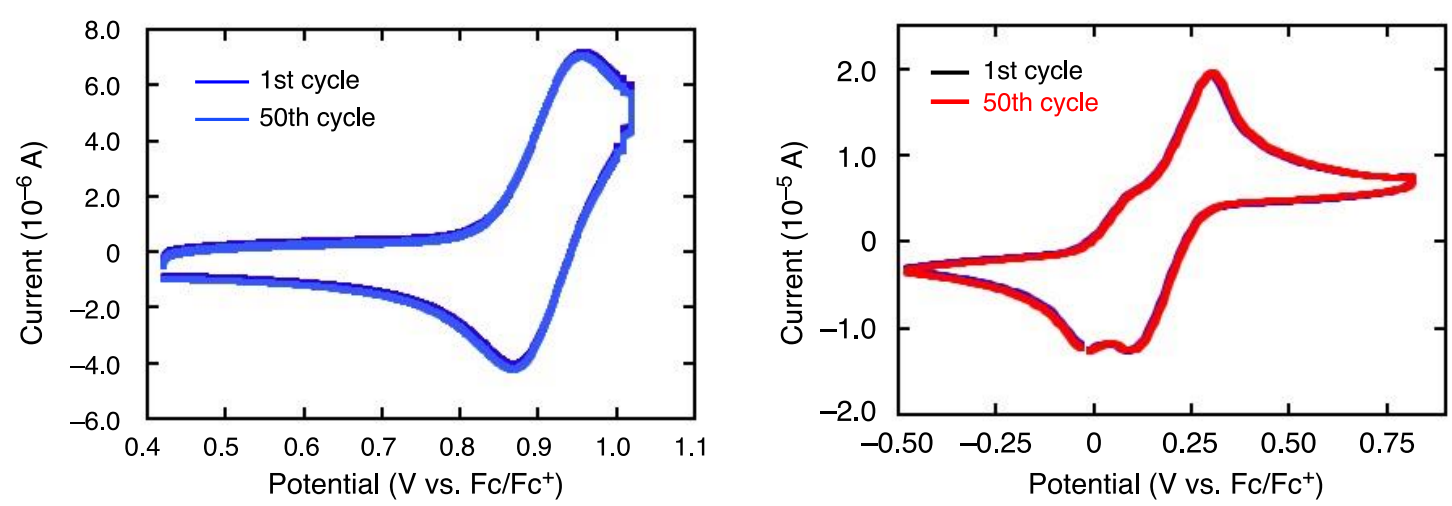

Figure S8. Cyclic voltammograms of rac-1 (left) and 5 (right) in dichloromethane $(0.5$ $\mathrm{mM}$ solution with $0.1 \mathrm{M} \mathrm{Bu}_{4} \mathrm{NPF}_{6}$ electrolyte). 


\section{Thermal studies}

Thermogravimetry-differential thermal analysis (TG-DTA) was performed on a Rigaku ThermoPlus 2 thermal analyzer (TG 8120). Sample was placed in an aluminum pan and heated to $500{ }^{\circ} \mathrm{C}$ at the rate of $10 \mathrm{~K} / \mathrm{min}$ under $\mathrm{N}_{2}$ purge at a flow rate of 10 $\mathrm{mL} / \mathrm{min} . \mathrm{Al}_{2} \mathrm{O}_{3}$ was used as reference material. Differential scanning calorimetry (DSC) was performed on a SII Nanotechnology (DSC6220) instrument. Samples were placed in aluminum pans and heated at $10 \mathrm{~K} / \mathrm{min}$, under $\mathrm{N}_{2}$ gas at a flow rate of $50 \mathrm{~mL} / \mathrm{min}$.

\section{Ionization potential}

Photoelectron yield spectroscopy (PYS) measurement was performed with PYS-201 (Sumitomo Heavy Industries, Ltd).
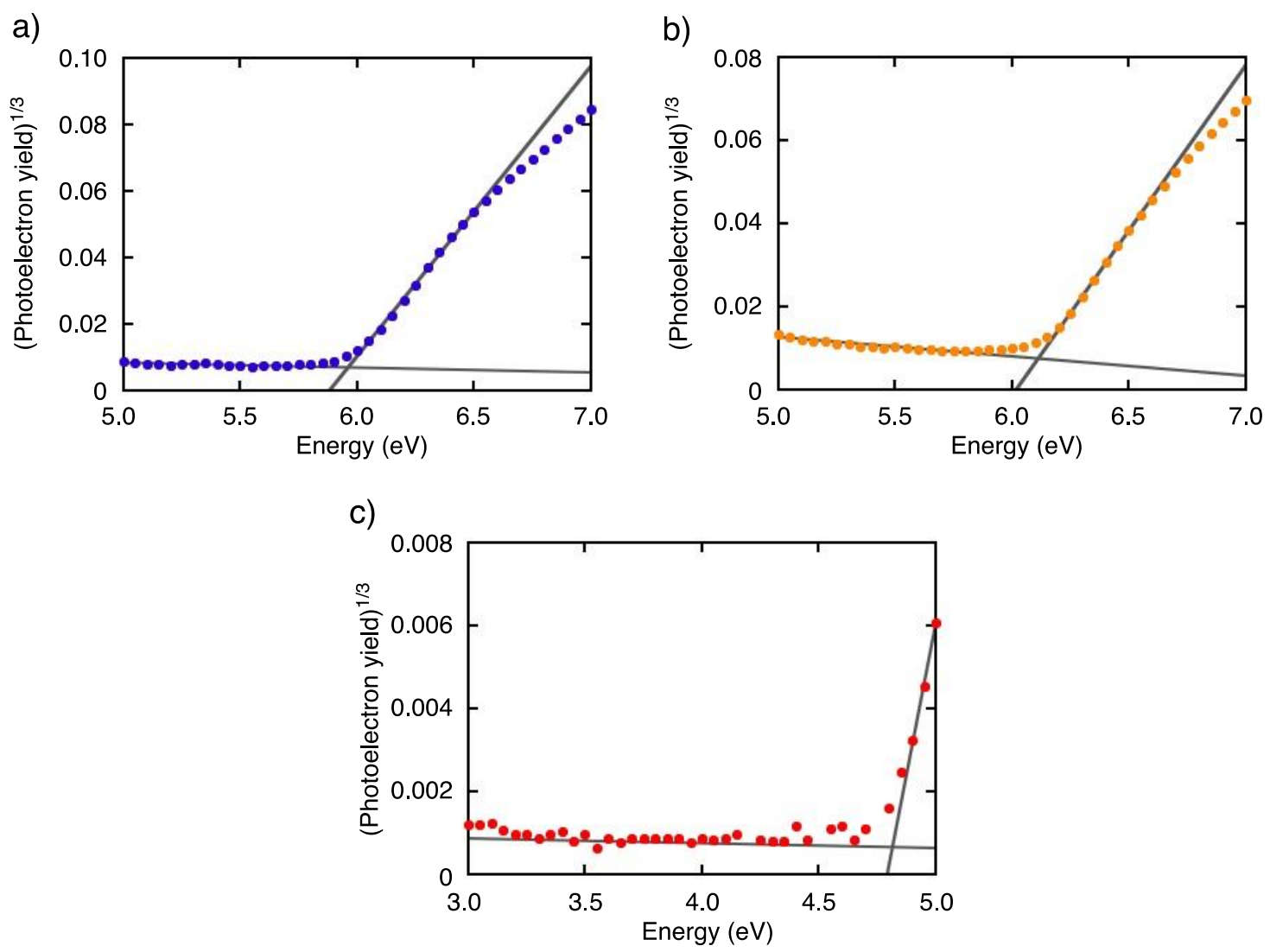

Figure S9. PYS data of films of a) $r a c-1$, b) COPV1, and c) $r a c-5$ on ITO substrate. Light sources are $\mathrm{D}_{2}$ lamp for $r a c-\mathbf{1}$ and COPV1, and Xe lamp for rac-5. 


\section{Hole mobility}

The hole mobilities were measured by the space charge limited current (SCLC) method with a device configuration of ITO/PEDOT:PSS/HTL/MoO $/ \mathrm{O}_{3} / \mathrm{Ag}$. A solution of TFSI-doped 5 was prepared by mixing $5(60 \mathrm{mg} / \mathrm{mL}, 1.0 \mathrm{~mL})$ in chlorobenzene and dopant $(15 \mu \mathrm{K}, 520 \mathrm{mg} / \mathrm{mL}$ LiTFSI in acetonitrile and $22.5 \mu \mathrm{L}$ 2,6-di-tert-butylpyridine).

ITO glasses (Techno Print Co., Ltd., Japan) were used as a substrate. The patterned ITO glass was treated by UV-ozone irradiation for $5 \mathrm{~min}$. A thin PEDOT:PSS layer was prepared on the ITO surface by spin-coating at $500 \mathrm{rpm}$ for $3 \mathrm{sec}$, and 3000 $\mathrm{rpm}$ for $30 \mathrm{sec}$. The substrate was annealed at $120^{\circ} \mathrm{C}$ for $30 \mathrm{~min}$ under ambient conditions. A solution of $5(60 \mathrm{mg} / \mathrm{mL}$ in chlorobenzene) or TFSI-doped 5 was spin-coated on the PEDOT:PSS layer at $500 \mathrm{rpm}$ for $3 \mathrm{sec}$, and then at $2000 \mathrm{rpm}$ for 60 sec. The resulting substrate was heated at $120{ }^{\circ} \mathrm{C}$ for $15 \mathrm{~min}$ under ambient conditions. $\mathrm{MoO}_{3}$ layer and $\mathrm{Ag}$ as a counter electrode were deposited on the HTL by vacuum evaporation. $J-V$ characteristics of the devices were measured on a Keithley 2400 source measurement unit. The SLCL is described as the following:

$$
J_{\mathrm{SCLC}}=\frac{9}{8} \mu_{\mathrm{SCLC}} \varepsilon_{0} \varepsilon_{r} \frac{V^{2}}{d^{3}}
$$

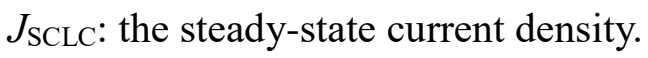

$V$ : the applied voltage.

$d$ : the film thickness.

$\mu_{\mathrm{SCLC}}$ : the carrier mobility.

$\mathcal{E}_{\mathrm{r}}$ : the dielectric constant assumed to be 3, a typical value for organic HTMs.

$\mathcal{E}_{\square}$ : the permittivity of the free space. 

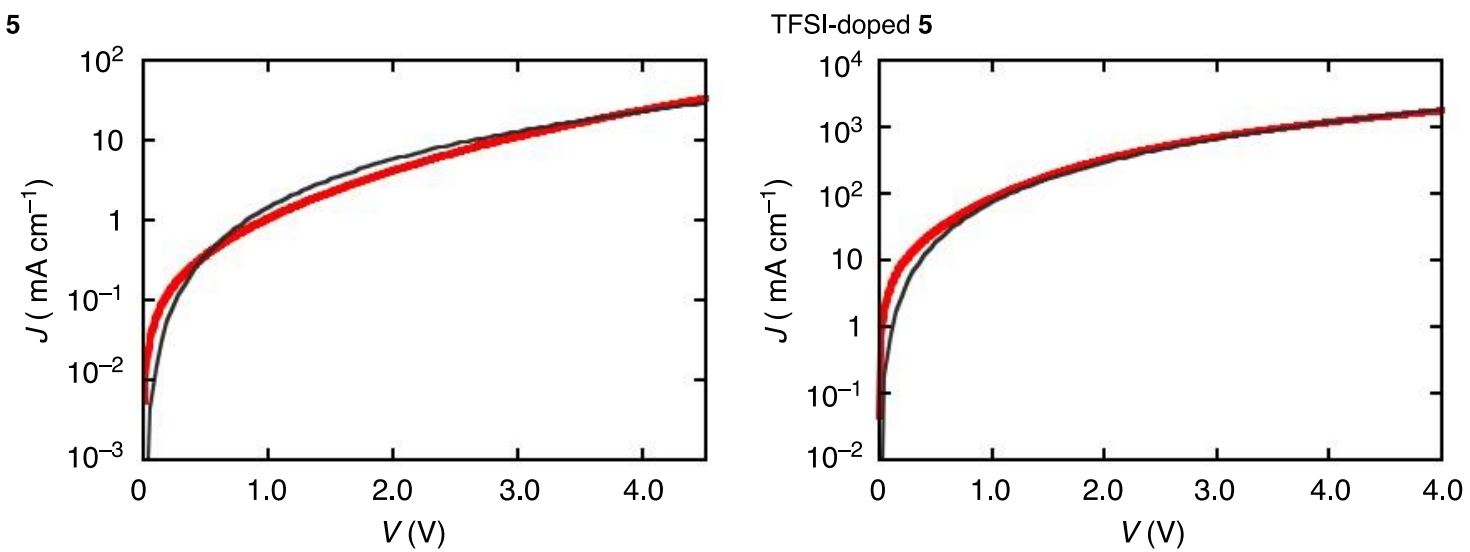

Figure S10 $J-V$ curves of hole-only transporting devices for nondoped (left) and TFSI-doped rac-5 (right). Gray lines shows fitting curves.

\section{Electron spin resonance (ESR) spectrum}

ESR spectra were recorded using a JEOL JES-FA200 ESR spectrometer with a Mn marker as a reference.

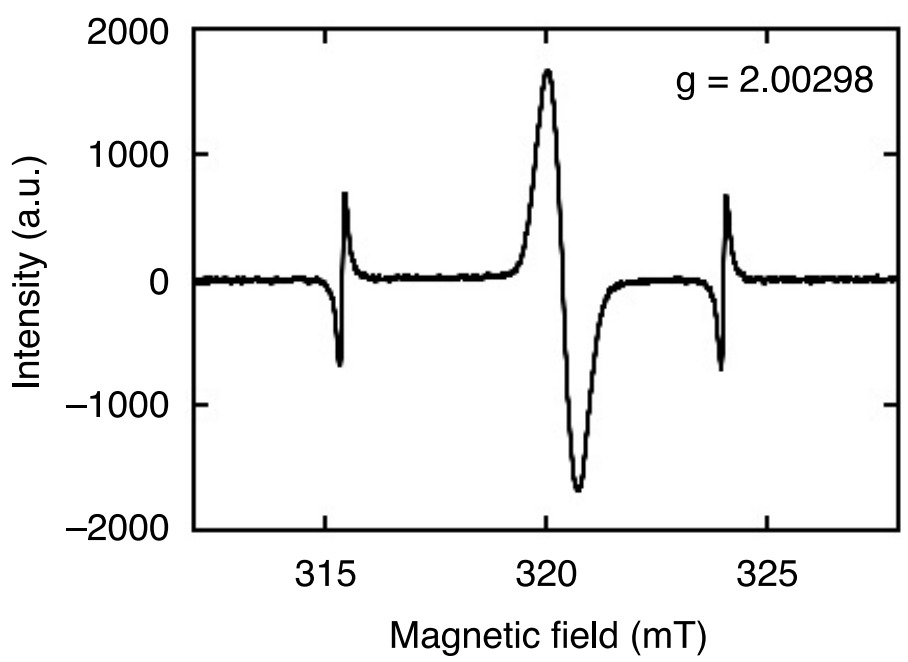

Figure S11. ESR spectra of radical cationic rac-5 in chlorobenzene doped by 1.0 equivalent of $\mathrm{NOPF}_{6}$ solution in acetonitrile as an oxidant.

\section{Perovskite solar cell}

In order to confirm that compound $\mathbf{5}$ works as HTM in optoelectronic device, we fabricated perovskite solar cells with the device structures of a) $\mathrm{FTO} / \mathrm{TiO}_{\mathrm{x}} / \mathrm{MAPbI}_{3}$ ${ }_{\mathrm{x}} \mathrm{Cl}_{\mathrm{x}} / \mathrm{HTM} / \mathrm{Au}$ and b) ITO/SnO $/ \mathrm{FA}_{0.9} \mathrm{Cs}_{0.1} \mathrm{~Pb}_{2.7} \mathrm{Br}_{0.3} / \mathrm{HTM} / \mathrm{Ag}$. For device structure a), a fluorine-doped tin oxide (FTO) layer on a glass substrate was used for this study. Prior 
to the formation of the buffer layer, the patterned FTO glass was ultrasonically cleaned using a surfactant, rinsed with water and then finally given 3 min UV-ozone treatment. A $45 \mathrm{~nm}$ thick electron-transporting layer of $\mathrm{TiO}_{\mathrm{x}}$ was deposited by spin-coating (3000 $\mathrm{rpm}$ for $30 \mathrm{~s}$ ) of the precursor solution and annealed at $500{ }^{\circ} \mathrm{C}$ for $30 \mathrm{~min}$ in air atmosphere. To form the $\mathrm{MAPI}_{3-\mathrm{x}} \mathrm{Cl}_{\mathrm{x}}$ layer, a $40 \mathrm{wt} \%$ precursor solution (4:1:1 mol ratio of MAI:PbI $2: \mathrm{PbCl}_{2}$ ) in DMF was spin-coated onto the $\mathrm{TiO}_{\mathrm{x}}$ layer at $500 \mathrm{rpm}$ for $3 \mathrm{~s}$ and $4000 \mathrm{rpm}$ for $30 \mathrm{~s}$. Further, it was annealed at $100{ }^{\circ} \mathrm{C}$ for $35 \mathrm{~min}$ in a $\mathrm{N}_{2}$ - filled glovebox. The HTM $(60 \mathrm{mg} / \mathrm{mL})$ in chlorobenzene with dopants $(15 \mu \mathrm{L}, 520 \mathrm{mg} / \mathrm{mL} \mathrm{Li-TFSI} \mathrm{in}$ $\mathrm{CH}_{3} \mathrm{CN}$ and $22.5 \mu \mathrm{L}$ TBP) was then deposited by spin-coating (2200 rpm for $30 \mathrm{~s}$ ). The top electrode ( $\mathrm{Au}, 80 \mathrm{~nm}$ ) was deposited through a metal shadow mask, which defined a $2 \mathrm{~mm}$ stripe pattern perpendicular to the ITO stripe. For device structure b), $\mathrm{FA}_{0.9} \mathrm{Cs}_{0.1} \mathrm{PbI}_{2.7} \mathrm{Br}_{0.3}$ layer was formed from a $40 \mathrm{wt} \%$ precursor solution (9:9:1.5:1 mol ratio of $\mathrm{FAI}: \mathrm{PbI}_{2}: \mathrm{PbBr}_{2}: \mathrm{CsI}$ ) in $\mathrm{DMF}$ spin-coated onto $\mathrm{SnO}_{2}$ layer on ITO substrate at $100 \mathrm{rpm}$ for $10 \mathrm{~s}$ and $6000 \mathrm{rpm}$ for 30s. Further, it was annealed at $100{ }^{\circ} \mathrm{C}$ for $60 \mathrm{~min}$ in a $\mathrm{N}_{2}$ - filled glovebox. The HTM $(60 \mathrm{mg} / \mathrm{mL})$ in chlorobenzene with dopants $(15 \mu \mathrm{L}$, $520 \mathrm{mg} / \mathrm{mL} \mathrm{Li}$-TFSI in $\mathrm{CH}_{3} \mathrm{CN}$ and $22.5 \mu \mathrm{L}$ TBP) was then deposited by spin-coating (2200 rpm for $30 \mathrm{~s})$. The top electrode (Ag, $100 \mathrm{~nm}$ ) was deposited through a metal shadow mask, which defined a $1 \mathrm{~mm}$ stripe pattern perpendicular to the ITO stripe.

Table S5. Device performances of perovskite solar cells with $\mathbf{5}$ and spiro-OMeTAD as HTMs.

\begin{tabular}{llllll}
\hline HTM & $\begin{array}{l}\text { Device } \\
\text { structure }\end{array}$ & $\begin{array}{l}V_{\mathrm{OC}} \\
(\mathrm{V})\end{array}$ & $\begin{array}{l}J_{\mathrm{SC}} \\
\left(\mathrm{mA} / \mathrm{cm}^{2}\right)\end{array}$ & FF & $\begin{array}{l}\text { PCE } \\
(\%)\end{array}$ \\
\hline Spiro-OMeTAD $^{6}$ & a) & 0.98 & 18.4 & 0.68 & 12.2 \\
$\mathbf{5}$ & a) & 1.04 & 19.4 & 0.64 & 12.9 \\
$\mathbf{5}$ & b) & 0.96 & 21.7 & 0.68 & 14.1 \\
\hline
\end{tabular}

a) $\mathrm{FTO} / \mathrm{TiO}_{\mathrm{x}} / \mathrm{MAPbI}_{3-\mathrm{x}} \mathrm{Cl}_{\mathrm{x}} / \mathrm{HTM} / \mathrm{Au}$ and b) $\mathrm{ITO} / \mathrm{SnO}_{2} / \mathrm{FA}_{0.9} \mathrm{Cs}_{0.1} \mathrm{PbI}_{2.7} \mathrm{Br}_{0.3} / \mathrm{HTM} / \mathrm{Ag}$. 

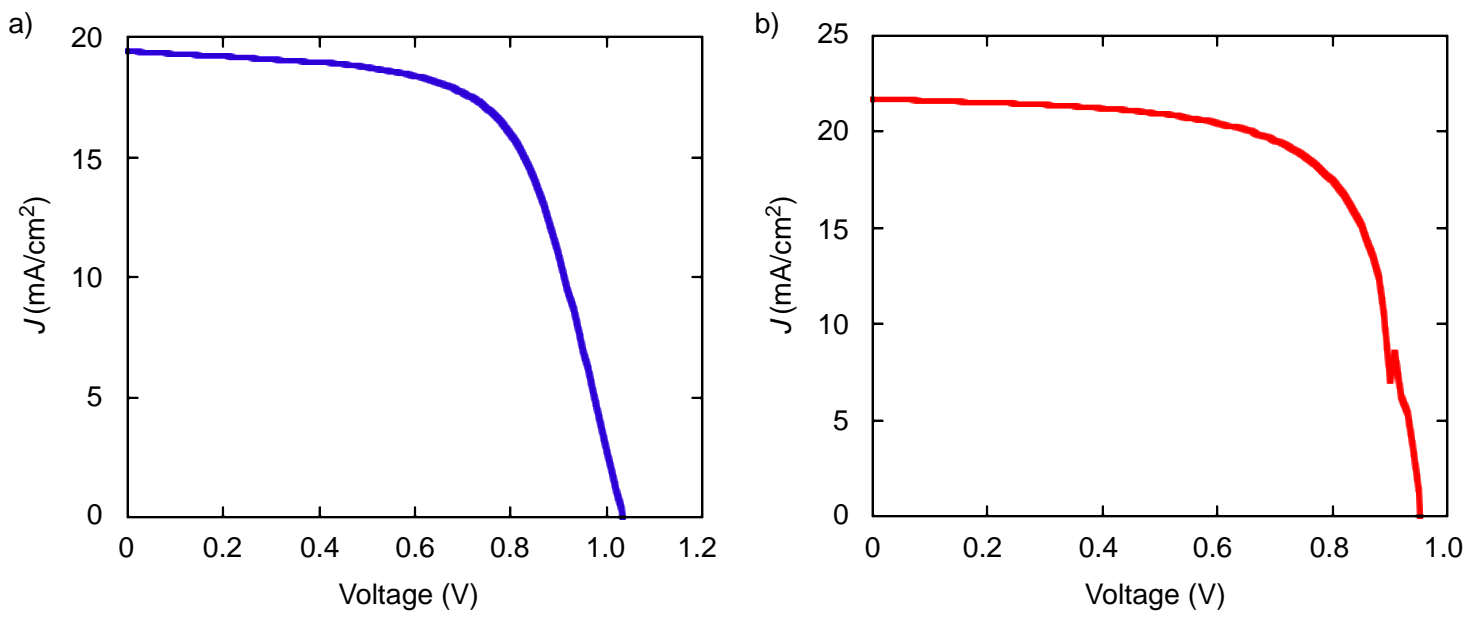

Figure S12. J-V characteristics of perovskite solar cells with $\mathbf{5}$ as HTM. Device structures are a) $\quad \mathrm{FTO} / \mathrm{TiO}_{\mathrm{x}} / \mathrm{MAPbI}_{3-\mathrm{x}} \mathrm{Cl}_{\mathrm{x}} / \mathrm{HTM} / \mathrm{Au}$ and b) $\mathrm{ITO} / \mathrm{SnO}_{2} / \mathrm{FA}_{0.9} \mathrm{Cs}_{0.1} \mathrm{PbI}_{2.7} \mathrm{Br}_{0.3} / \mathrm{HTM} / \mathrm{Ag}$. 


\section{NMR charts}

${ }^{1} \mathrm{H}$ NMR spectrum of $\mathbf{1 7}$ in $\mathrm{CDCl}_{3}$.

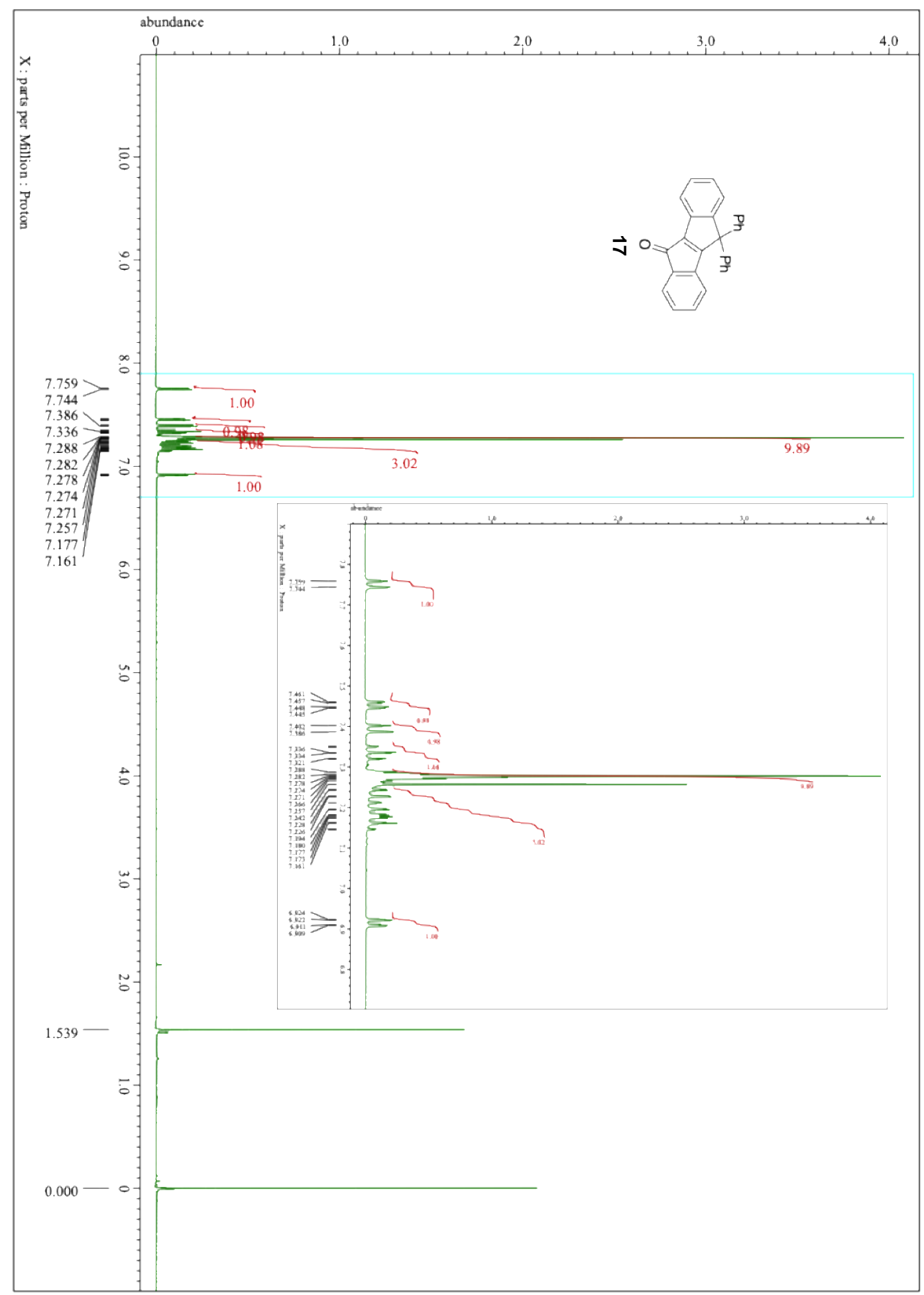


${ }^{13} \mathrm{C}$ NMR spectrum of $\mathbf{1 7}$ in $\mathrm{CDCl}_{3}$.

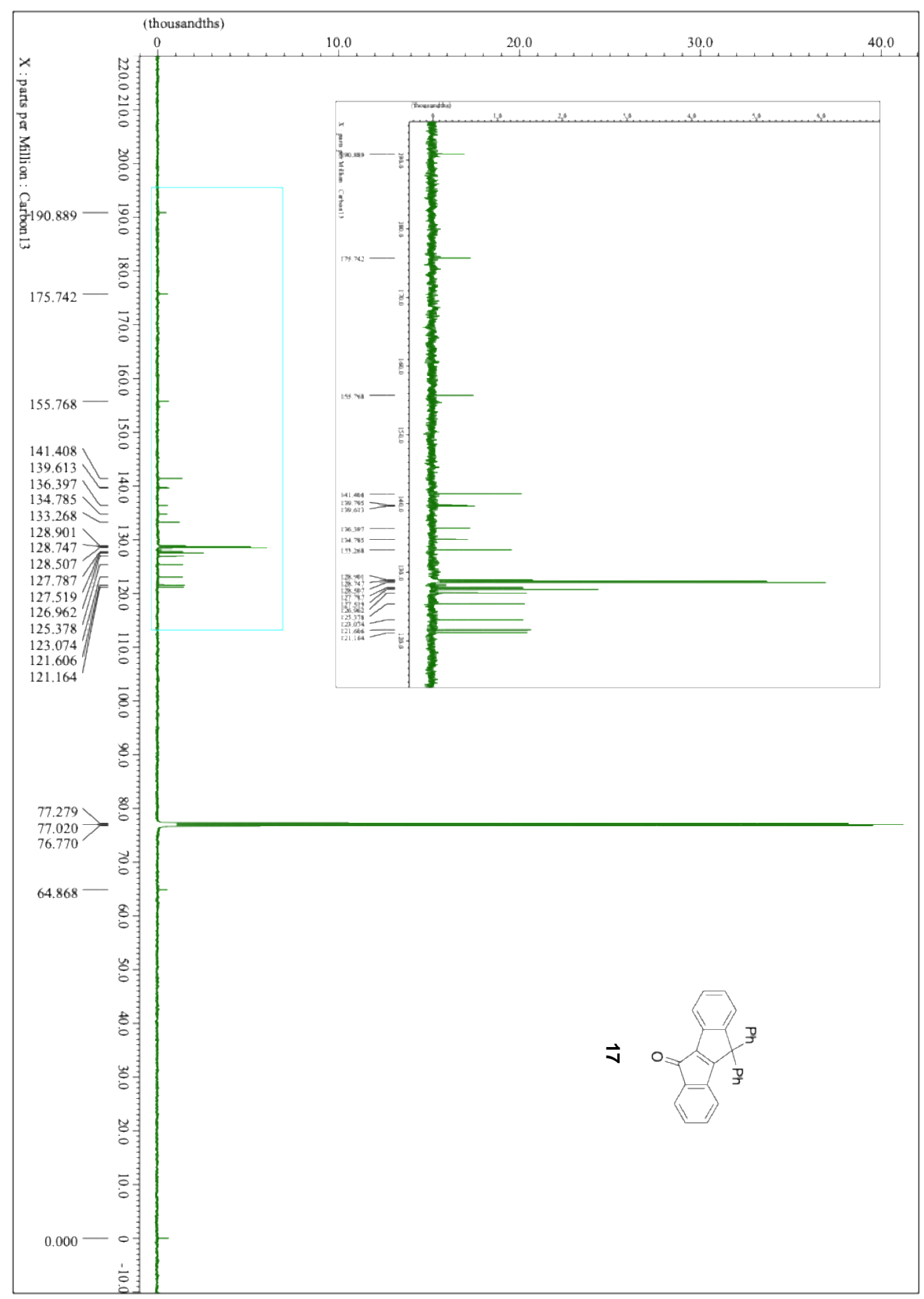


${ }^{1} \mathrm{H}$ NMR spectrum of spiro-CPV (1) in $\mathrm{CDCl}_{3}$.

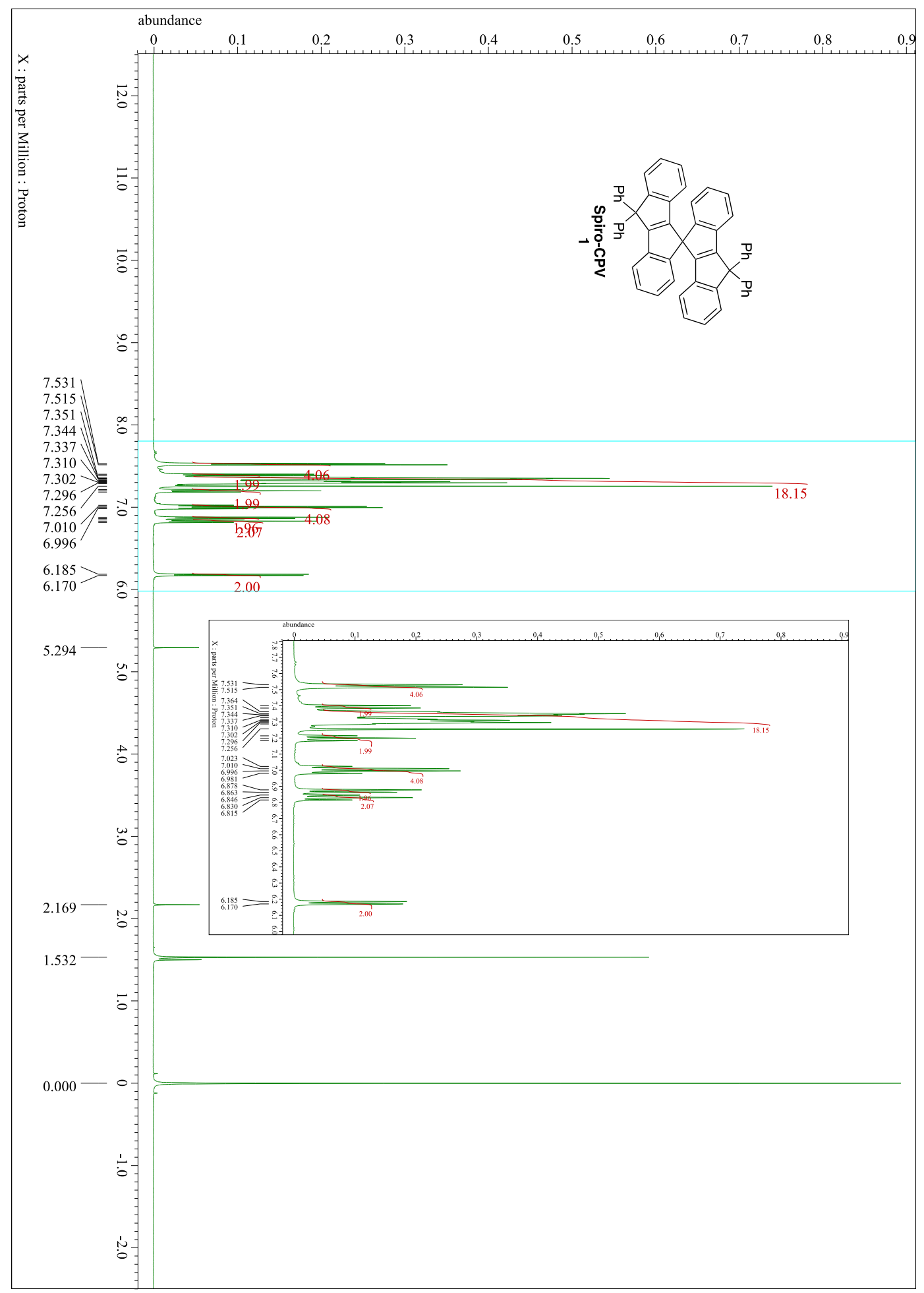


${ }^{13} \mathrm{C}$ NMR spectrum of spiro-CPV (1) in $\mathrm{CDCl}_{3}$.

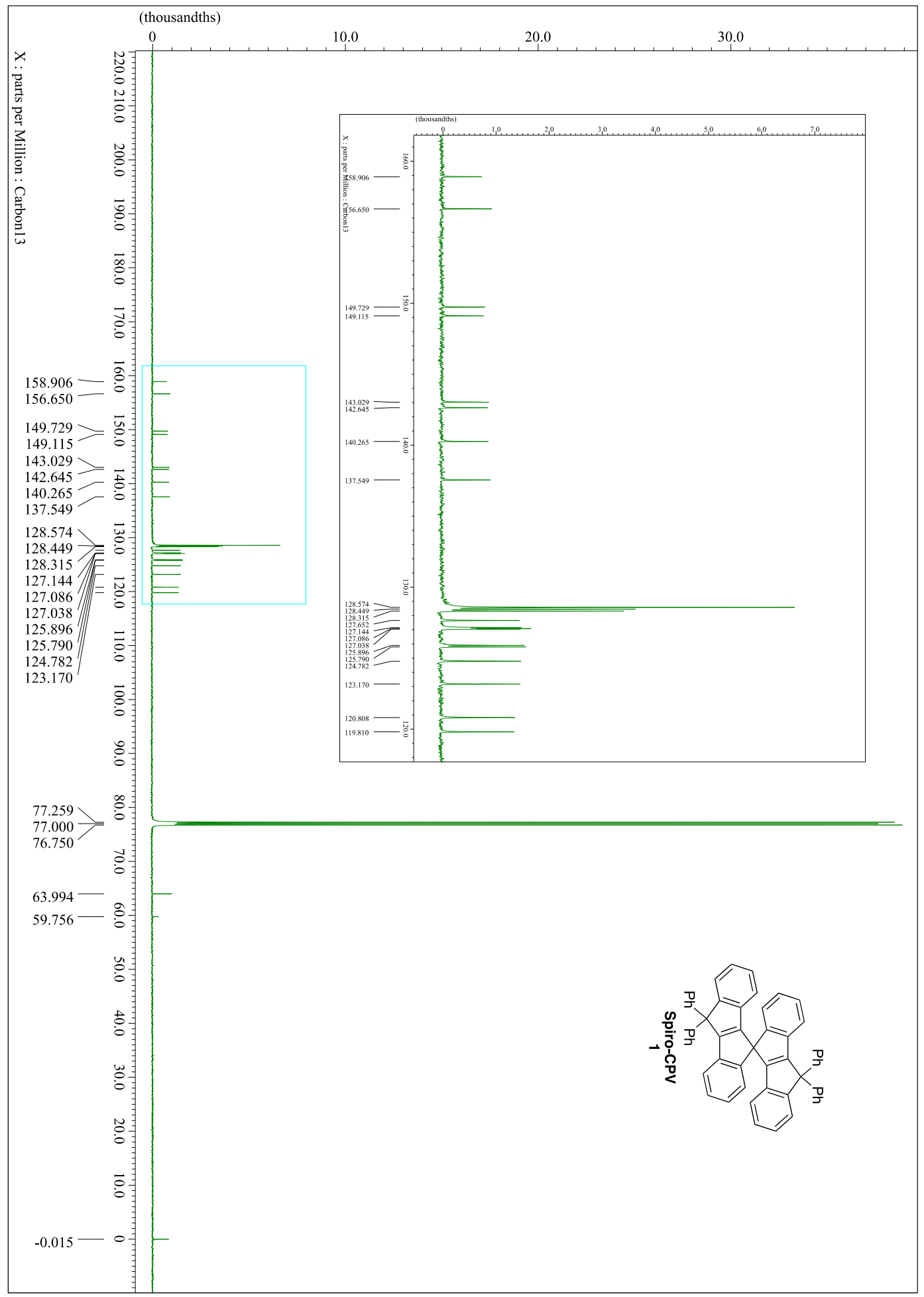


${ }^{1} \mathrm{H}$ NMR spectrum of 1-(4-Methoxyphenyl)ethynyl-2-diphenylhydroxybenzene in $\mathrm{CD}_{2} \mathrm{Cl}_{2}$.

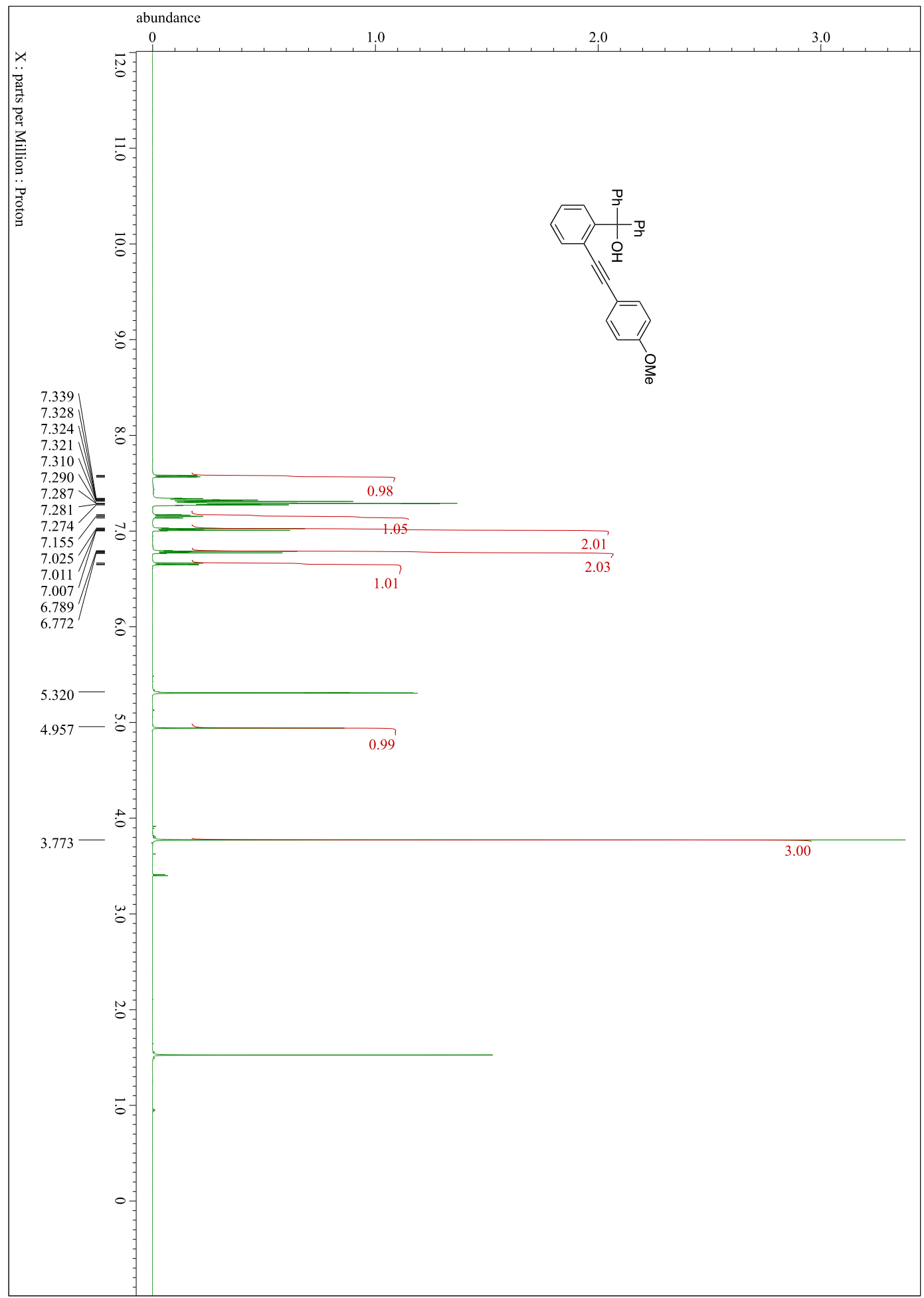


${ }^{13} \mathrm{C}$ NMR spectrum of 1-(4-Methoxyphenyl)ethynyl-2-diphenylhydroxybenzene in $\mathrm{CD}_{2} \mathrm{Cl}_{2}$.

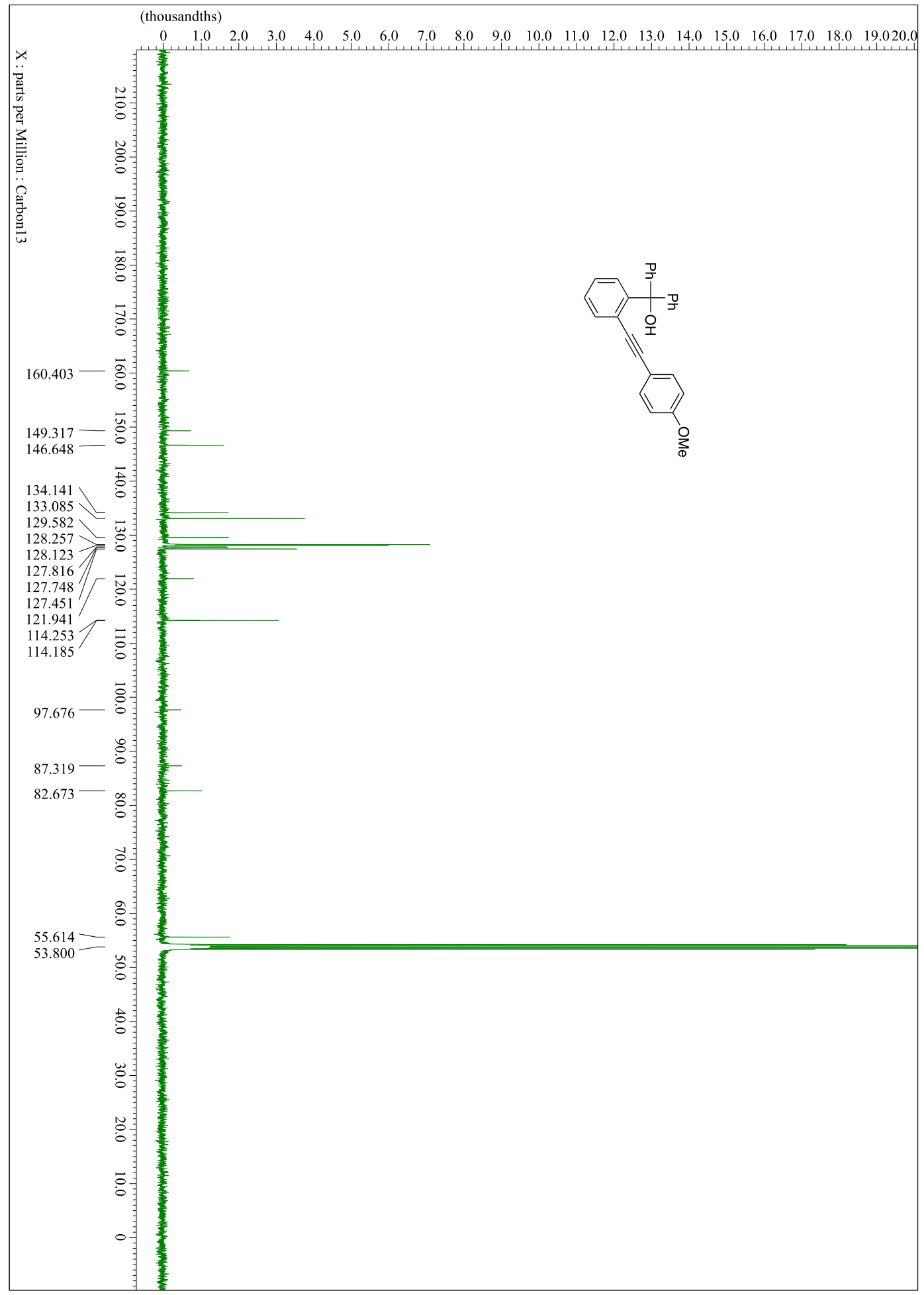


${ }^{1} \mathrm{H}$ NMR spectrum of 19 in $\mathrm{CD}_{2} \mathrm{Cl}_{2}$.

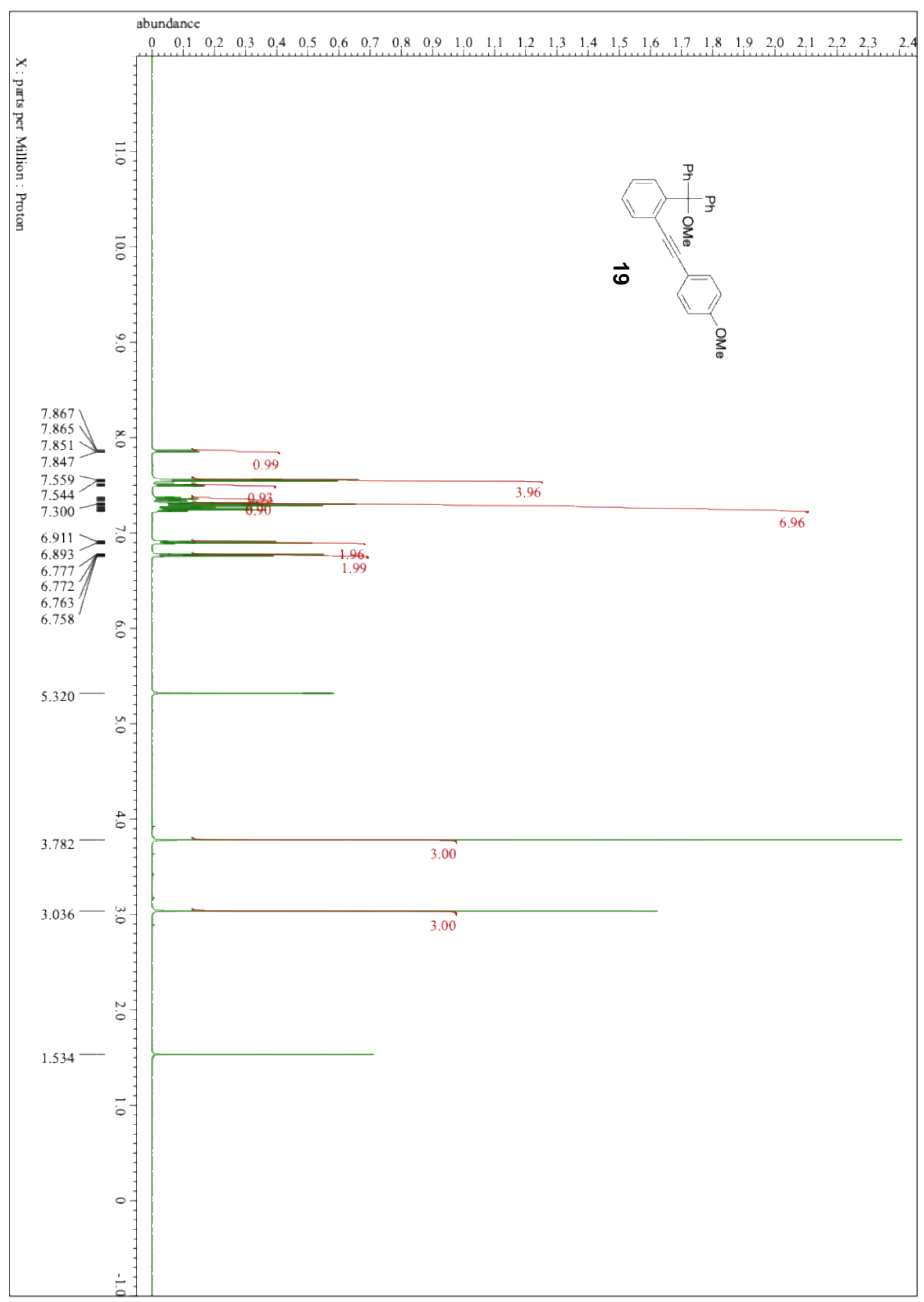


${ }^{13} \mathrm{C}$ NMR spectrum of 19 in $\mathrm{CD}_{2} \mathrm{Cl}_{2}$.

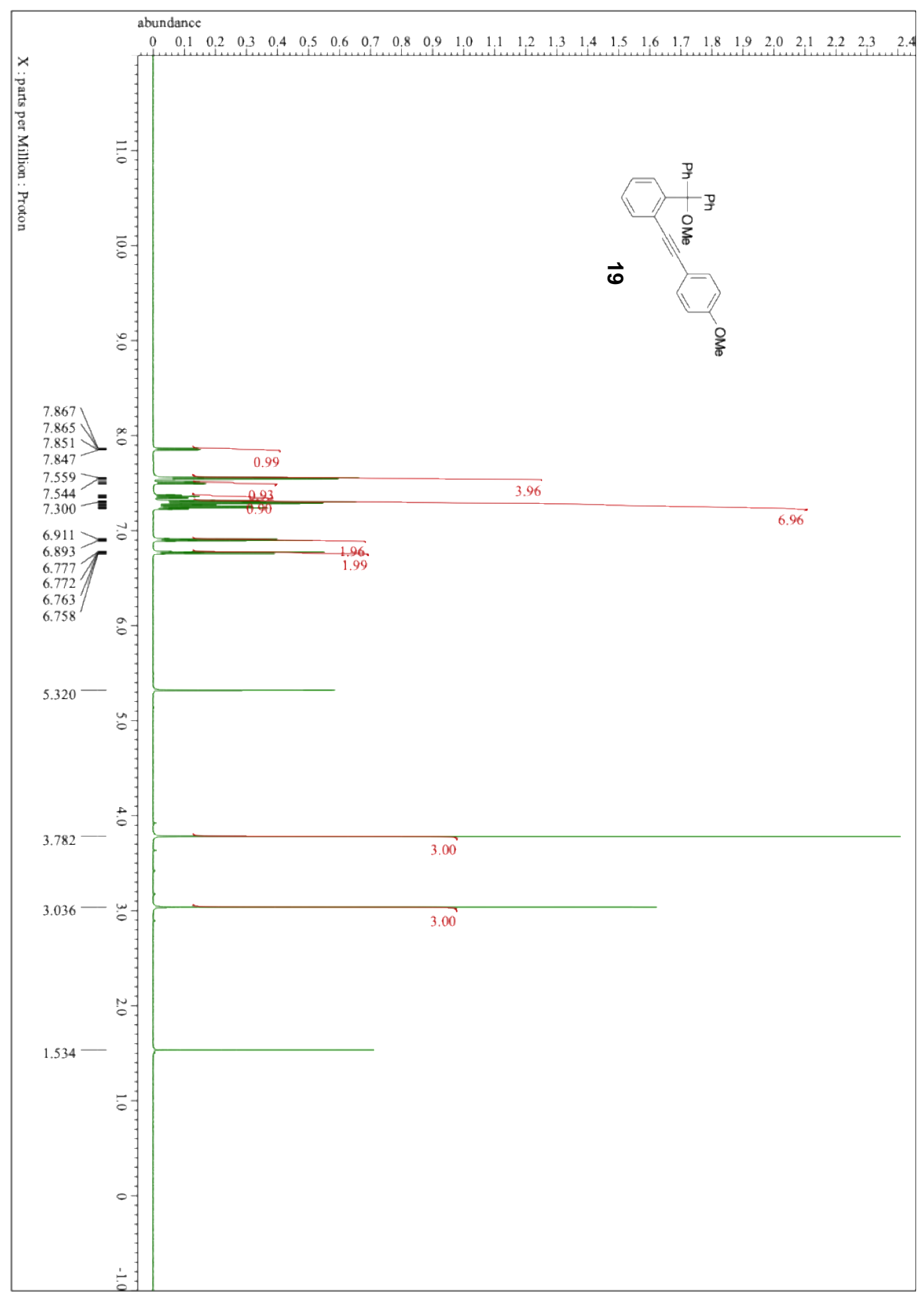


${ }^{1} \mathrm{H}$ NMR spectrum of 21 in $\mathrm{CD}_{2} \mathrm{Cl}_{2}$.

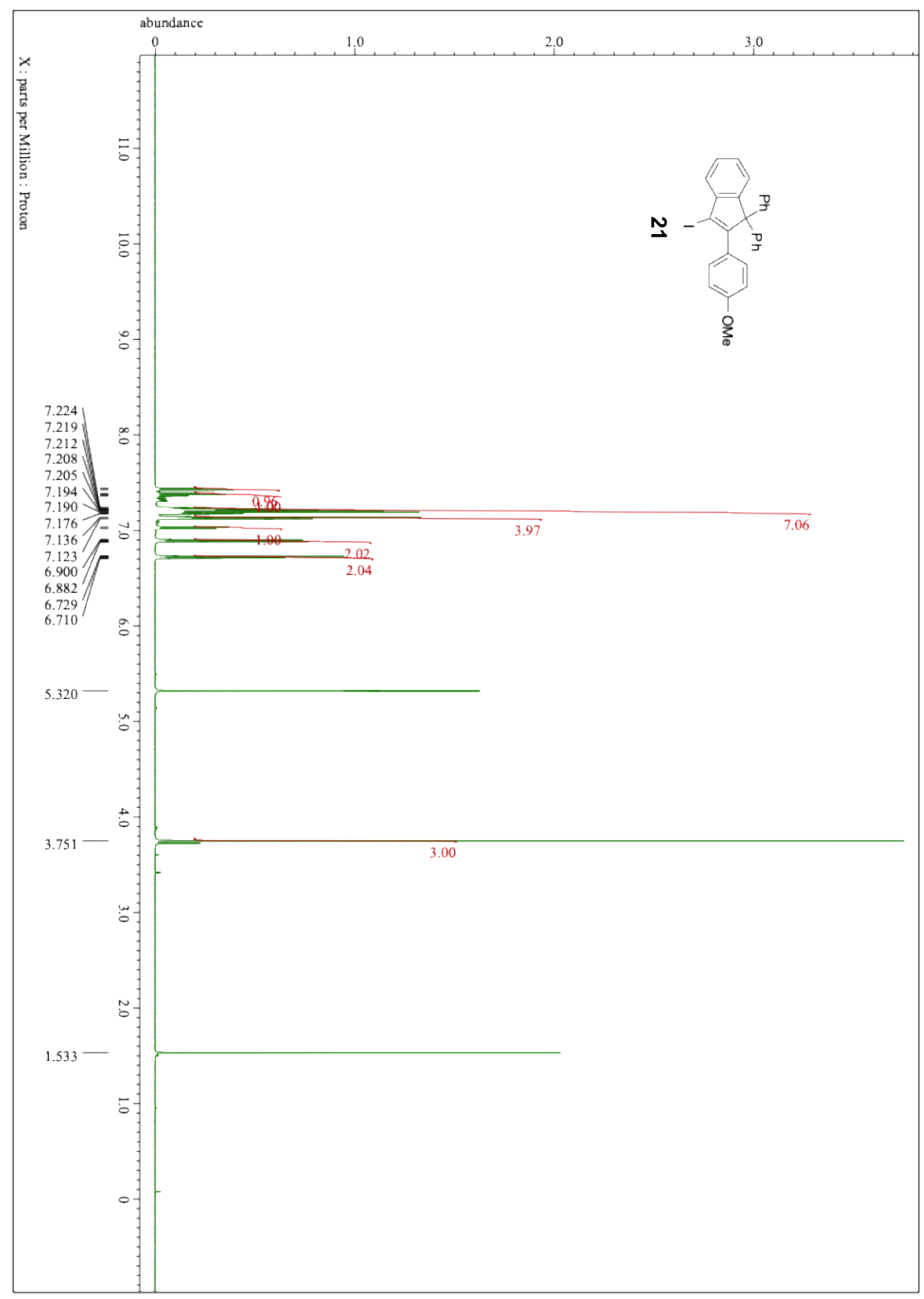


${ }^{13} \mathrm{C}$ NMR spectrum of 21 in $\mathrm{CD}_{2} \mathrm{Cl}_{2}$.

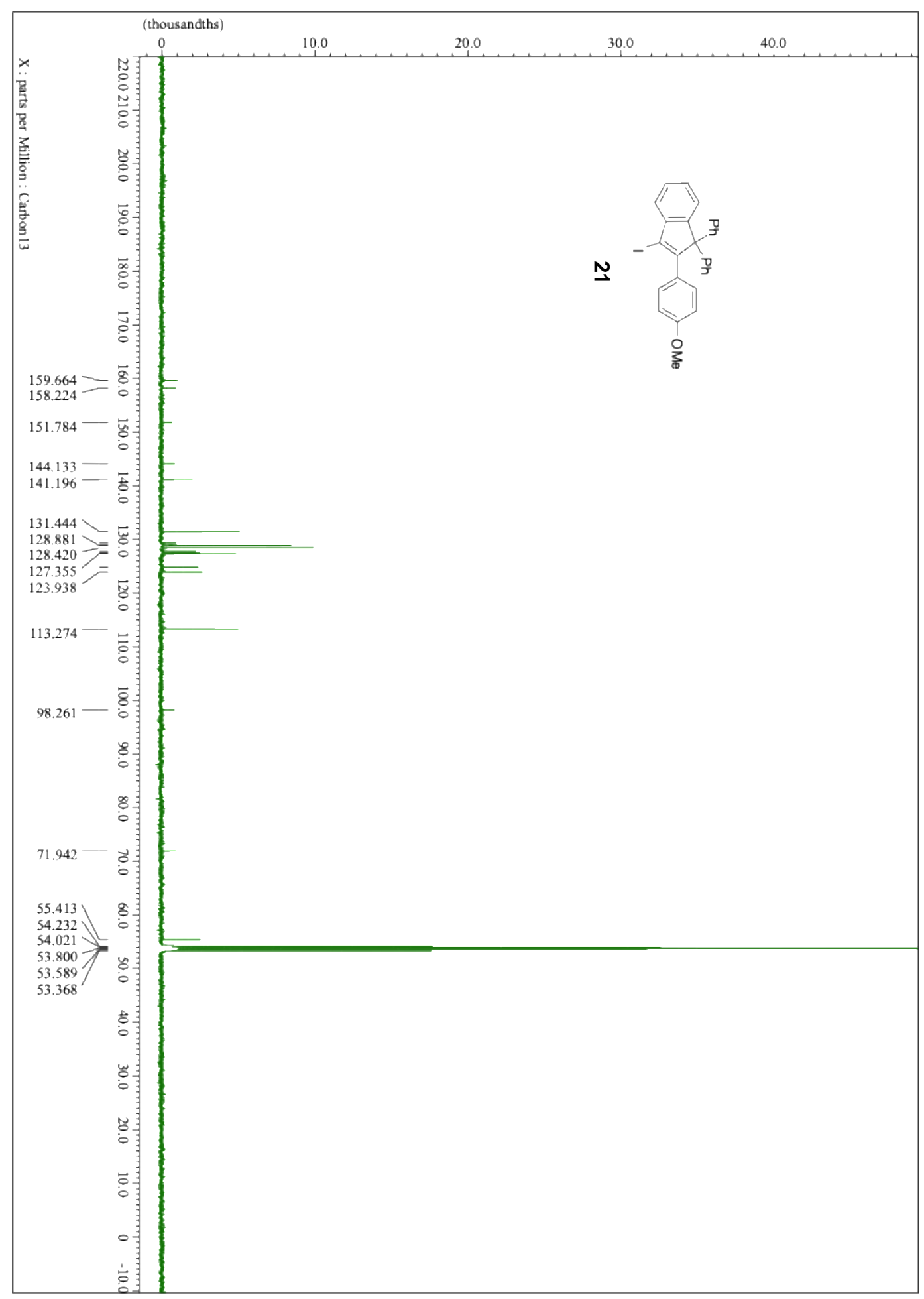


${ }^{1} \mathrm{H}$ NMR spectrum of $\mathbf{2 2}$ in $\mathrm{CD}_{2} \mathrm{Cl}_{2}$.

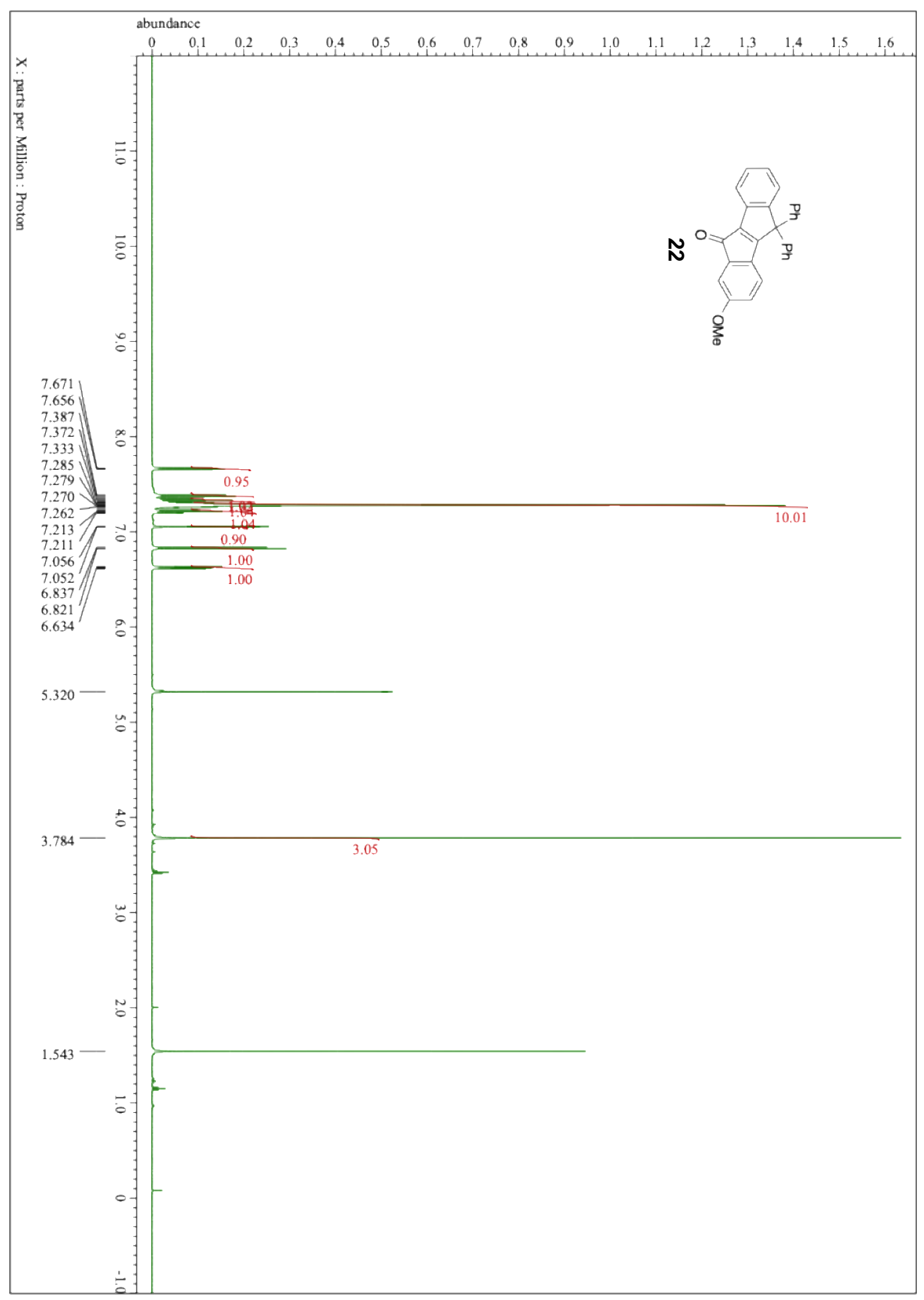


${ }^{13} \mathrm{C}$ NMR spectrum of 22 in $\mathrm{CD}_{2} \mathrm{Cl}_{2}$.

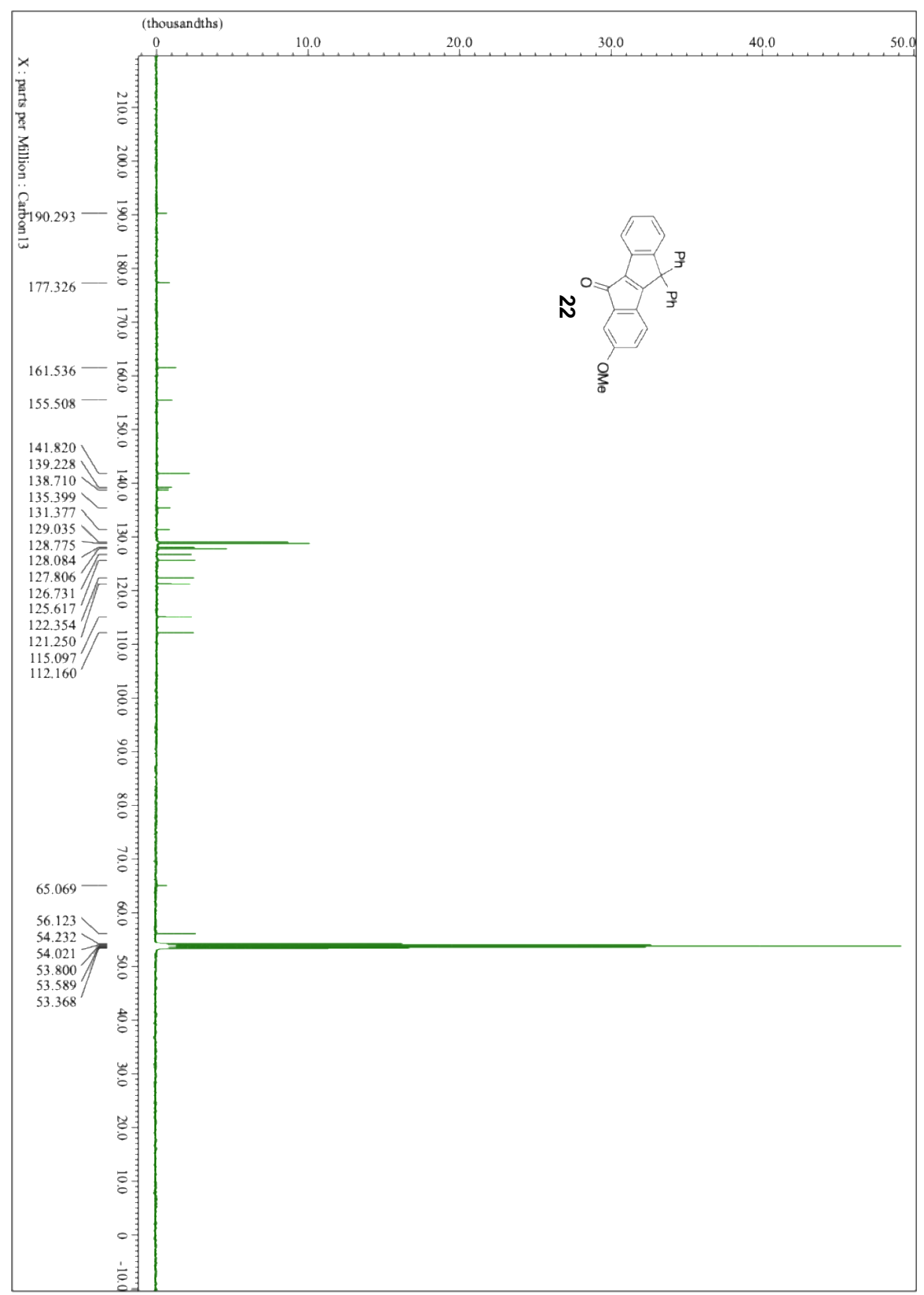


${ }^{1} \mathrm{H}$ NMR spectrum of $\mathbf{6}$ in $\mathrm{CD}_{2} \mathrm{Cl}_{2}$.

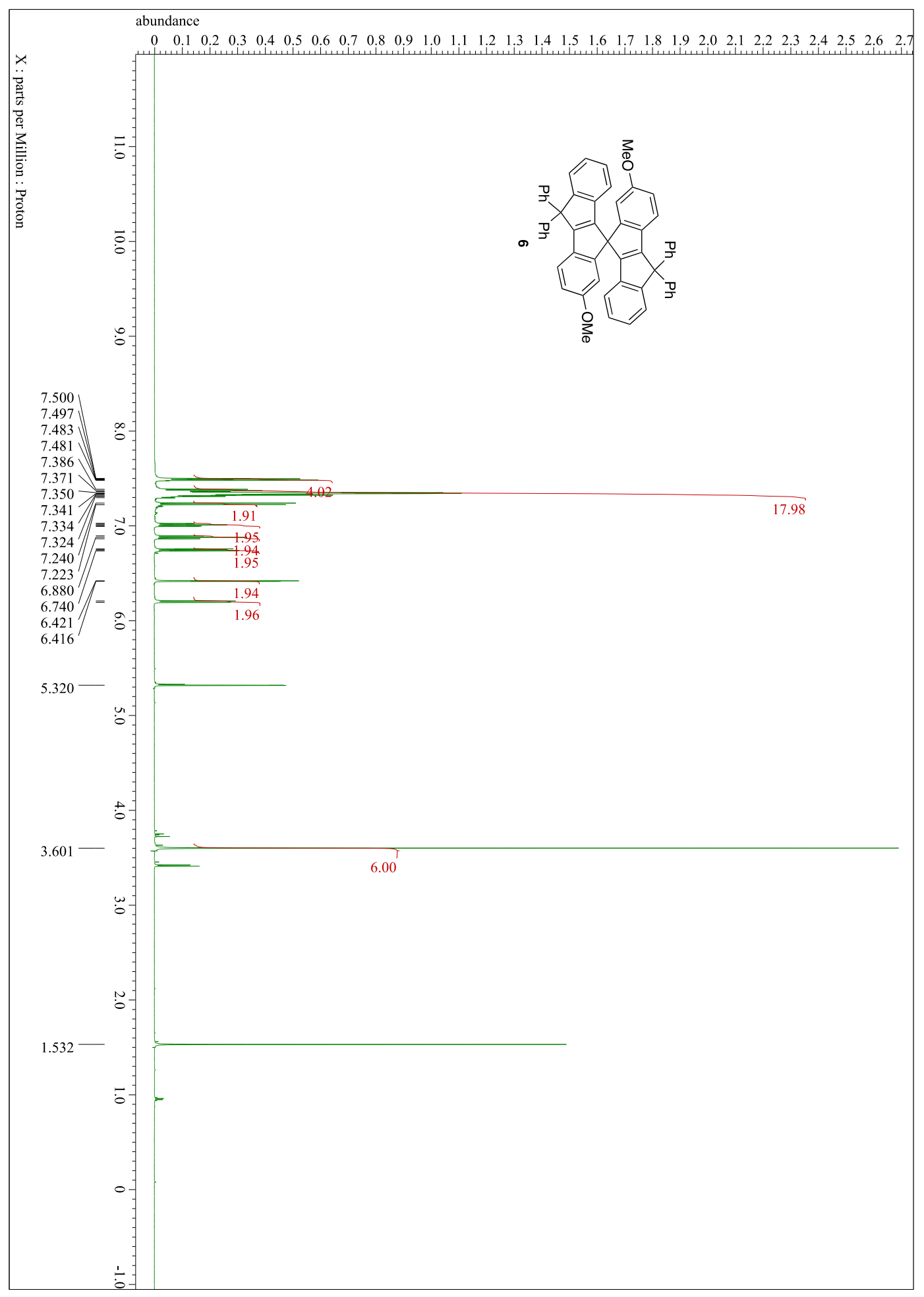


${ }^{13} \mathrm{C}$ NMR spectrum of 6 in $\mathrm{CD}_{2} \mathrm{Cl}_{2}$.

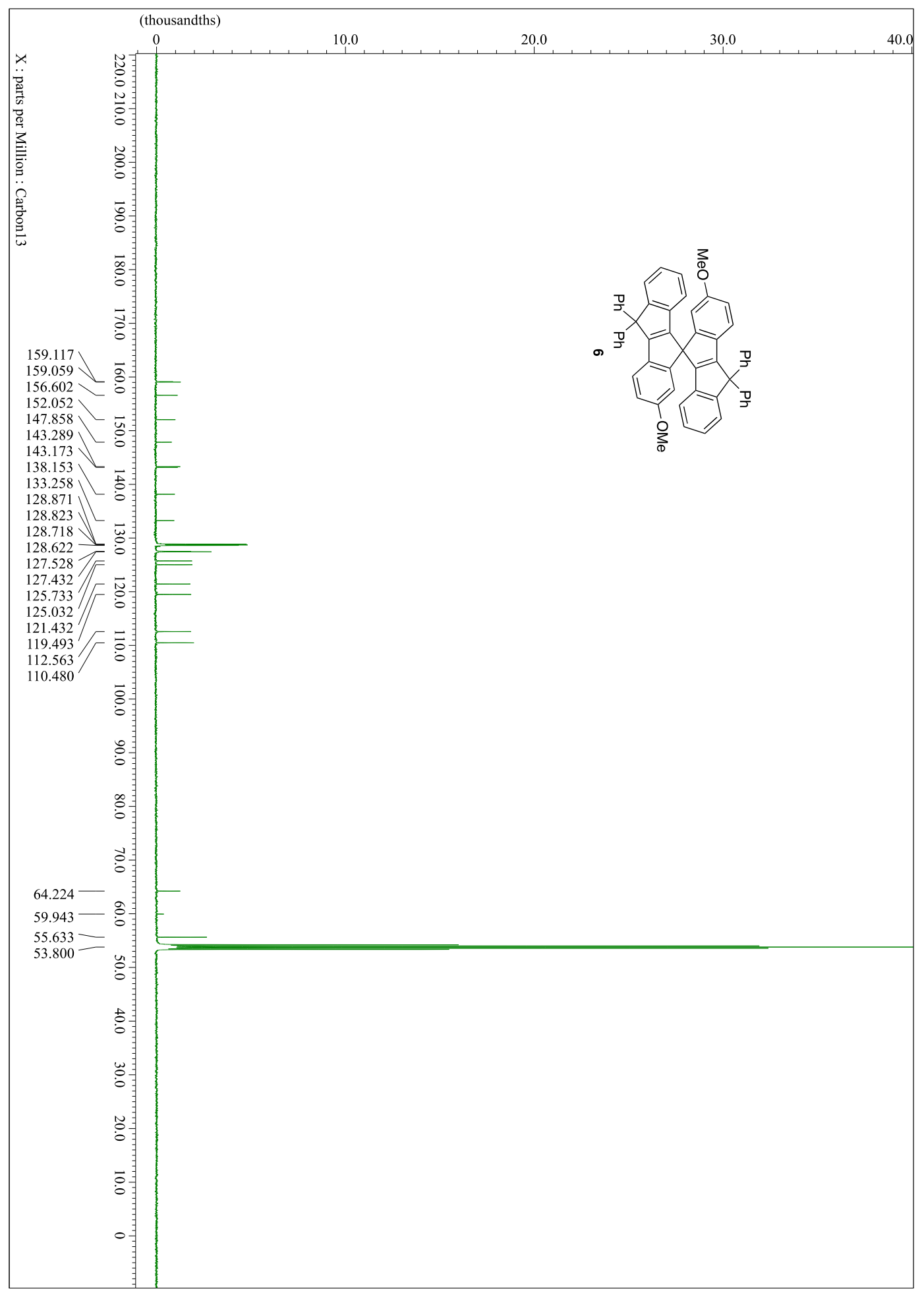


${ }^{1} \mathrm{H}$ NMR spectrum of 7 in $\mathrm{CD}_{2} \mathrm{Cl}_{2}$.

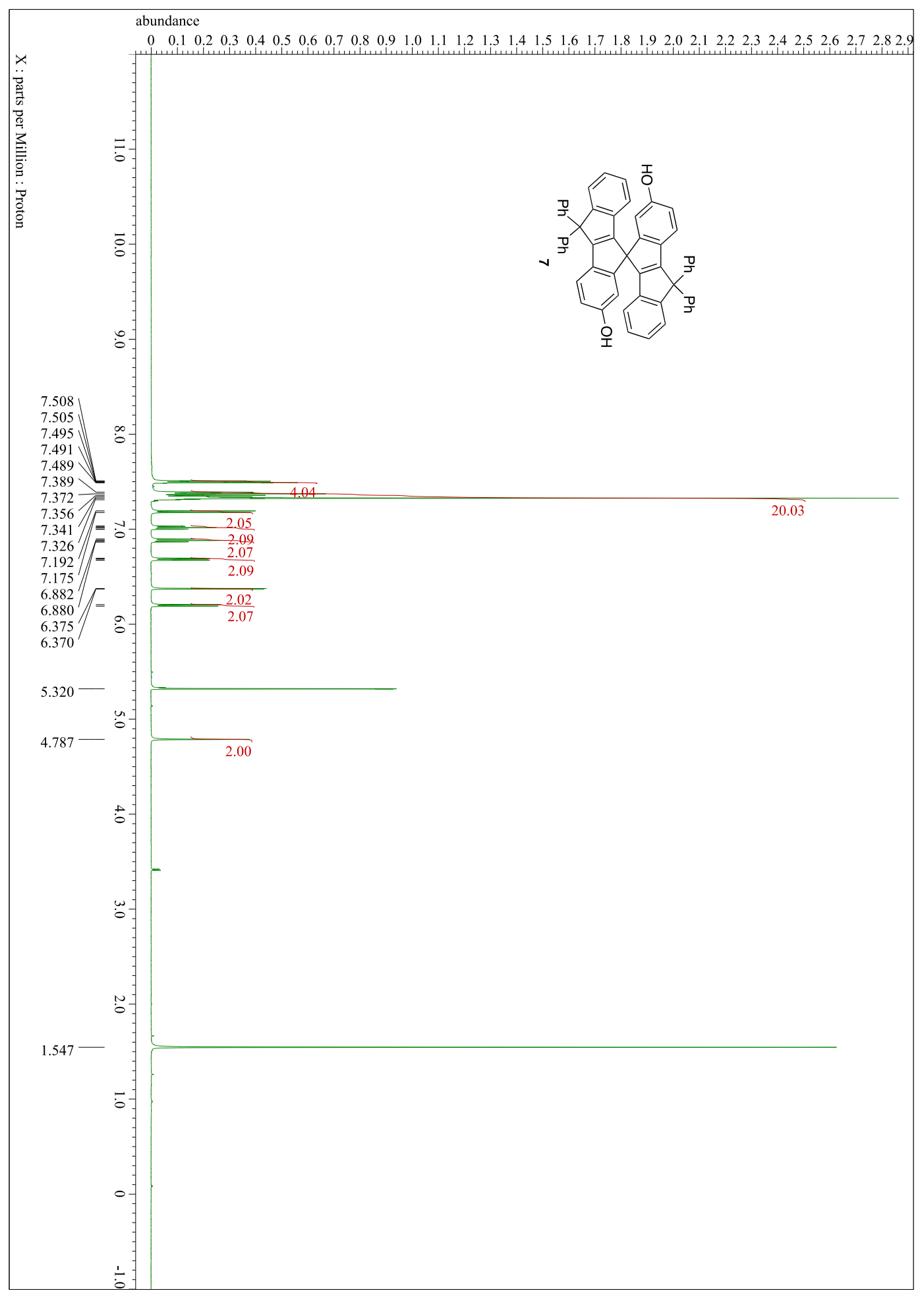


${ }^{13} \mathrm{C}$ NMR spectrum of 7 in $\mathrm{CD}_{2} \mathrm{Cl}_{2}$.

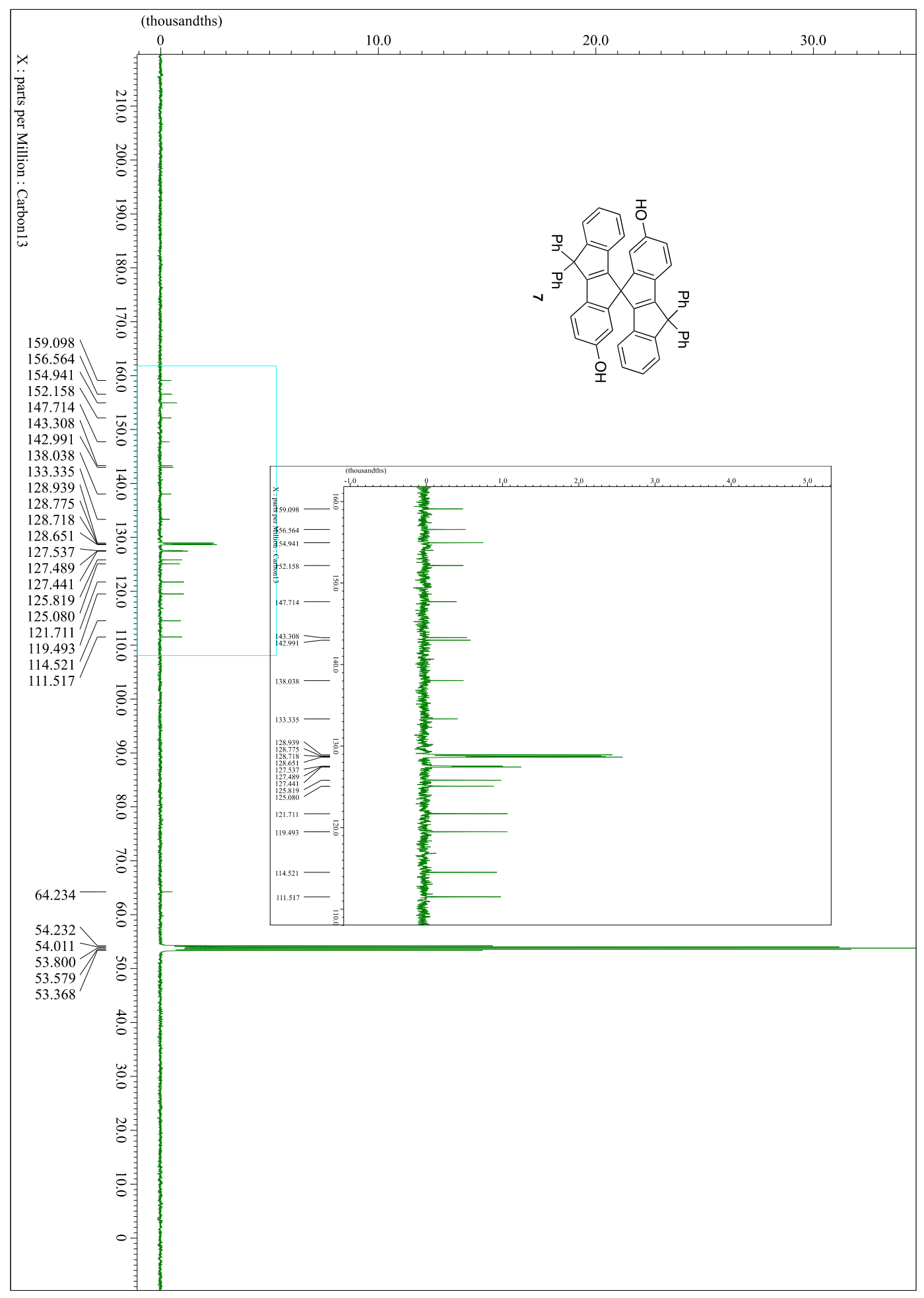


${ }^{1} \mathrm{H}$ NMR spectrum of $\mathbf{1 0}$ in $\mathrm{CD}_{2} \mathrm{Cl}_{2}$.

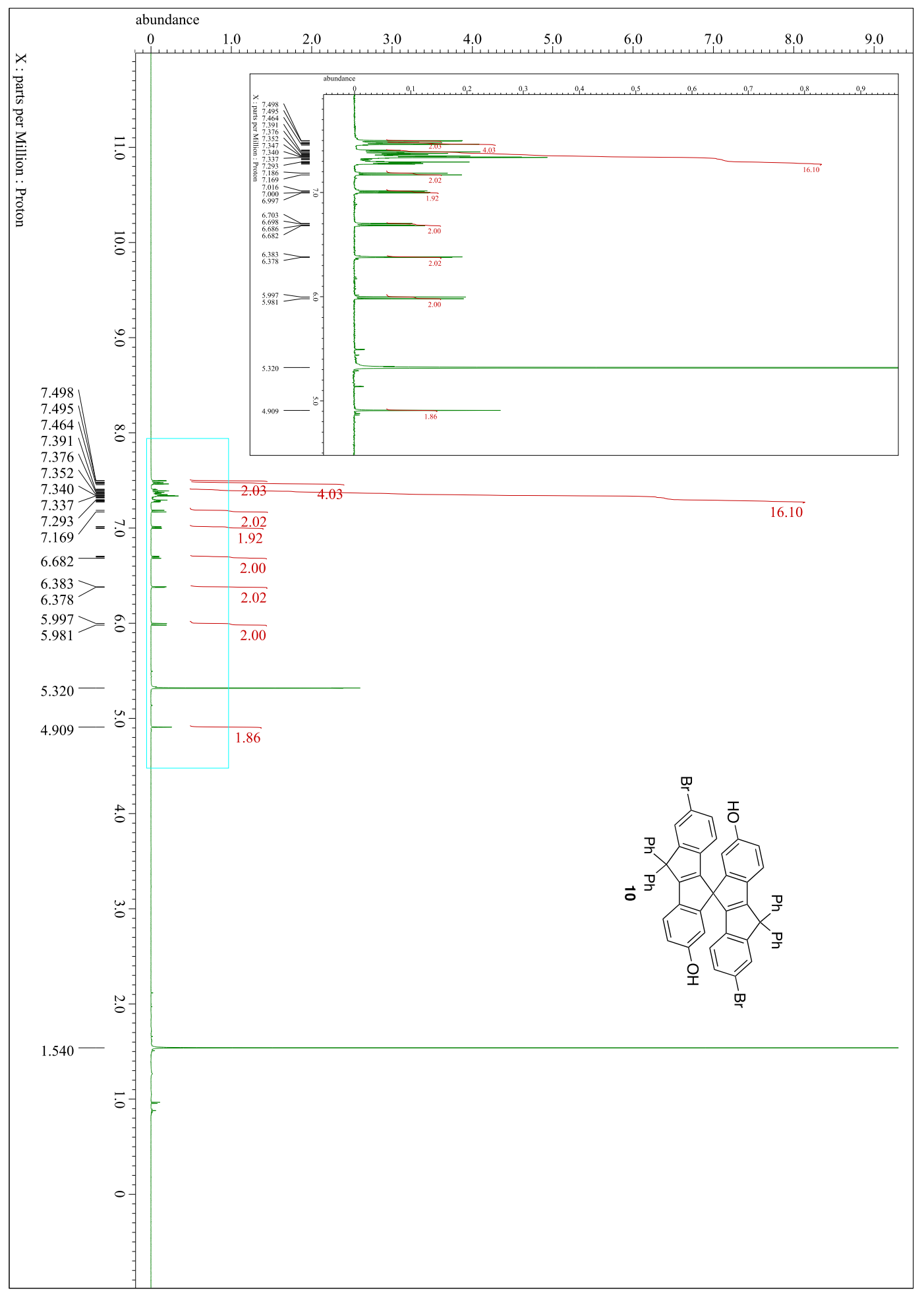


${ }^{13} \mathrm{C}$ NMR spectrum of $\mathbf{1 0}$ in $\mathrm{CD}_{2} \mathrm{Cl}_{2}$.

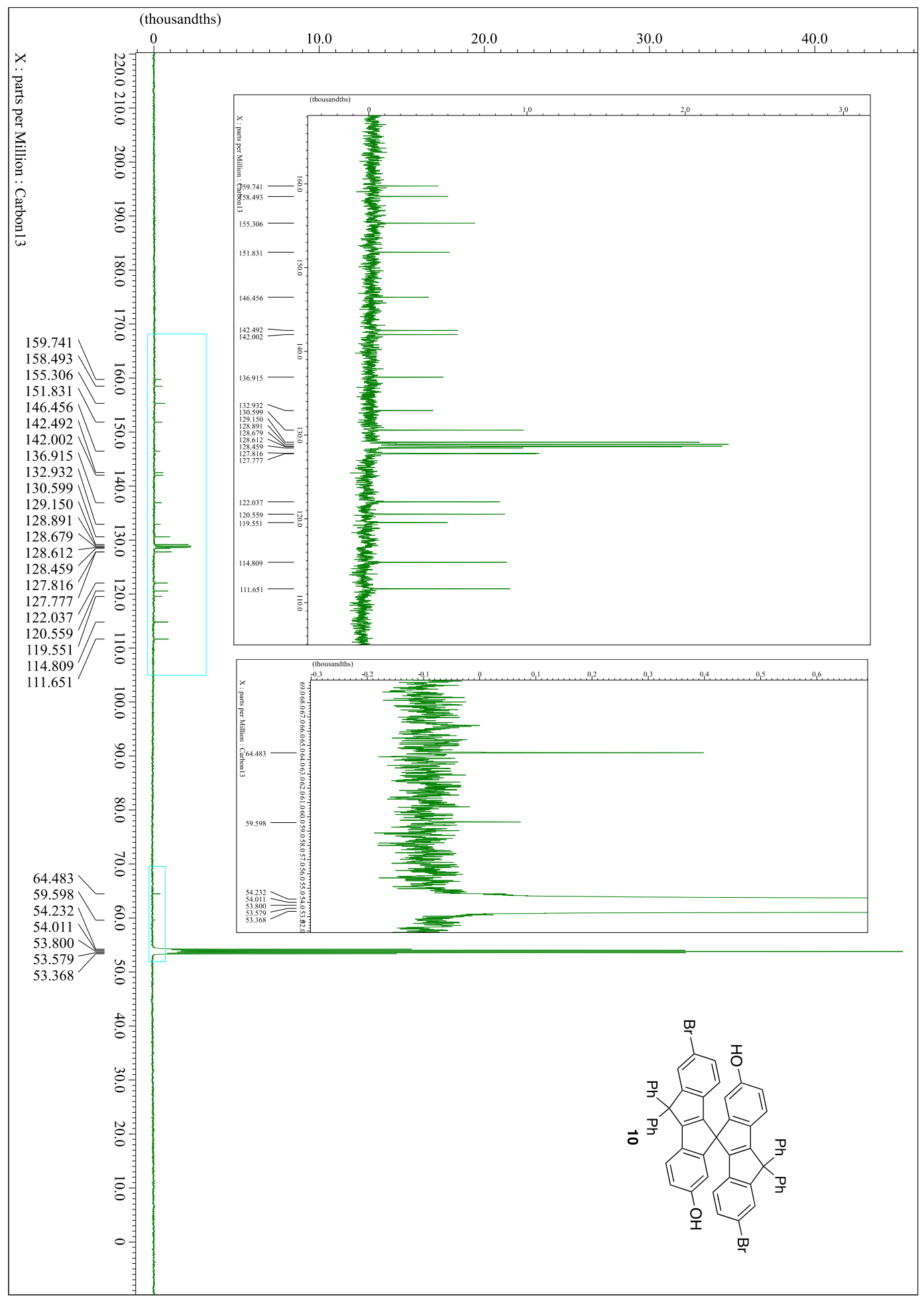


${ }^{1} \mathrm{H}$ NMR spectrum of $\mathbf{8}$ in $\mathrm{CD}_{2} \mathrm{Cl}_{2}$.

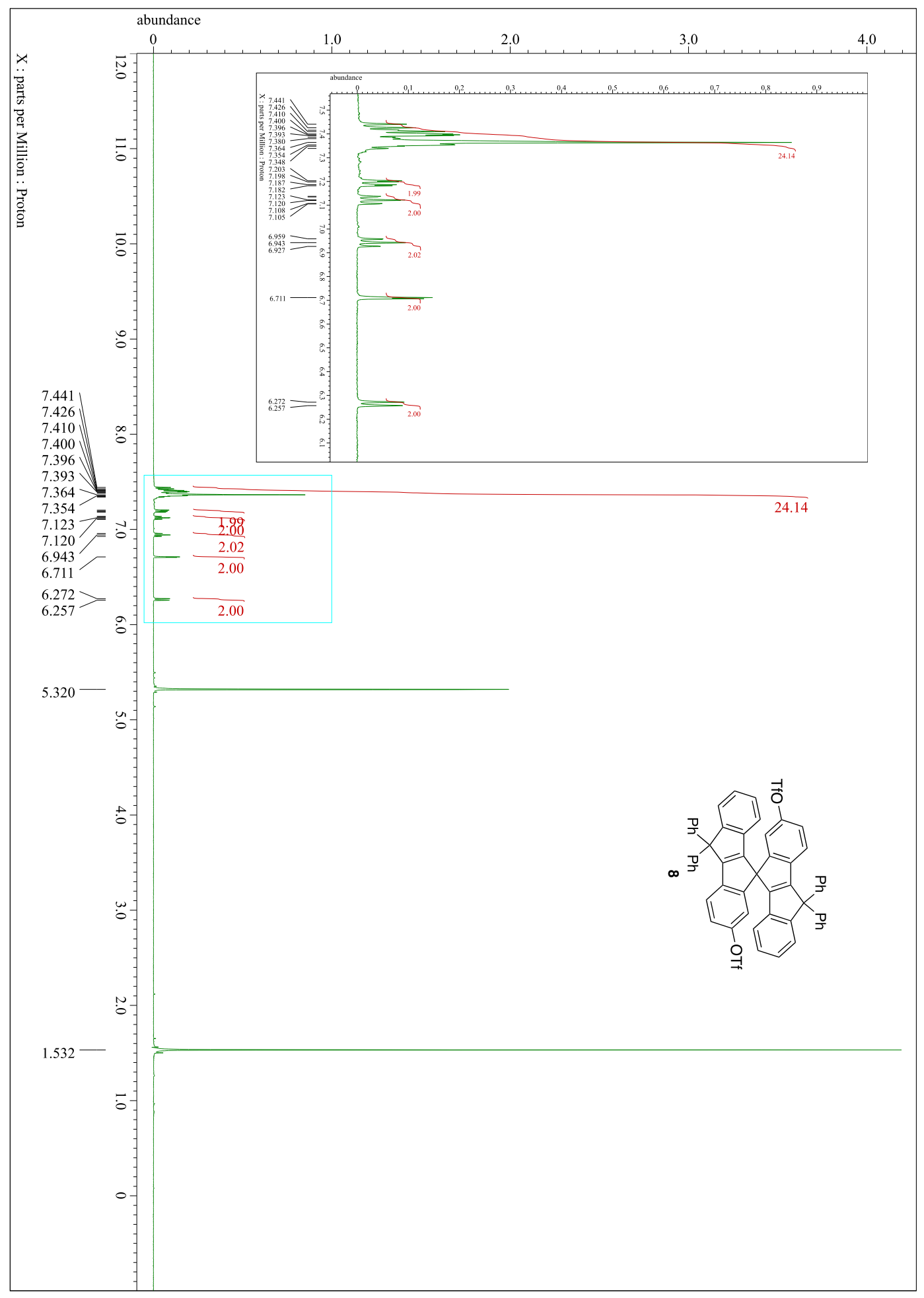


${ }^{13} \mathrm{C}$ NMR spectrum of 8 in $\mathrm{CD}_{2} \mathrm{Cl}_{2}$.

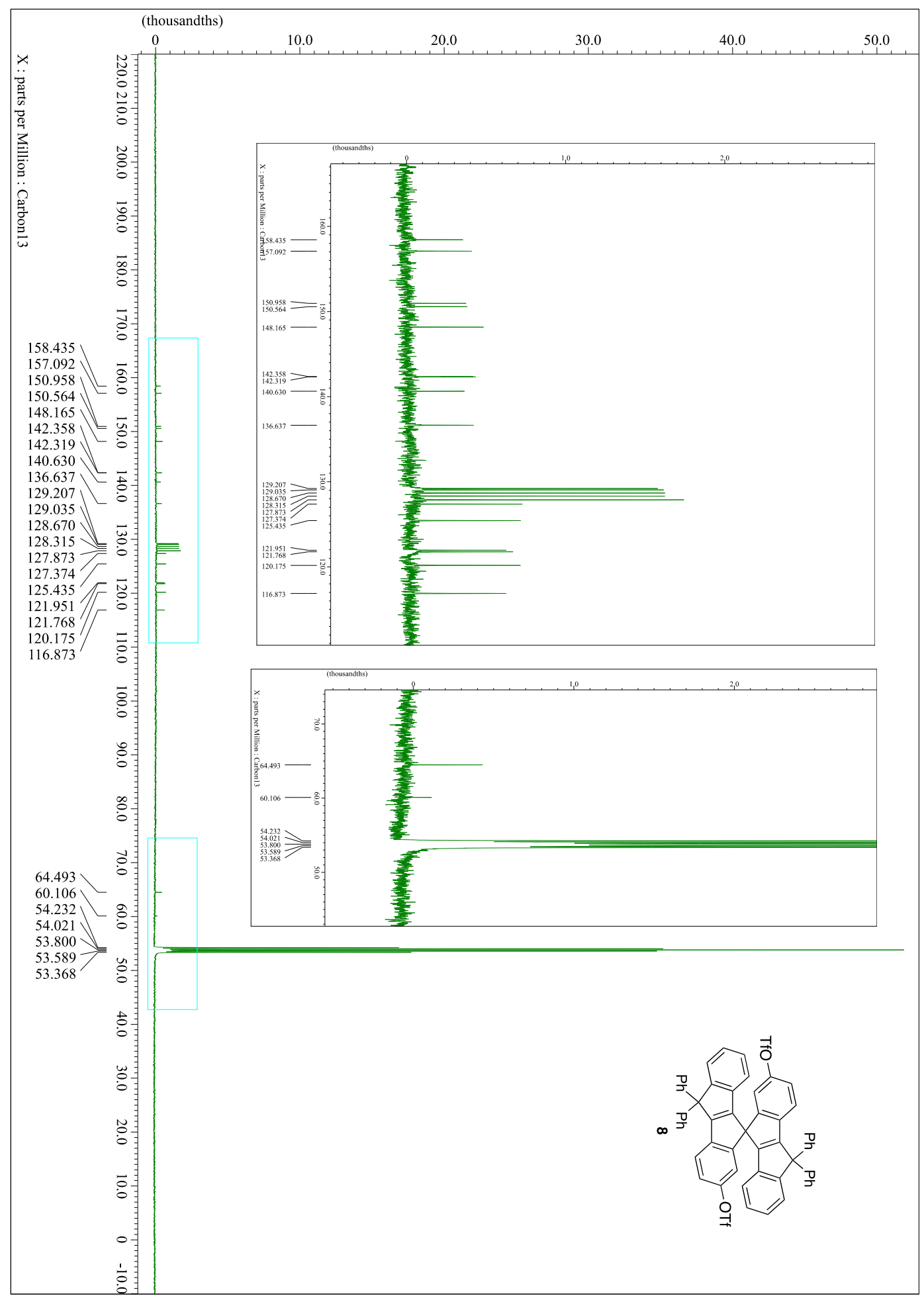


${ }^{1} \mathrm{H}$ NMR spectrum of $\mathbf{1 1}$ in $\mathrm{CD}_{2} \mathrm{Cl}_{2}$.

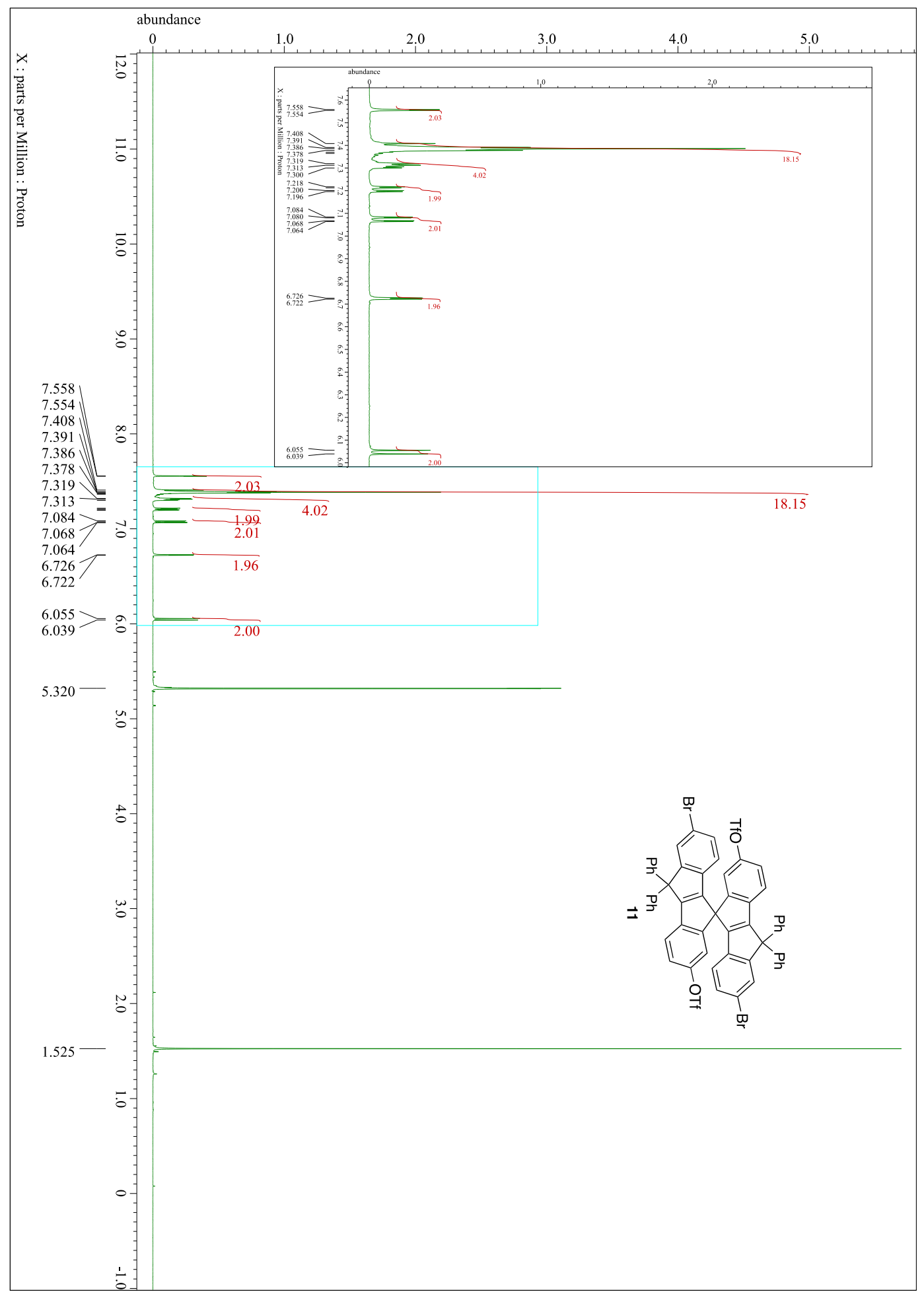


${ }^{13} \mathrm{C}$ NMR spectrum of $\mathbf{1 1}$ in $\mathrm{CD}_{2} \mathrm{Cl}_{2}$.

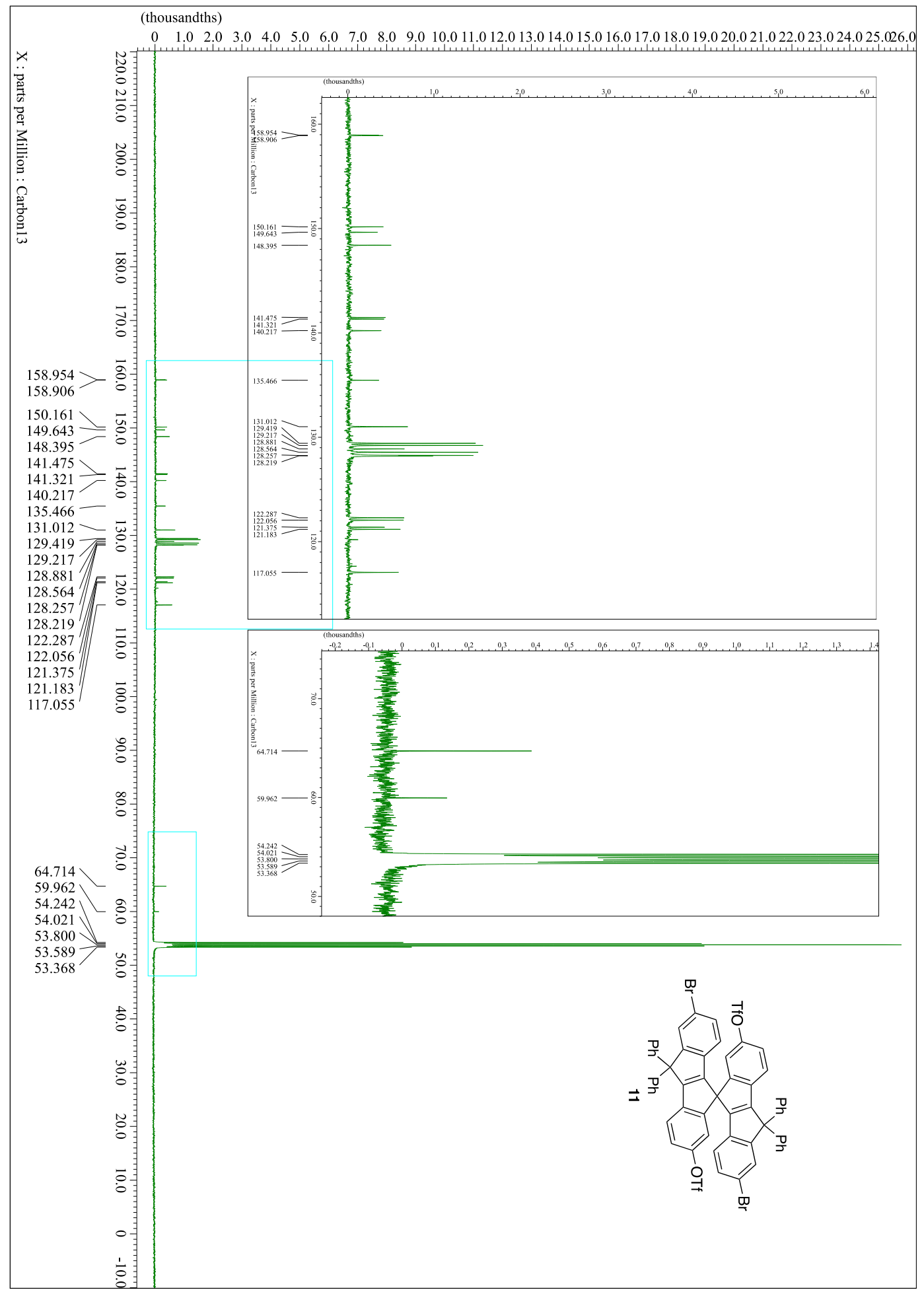


${ }^{1} \mathrm{H}$ NMR spectrum of $\mathbf{2}$ in $\mathrm{CD}_{2} \mathrm{Cl}_{2}$.

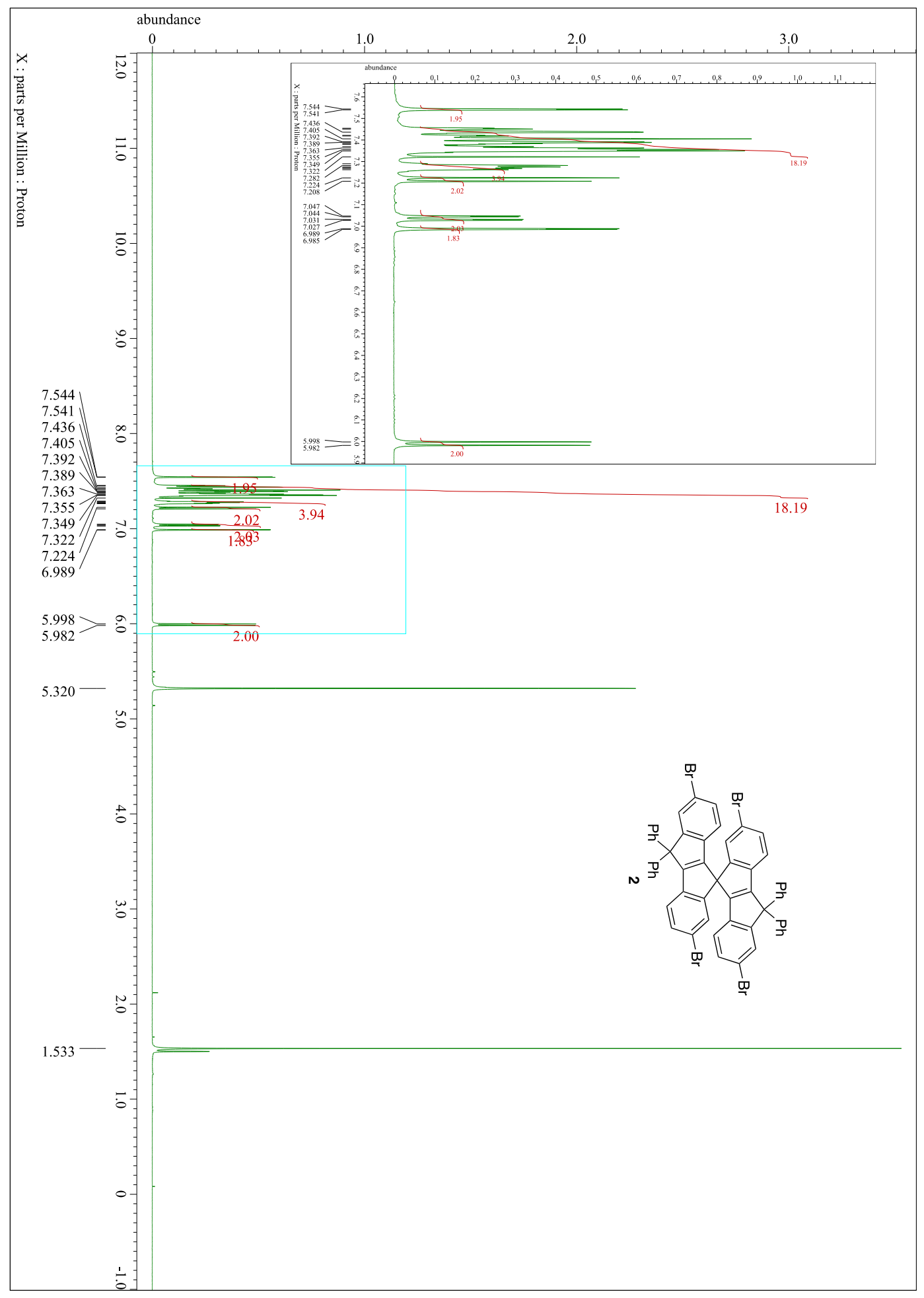


${ }^{13} \mathrm{C}$ NMR spectrum of 2 in $\mathrm{CD}_{2} \mathrm{Cl}_{2}$.

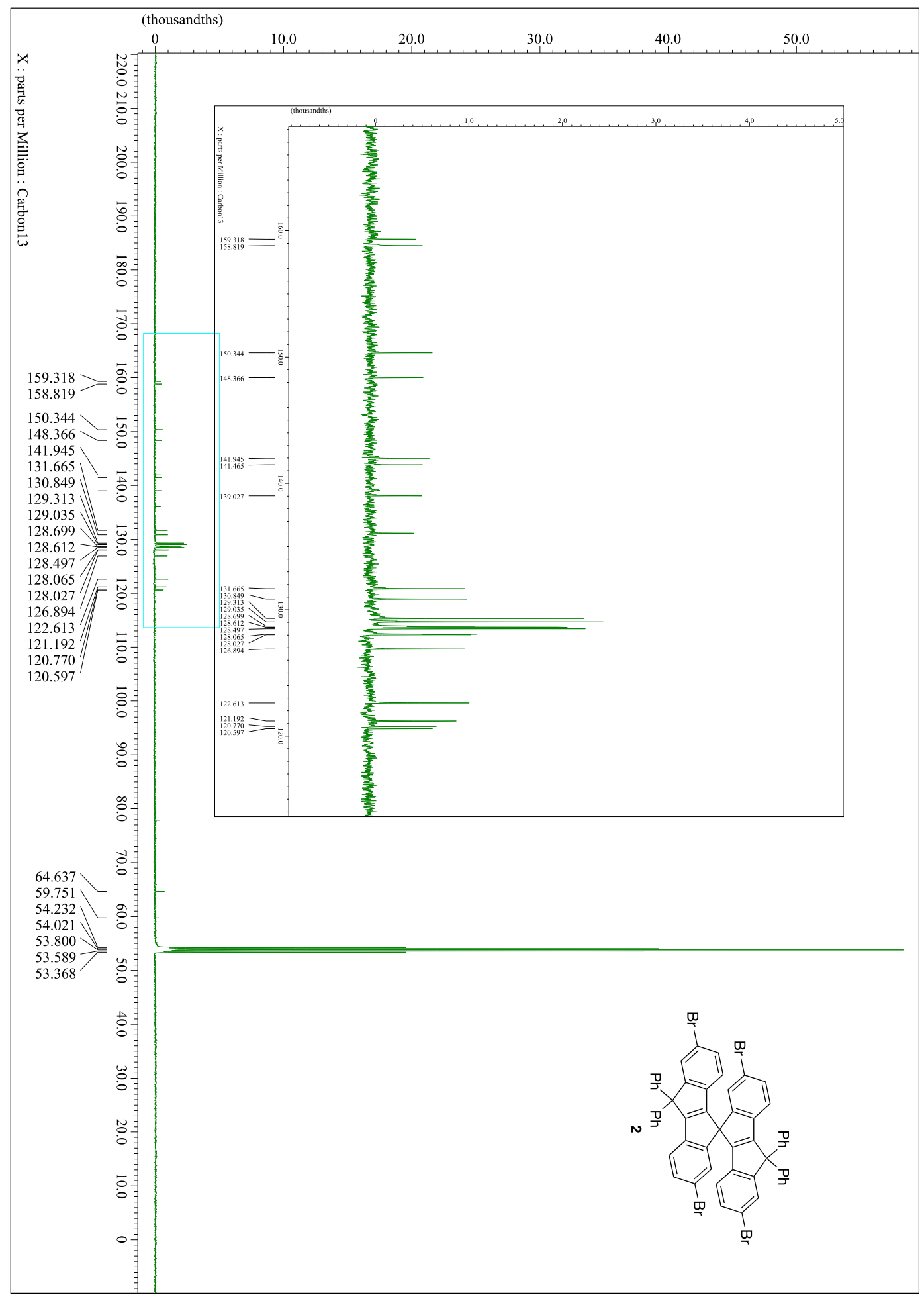


${ }^{1} \mathrm{H}$ NMR spectrum of 9 in $\mathrm{CD}_{2} \mathrm{Cl}_{2}$.

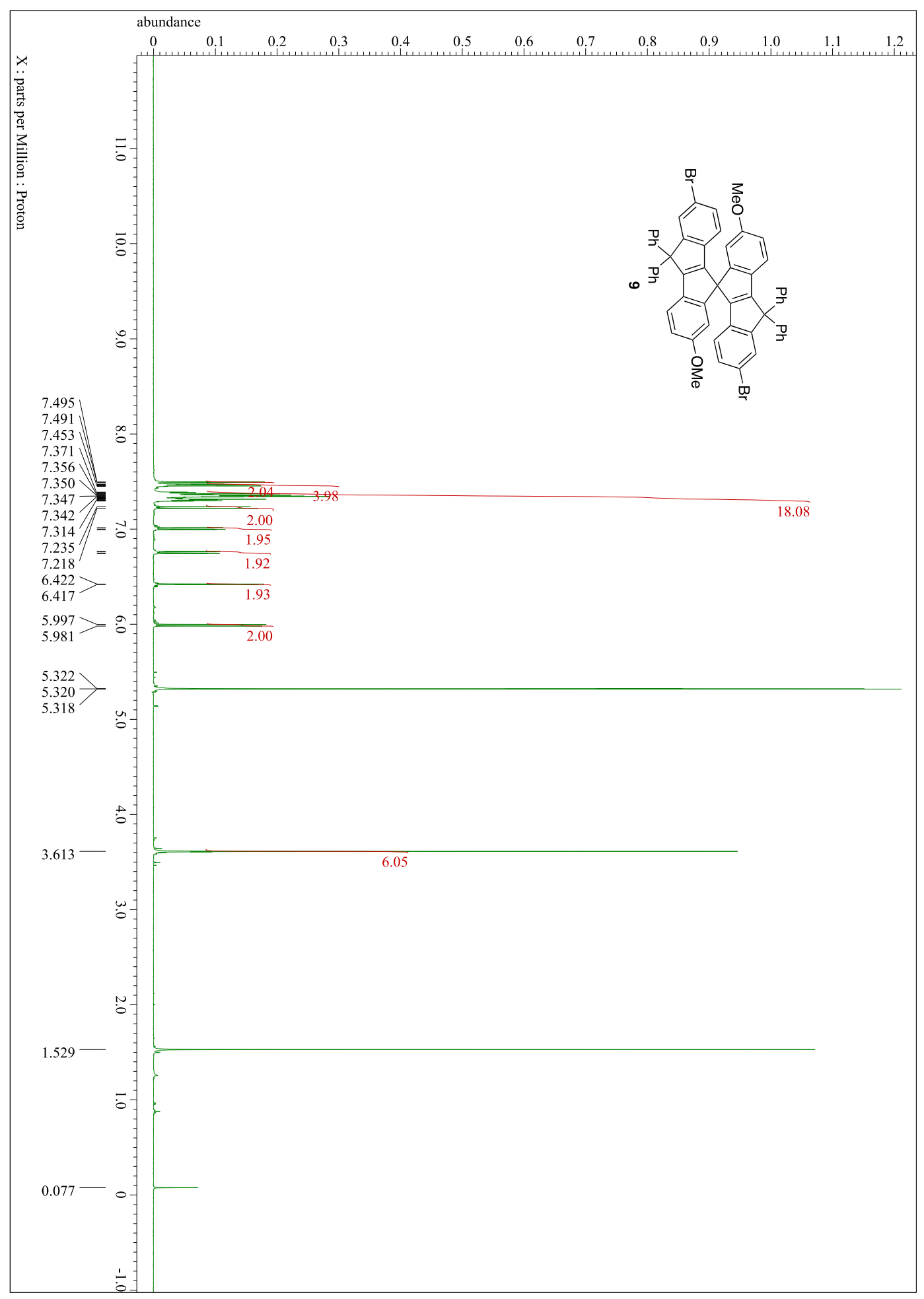


${ }^{13} \mathrm{C}$ NMR spectrum of 9 in $\mathrm{CD}_{2} \mathrm{Cl}_{2}$.

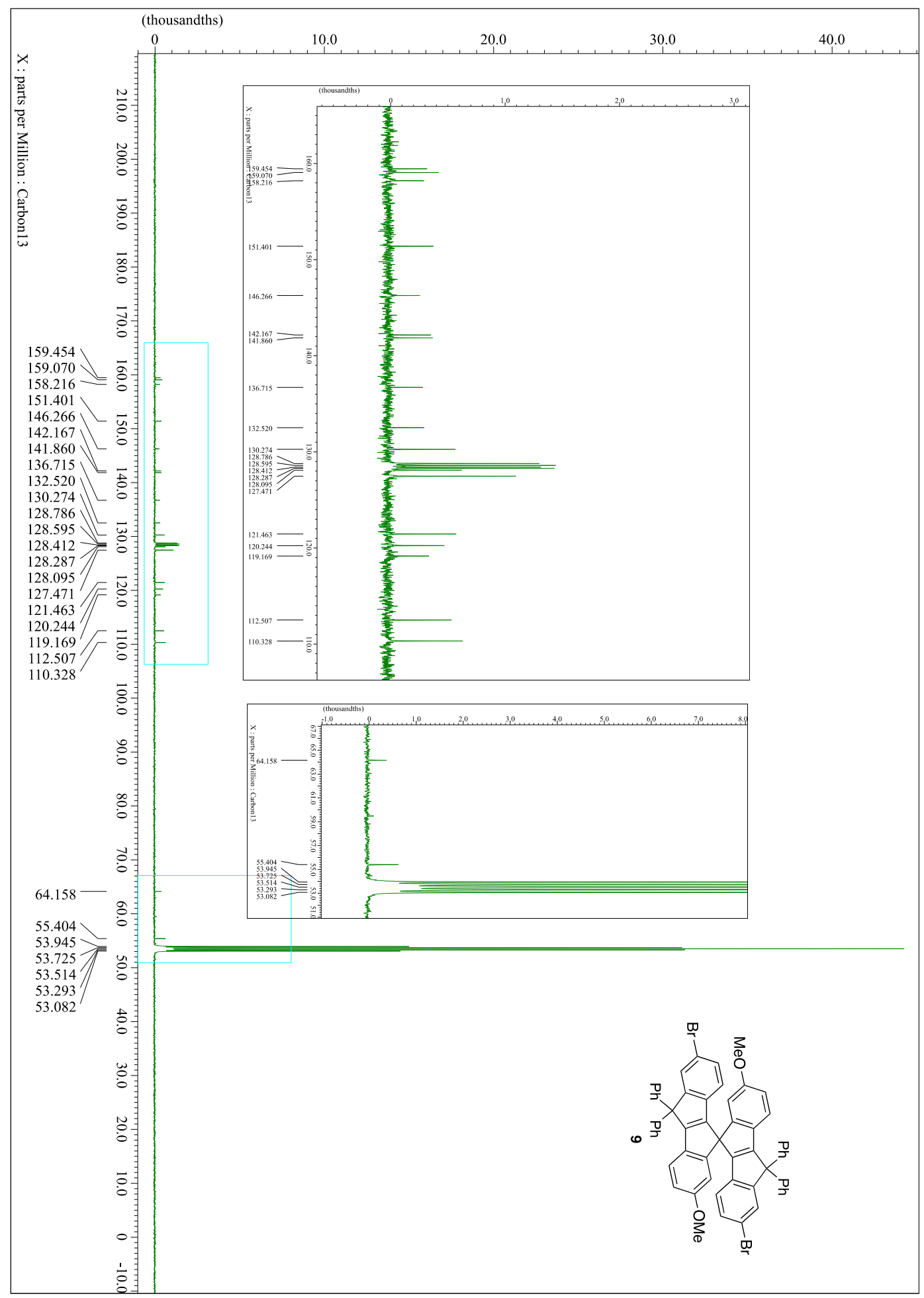


${ }^{1} \mathrm{H}$ NMR spectrum of 3 in $\mathrm{CD}_{2} \mathrm{Cl}_{2}$.

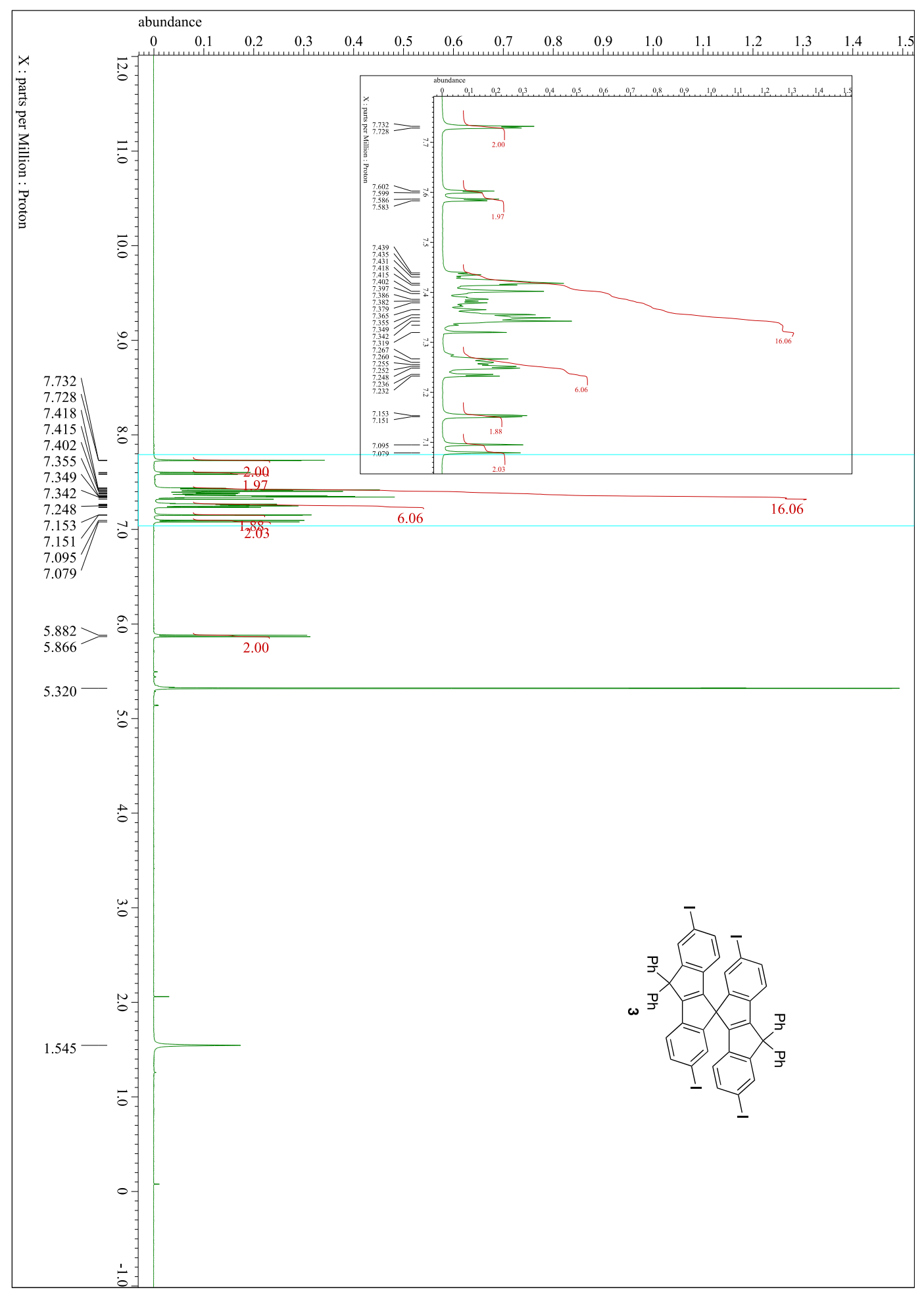


${ }^{13} \mathrm{C}$ NMR spectrum of 3 in $\mathrm{CD}_{2} \mathrm{Cl}_{2}$.

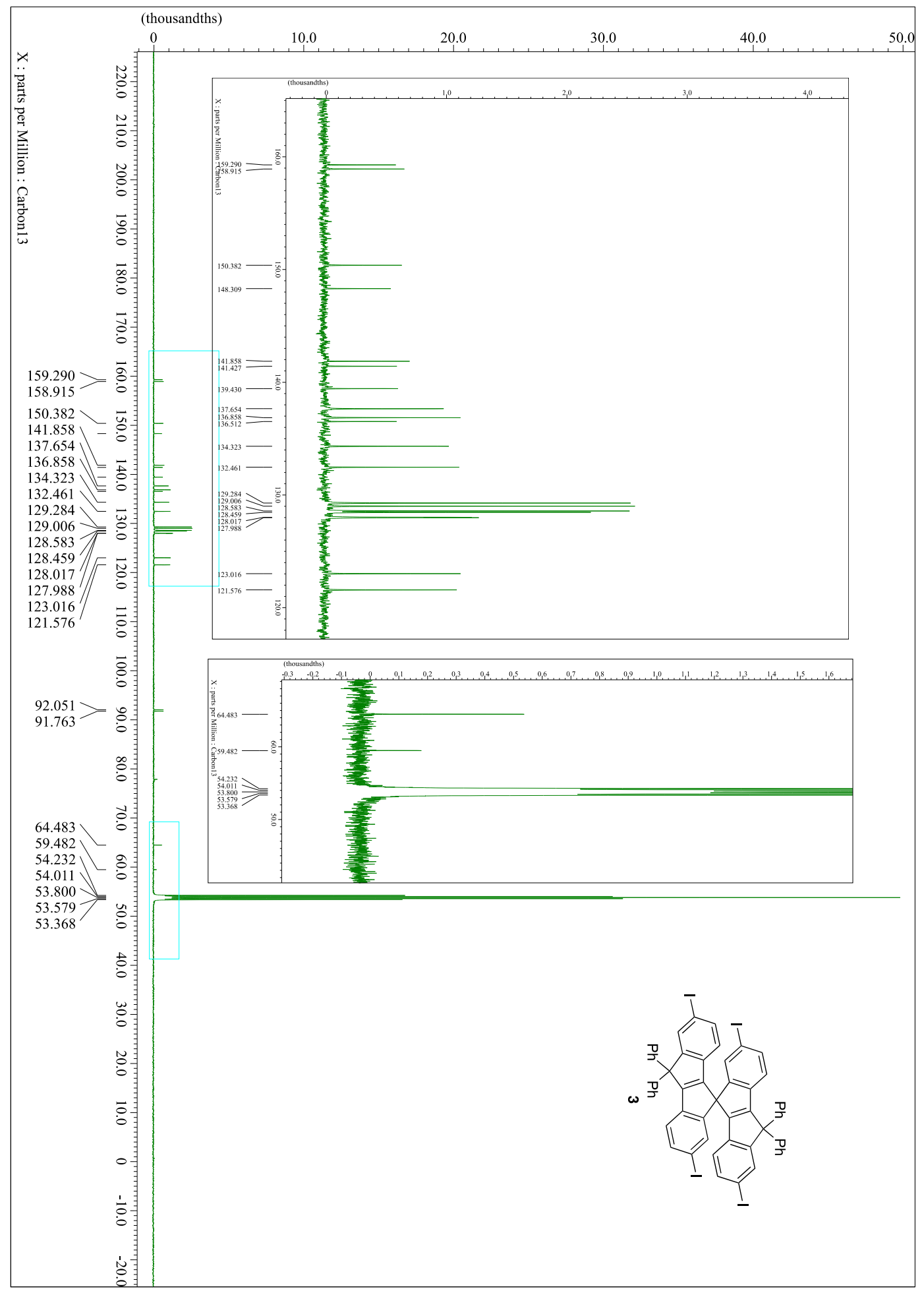


${ }^{1} \mathrm{H}$ NMR spectrum of $\mathbf{4}$ in $\mathrm{CD}_{2} \mathrm{Cl}_{2}$.

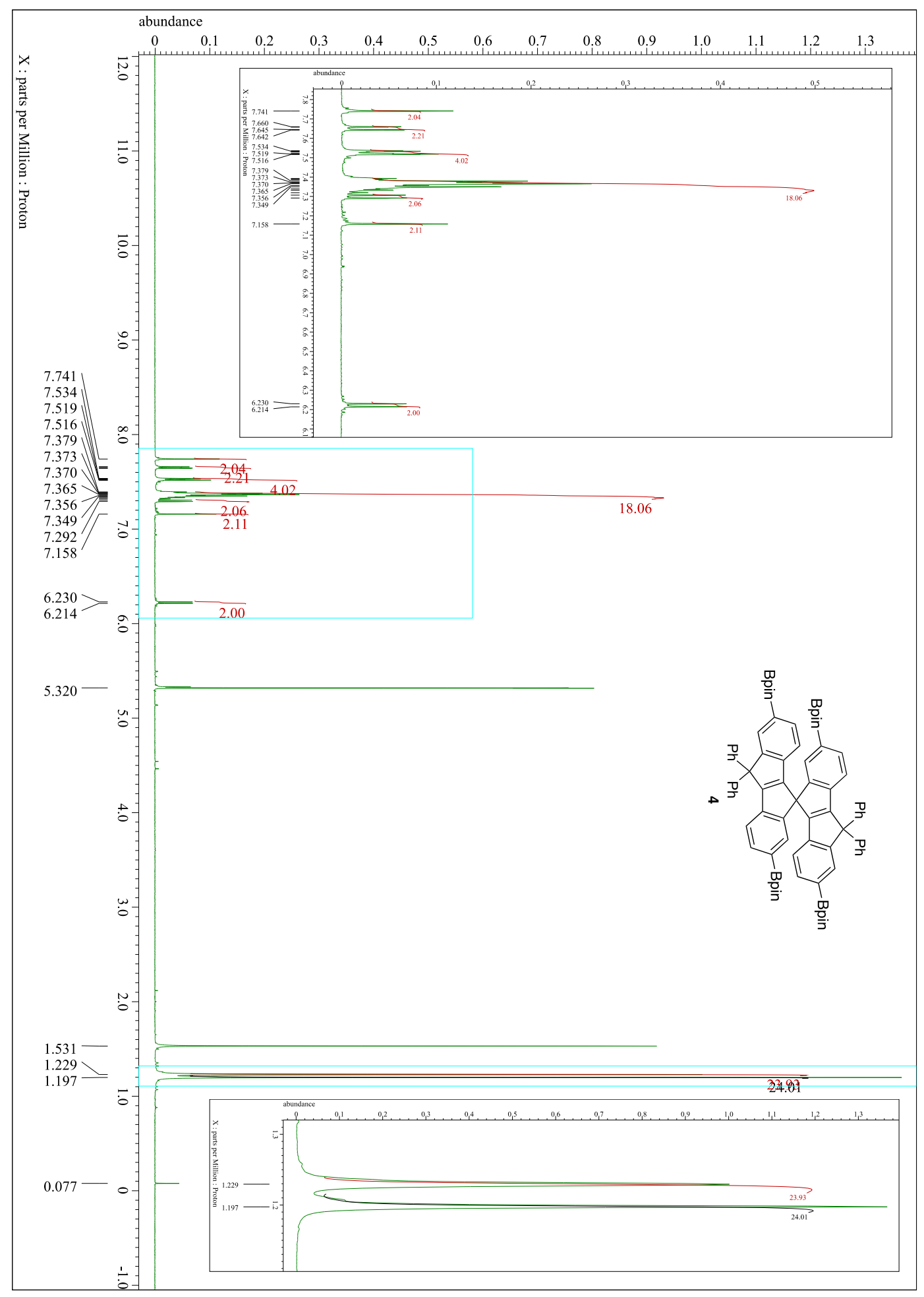


${ }^{13} \mathrm{C}$ NMR spectrum of 4 in $\mathrm{CD}_{2} \mathrm{Cl}_{2}$.

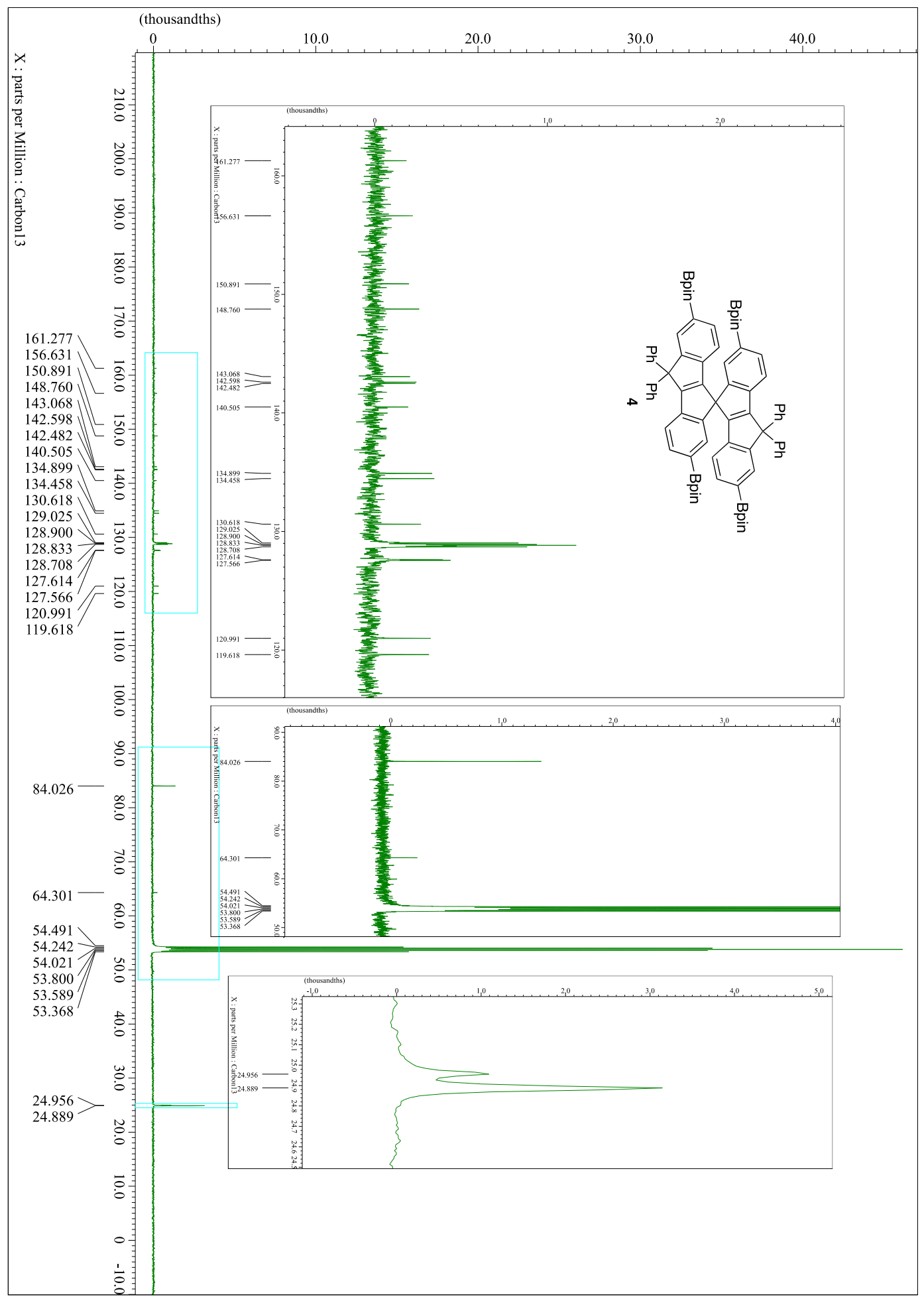


${ }^{1} \mathrm{H}$ NMR spectrum of $\mathbf{1 2}$ in $\mathrm{CD}_{2} \mathrm{Cl}_{2}$.

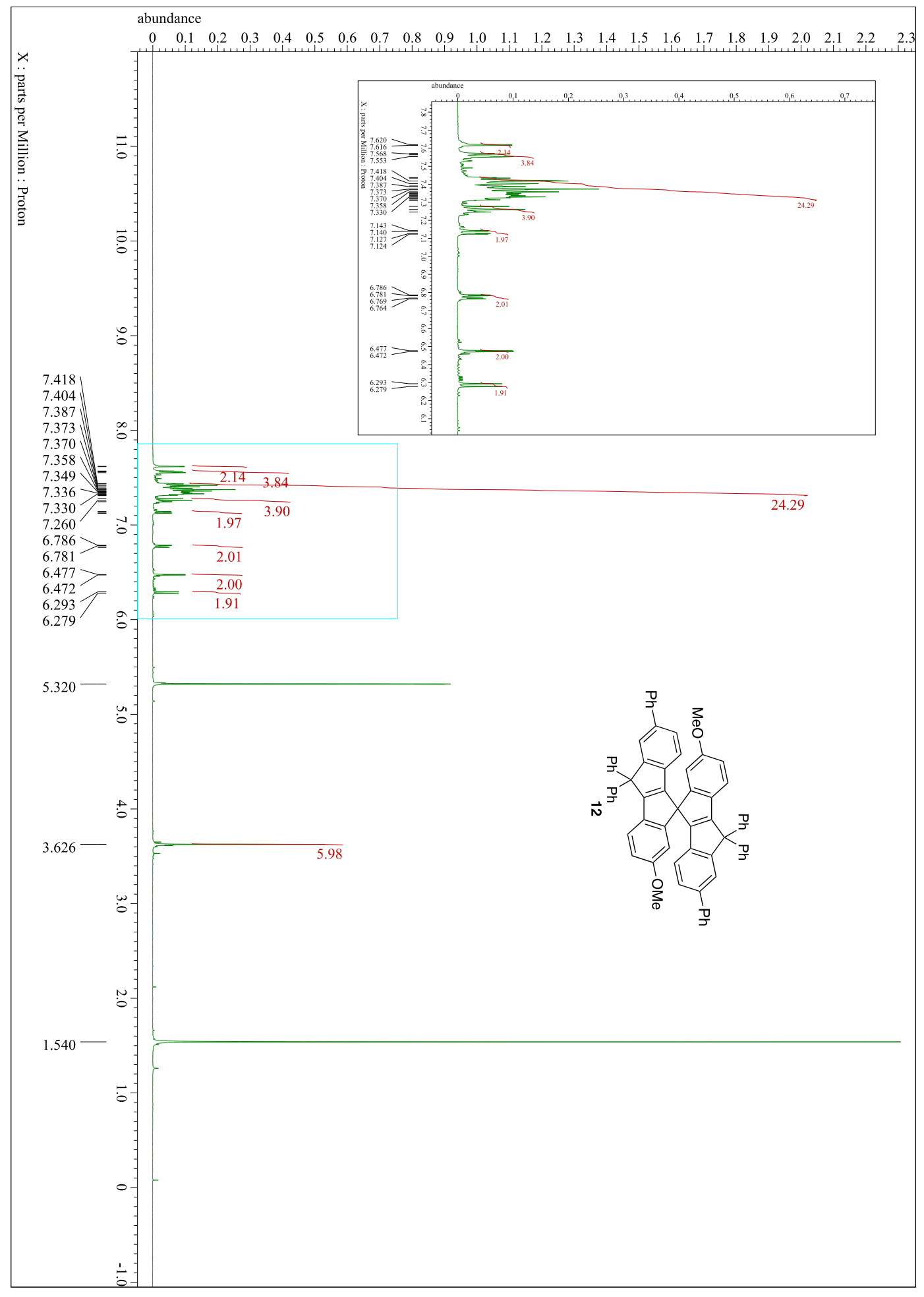


${ }^{13} \mathrm{C}$ NMR spectrum of $\mathbf{1 2}$ in $\mathrm{CD}_{2} \mathrm{Cl}_{2}$.

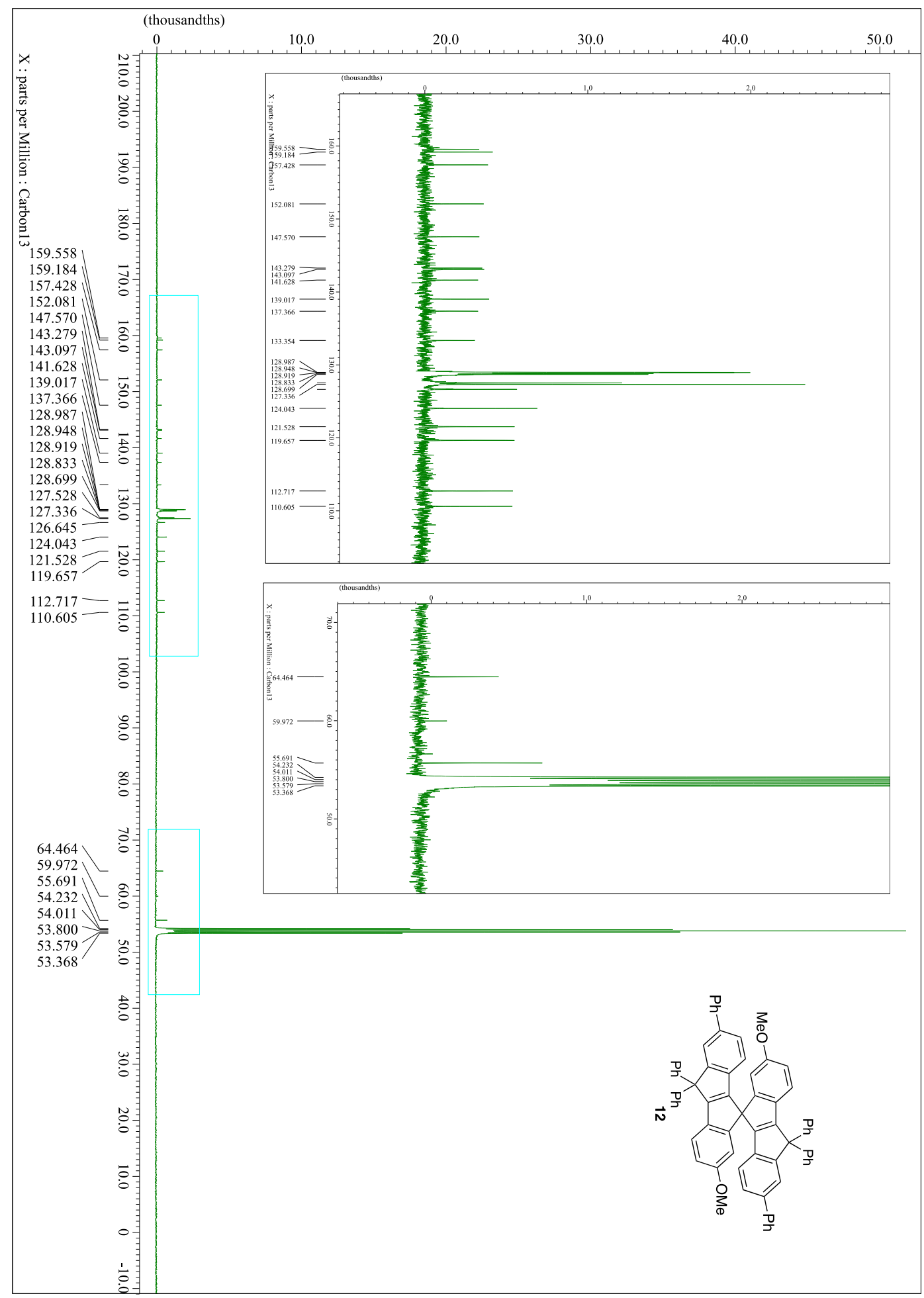


${ }^{1} \mathrm{H}$ NMR spectrum of $\mathbf{1 3}$ in $\mathrm{CD}_{2} \mathrm{Cl}_{2}$.

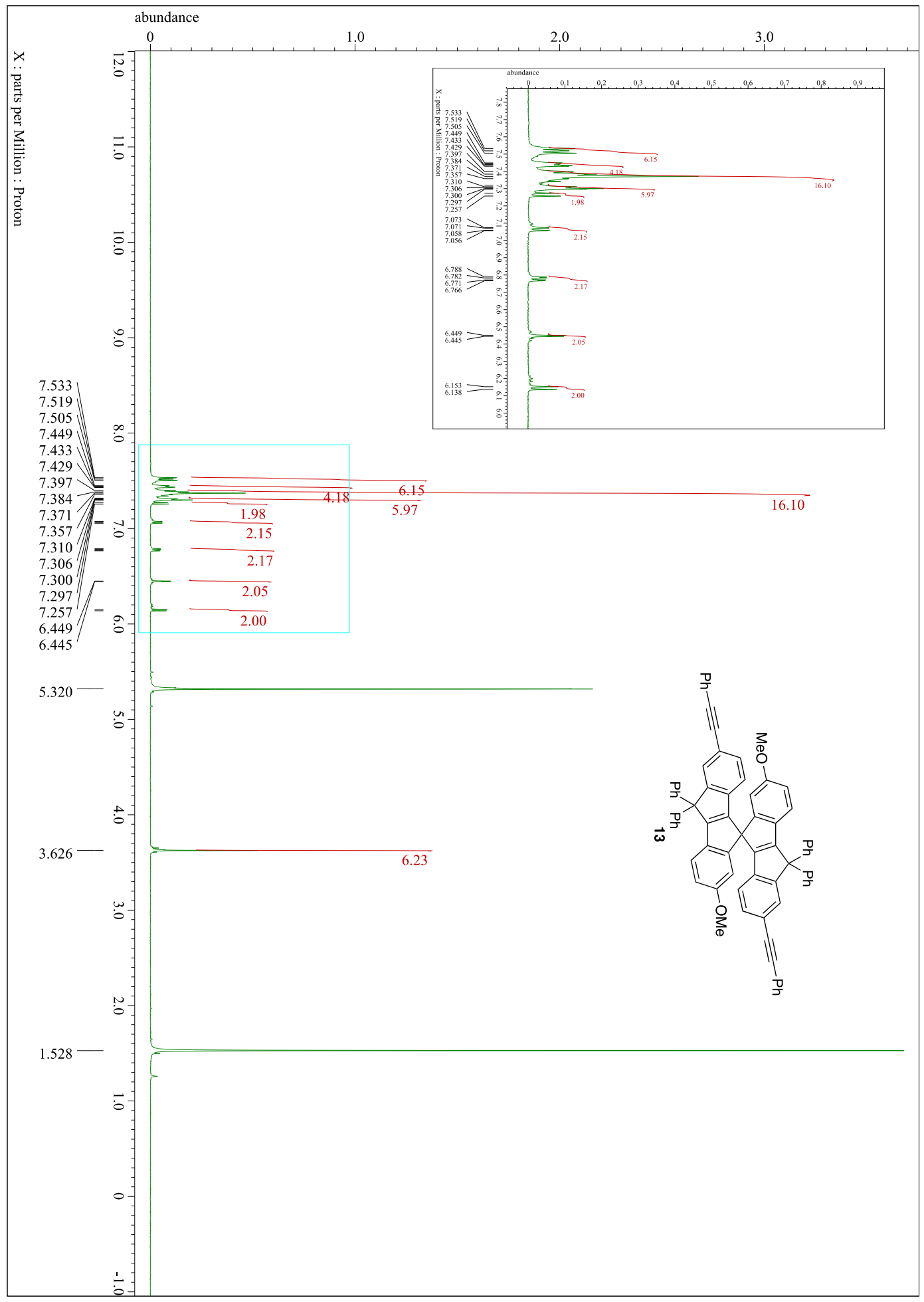


${ }^{13} \mathrm{C}$ NMR spectrum of 13 in $\mathrm{CD}_{2} \mathrm{Cl}_{2}$.

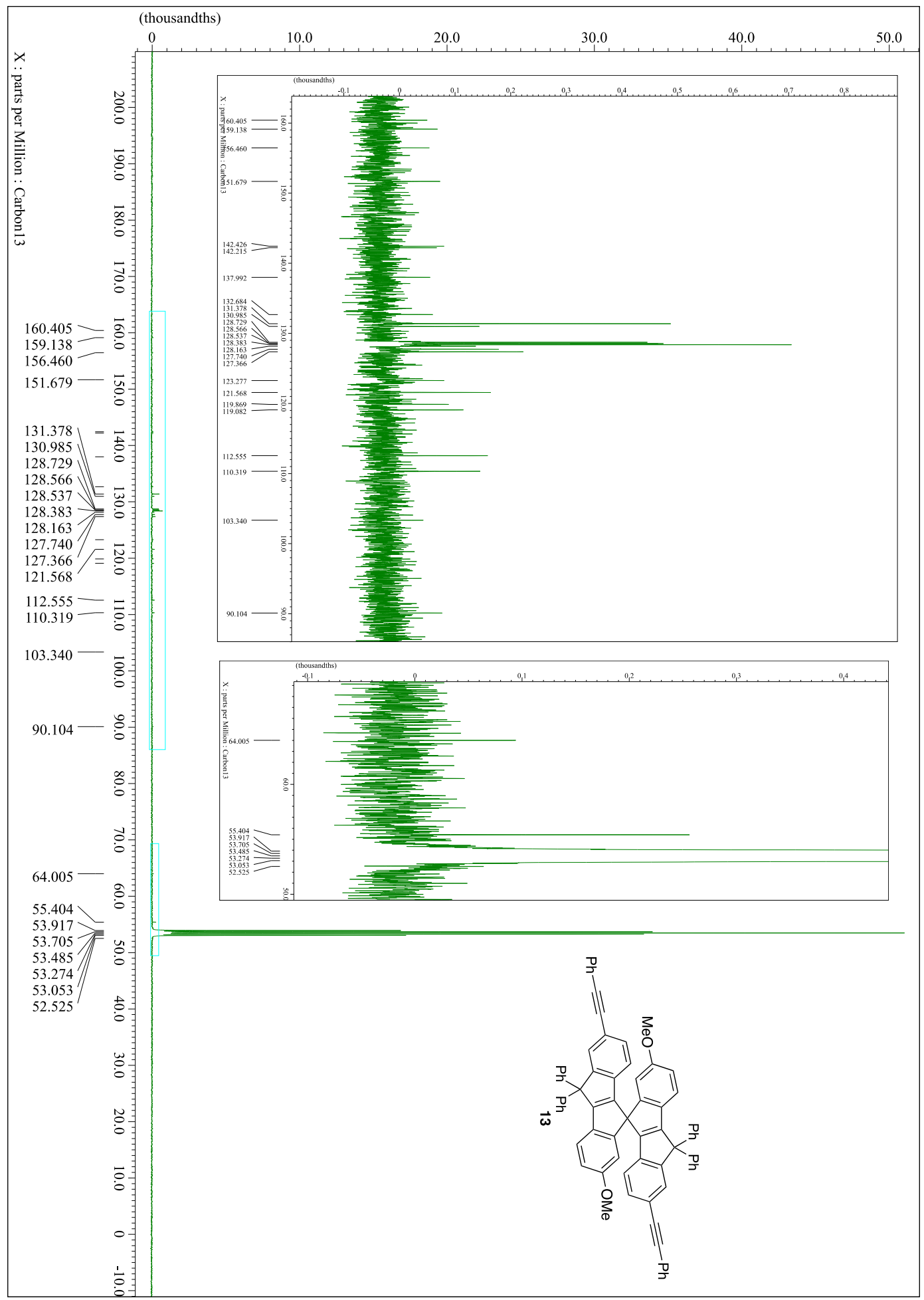


${ }^{1} \mathrm{H}$ NMR spectrum of $\mathbf{5}$ in $\mathrm{CD}_{2} \mathrm{Cl}_{2}$.

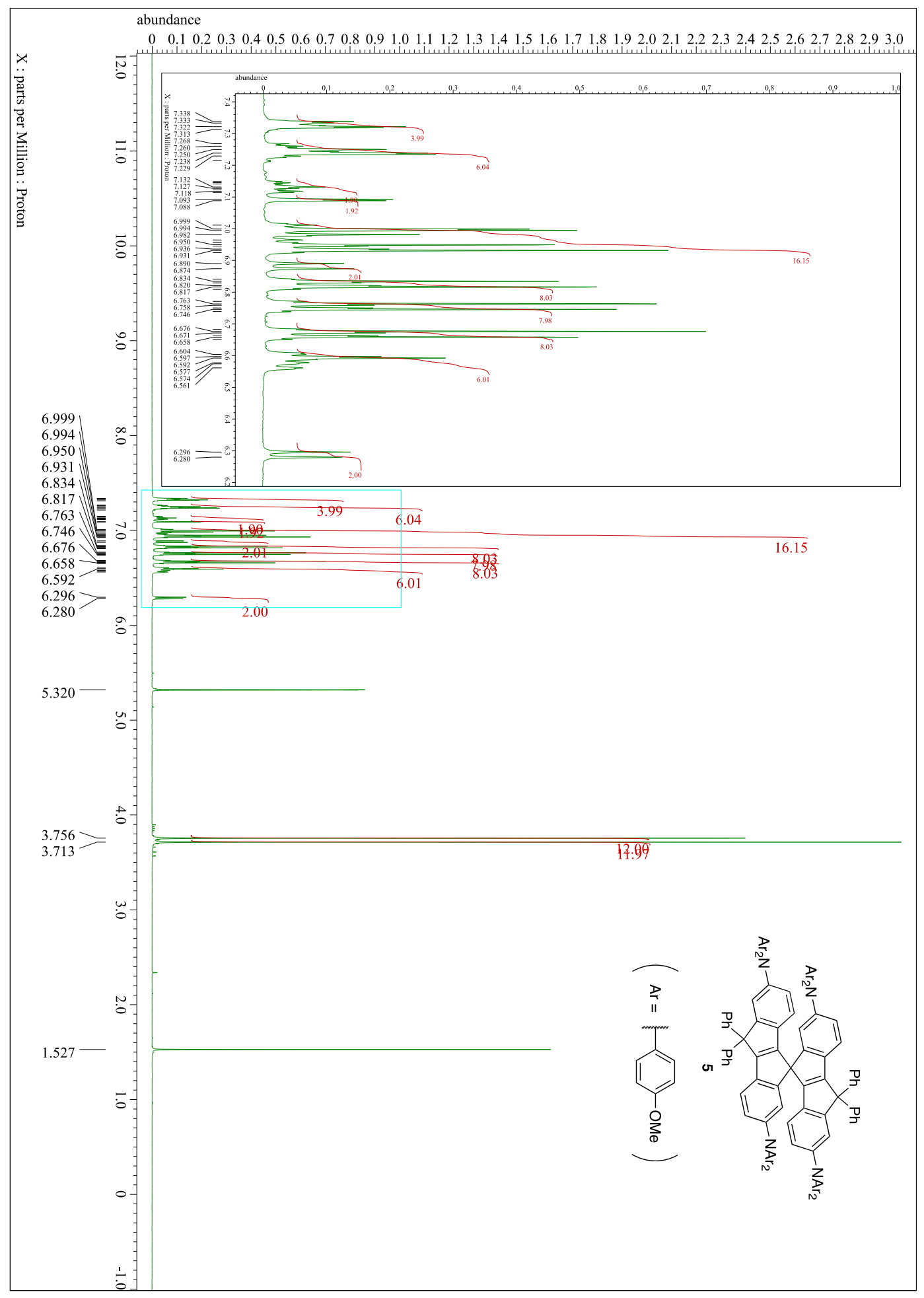


${ }^{13} \mathrm{C}$ NMR spectrum of 5 in $\mathrm{CD}_{2} \mathrm{Cl}_{2}$.

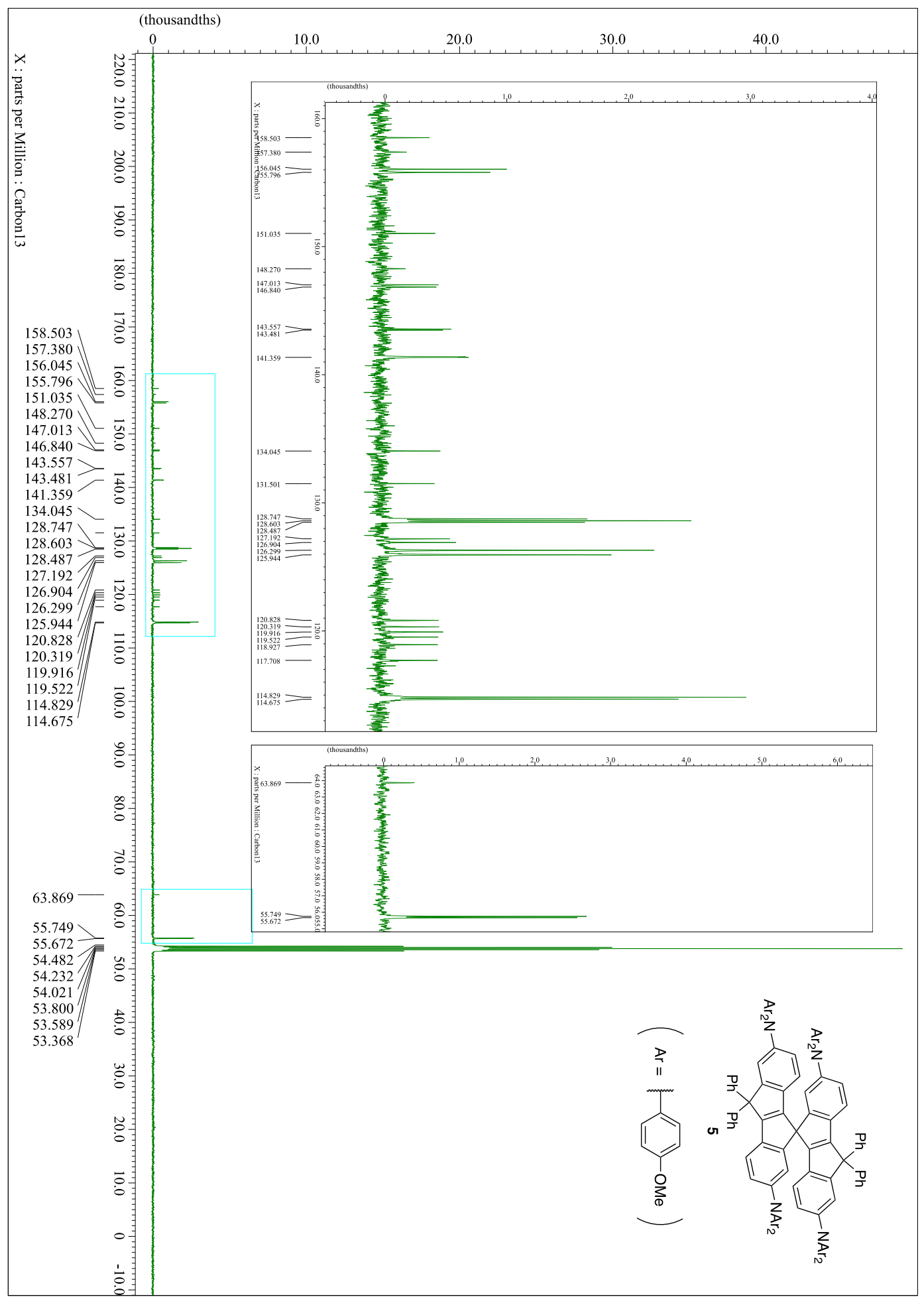




\section{References}

1 Still, W. C.; Kahn, M.; Mitra, A. Rapid chromatographic technique for preparative separations with moderate resolution. J. Org. Chem. 1978, 43, 2923-2925.

2 Zhu, X.; Mitsui, C.; Tsuji, H.; Nakamura, E. Modular Synthesis of $1 H$-Indenes, Dihydro- $s$-Indacene, and Diindenoindacene-a Carbon-Bridged $p$-Phenylene Congener. J. Am. Chem. Soc. 2009, 131, 13596-13597.

3 Sheldrick, G. M. SHELXT - Integrated space-group and crystal-structure determination. Acta Crystallogr A Found Adv. 2015, 71, 3-8.

4 Kabuto, C.; Akine, S.; Nemoto, T.; Kwon, E. Release of Software (Yadokari-XG 2009) for Crystal Structure Analyses. J. Cryst. Soc. Jpn., 2009, 51, 218-224.

5 Gaussian 09, Revision B.01, Frisch, M. J.; Trucks, G. W.; Schlegel, H. B.; G. E. Scuseria, ; Robb, M. A.; Cheeseman, J. R.; Scalmani, G.; Barone, V.; Mennucci, B.; Petersson, G. A.; Nakatsuji, H.; Caricato, M.; Li, X.; Hratchian, H. P.; Izmaylov, A. F.; Bloino, J.; Zheng, G.; Sonnenberg, J. L.; Hada, M.; Ehara, M.; Toyota, K.; Fukuda, R.; Hasegawa, J.; Ishida, M.; Nakajima, T.; Honda, Y.; Kitao, O.; Nakai, H.; Vreven, T.; Montgomery Jr. J. A.; , Peralta, J. E.; Ogliaro, F.; Bearpark, M.; Heyd, J. J.; Brothers, E.; Kudin, K. N.; Staroverov, V. N.; Keith, T.; Kobayashi, R.; Normand, J.; Raghavachari, K.; Rendell, A.; Burant, J. C.; Iyengar, S. S.; Tomasi, J.; Cossi, M.; Rega, N.; Millam, J. M.; Klene, M.; Knox, J. E.; Cross, J. B.; Bakken, V.; Adamo, C.; Jaramillo, J.; Gomperts, R.; Stratmann, R. E.; Yazyev, O.; Austin, A. J.; Cammi, R.; Pomelli, C.; Ochterski, J. W.; Martin, R. L.; Morokuma, K.; Zakrzewski, V. G.; Voth, G. A.; Salvador, P.; Dan nenberg, J. J.; Dapprich, S.; Daniels, A. D.; Farkas, O.; Foresman, J. B.; Ortiz, J. V.; Cioslowski, J.; Fox, D. J. Gaussian, Inc., Wallingford CT, 2010.

6 Yan, Q.; Guo, Y.; Ichimura, A.; Tsuji, H.; Nakamura, E. Three-Dimensionally Homoconjugated Carbon-Bridged Oligophenylenevinylene for Perovskite Solar Cells. J. Am. Chem. Soc. 2016, 138, 10897-10904. 